\title{
A MASTOFAUNA DA FAZENDA FIGUEIRA EM UMA ÁREA DO BAIXO TIBAGI, MUNICÍPIO DE LONDRINA, PARANÁ
}

\author{
LIZIE JATKOSKE LAZO \\ Biólogo
}

Orientador: Prof. Dr. ÁLVARO FERNANDO DE ALMEIDA

Dissertação apresentada à Escola Superior de Agricultura "Luiz de Queiroz", Universidade de São Paulo, para a obtenção do título de Mestre em Recursos Florestais, com opção em Conservação de Ecossistemas Florestais.

P I R A C I C A B A

Estado de São Paulo - Brasil

Outubro - 2004 


\section{ERRATA}

Corrigindo a identificação taxonômica: Marmosops paulensis seria na realidade Gracilinanus cf. agilis.

Com relação à bibliografia, na página 7, segundo parágrafo, o correto seria:...(Tabarelli \& Mantovani, 1999); na página 64, primeiro parágrafo:...(Krebs, 1989)...; e na página 85: Martuscelli ao invés de Mastuscelli.

$\mathrm{Na}$ metodologia, página 28, quarto parágrafo, o correto seria:...(média de 94,8 espécies/hectare)... E na página 35, último parágrafo:...captura com 15 redes "neblina"...

Na página 56 (Tabela 5), o $\mathbf{n}$ das espécies foi: 1, 9, 61, 25, 3, 7, 1, 4, 4, 47, 1, 1, e 2.

Alerta-se para o fato da ordem Lagomorpha não ter sido citada, e corrigindo este erro: na página 61, onde se lê 7 ordens são 8 ordens; na página 62 (Tabela 7) faltou a Ordem Lagomorpha, à qual pertencem a espécies da família Leporidae; e na página 67 (Figura 15), os valores de Lagomorpha foram somados aos valores da ordem Rodentia. Separadamente Rodentia representou 19\% (Total), 14\% (FR), 32\% (MC), e 12\% (PA), e Lagomorpha 5\% (Total), 5\% (FR), 3\% (MC) e 11\% (PA).

Nas páginas 64 e 67, Figuras 14 e 15, FR, MC e PA significam: fragmento florestal, mata ciliar e pastagem; e nas páginas 68 e 69, Figuras 16 e 17, o número atribuído às espécies, na legenda, corresponde aos da Tabela 7, página 62.

Com relação às páginas 73 e 74, alerta-se para o uso cauteloso dos tempos mínimos estimados, pois embora suficientes para o registro de uma alta riqueza de espécies, podem resultar na exclusão de espécies raras, ou mesmo na ineficácia do levantamento em função das particularidades de cada localidade e dos períodos amostrais.

Na página 75, o segundo parágrafo inicia-se com: A riqueza e a diversidade... 
Dados Internacionais de Catalogação na Publicação (CIP) DIVISÃO DE BIBLIOTECA E DOCUMENTAÇÃO - ESALQIUSP

Lazo, Lizie Jatkoske

A mastofauna da fazenda Figueira em uma área do baixo Tibagi, municipio de Londrina, Paraná / Lizie Jatkoske Lazo. - - Piracicaba, 2004.

90 p. : il.

Dissertação (Mestrado) - - Escola Superior de Agricultura Luiz de Queiroz, 2004.

Bibliografia.

1. Biogeografia 2. Biologia animal 3. Comunidade animal 4. Desmatamento 5. Fauna - Conservação 6. Mamifero silvestre 7. Proteção animal 8 . Proteção ambiental 1. Titulo

CDD 639.9

"Permitida a copra total ou parcial deste documento, desde que citada a fonte - O autor" 
Dedico ao amox pela natuxera e pelos animais, que me serve como inspirsação paxa nunca desistix. 


\section{AGRADECIMENTOS}

Agradeço, primeiramente, ao Programa de Pós-graduação em Recursos Florestais da Escola Superior de Agricultura "Luiz de Queiroz", e a todos os funcionários do Departamento de Ciências Florestais desta instituição.

A todos os diretores e funcionários da Fundação de Estudos Agrários "Luiz de Queiroz", que tornaram possível o desenvolvimento deste projeto.

A todos os funcionários da Fazenda Figueira, em especial para Laísse e Renato, pela paciência durante os períodos de campo, à Dona Renilda, a Rose e ao Zé (do barracão) que tornaram a permanência na fazenda muito mais agradável.

Ao IBAMA e ao Instituto Ambiental do Paraná (IAP), pela concessão das autorizaç̃os necessárias para a realização do projeto; ao Instituto Agronômico do Paraná (IAPAR), pelos dados climáticos concedidos; e ao Museu de Zoologia da Universidade de São Paulo, em especial ao Prof. Mário, e a Caroline pela disposição e sugestões.

Ao Prof. Álvaro, pela orientação durante estes anos, aos professores Nivar, Thadeu e Neto, pela grande ajuda e disposição, fundamental para o desenvolvimento e conclusão deste projeto. Também à Profa. Teresa, pelos conselhos, ao Prof. Ricardo e Ricardo pelos dados de florística. Ao Prof. Nélio e Isaac, e a Profa. Ana Odete da Universidade Estadual de Londrina.

Ao Marcelo (Beliche) pela identificação dos pêlos coletados em campo, e pelo grande auxílio no desenvolvimento desta dissertação, além das dicas muito úteis que me ajudaram enormemente. Ao Alexandre e a Cláudia pela disposição e paciência.

Aos meus amigos Patrícia Silveira, Vânia, Carolina, Patrícia Tavoloni, Pérsio, Salim, Marcela, Guilherme e Marcio, pelo companheirismo, força, e bons momentos 
durante todos estes anos de esforço, e a todos os pós-graduandos freqüentadores da sala da pós.

Aos meus pais e a minha tia, pelo apoio e esforço que me deram durante tantos anos para que eu pudesse chegar até aqui, e aos meus irmãos pelo exemplo durante todos estes anos.

A todos que de alguma maneira contribuíram para a realização desta dissertação e de minha formação pessoal.

E, principalmente, a natureza, que me inspira e me dá forças para permanecer neste caminho. 


\section{SUMÁRIO}

Página

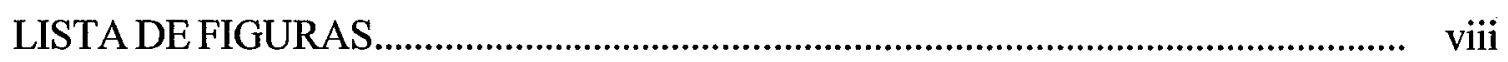

LISTA DE TABELAS..................................................................................

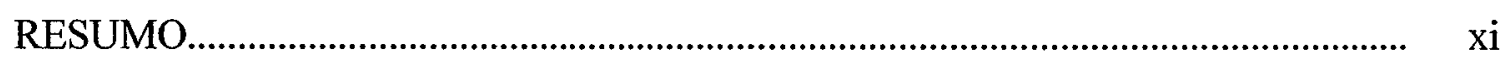

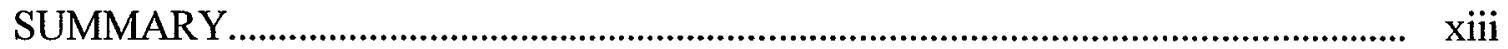

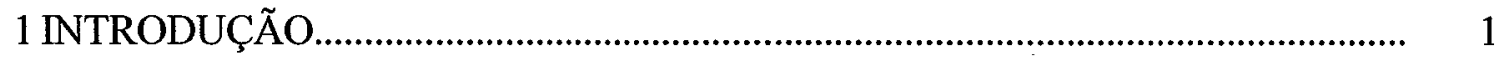

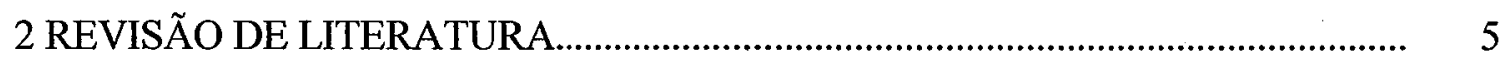

2.1 A mastofauna em florestas neotropicais.......................................................... 5

$2.2 \mathrm{O}$ processo de fragmentação dos hábitats....................................................... 7

2.3 O processo de fragmentação na Bacia do rio Tibagi............................................. 11

$2.4 \mathrm{O}$ ambiente entre os fragmentos florestais..................................................... 12

2.5 A susceptibilidade das espécies às alterações ambientais................................... 14

2.6 A fragmentação sobre comunidades de morcegos............................................... 16

2.7 A mastofauna terrestre em hábitats fragmentados............................................. 19

2.8 A conservação da mastofauna em ambientes fragmentados................................ 23

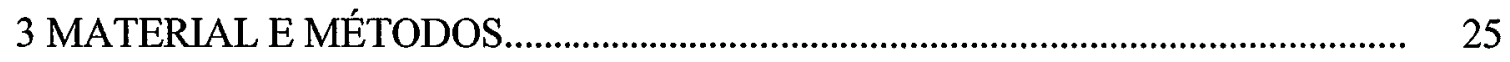

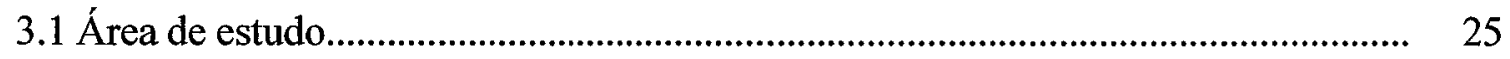

3.1.1 Características climáticas e geológicas............................................................. 26

3.1.2 Vegetação da Fazenda Figueira................................................................... 28

$3.2 \mathrm{O}$ estudo da mastofauna na Fazenda Figueira................................................... . 31

3.3 Estudo dos mamíferos voadores.................................................................... 35

3.4 Estudo dos mamíferos não-voadores............................................................. 36

3.4.1 Estudo de mamíferos de pequeno porte por meio de captura......................... 36 
3.4.2 Estudo qualitativo de mamíferos.......................................................................... 38

3.5 Análise dos dados........................................................................................... 39

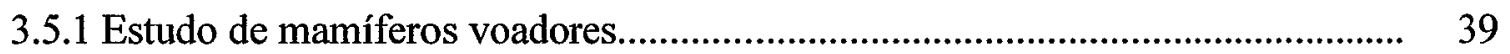

3.5.2 Estudo de mamíferos não-voadores........................................................................ 42

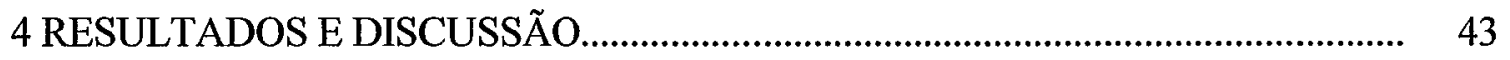

4.1 Estudo de mamíferos voadores.................................................................................... 43

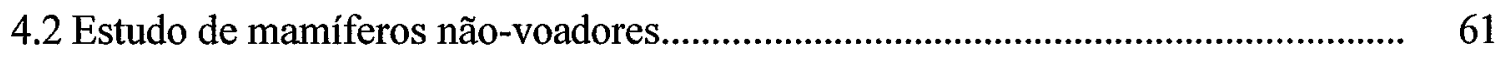

4.2.1 Estudo de mamíferos de pequeno porte por meio de captura................................ 61

4.2.2 Estudo qualitativo de mamíferos...................................................................... 61

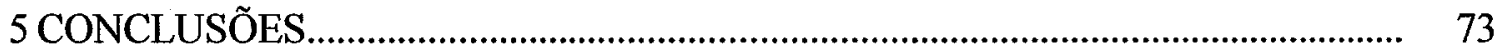

5.1 Estudo de mamíferos voadores.............................................................................. 73

5.2 Estudo de mamíferos não-voadores............................................................................ 74

5.3 Considerações finais............................................................................................ 75

REFERÊNCIAS BIBLIOGRÁFICAS............................................................. 78 


\section{LISTA DE FIGURAS}

Página

1 Localização geográfica da Fazenda Figueira dentro da Bacia Hidrográfica do rio Tibagi...................................................................................... 26

2 Área da Fazenda Figueira, contendo os remanescentes florestais que fazem parte da RPPN Estadual Mata do Barão.................................. 32

3 Parte do fragmento de Floresta Estacional Semidecídua de 266 ha......................... 33

4 Porção do maior trecho de Floresta Estacional Semidecídua Ribeirinha do rio Taquara.

5 Pastagem com início de sucessão secundária, pouco manejada.

6 Pastagem intensamente utilizada para a criação de gado bovino

7 Curva de tendência para o número acumulado de espécies de morcegos capturadas em função do tempo de captura com rede "neblina".

8 Porcentagem da abundância de morcegos nos diferentes ambientes da Fazenda Figueira 
9 Abundância das espécies de morcegos nos diferentes ambientes da Fazenda Figueira.

10 Porcentagem de indivíduos jovens e adultos entre as cinco espécies mais abundantes.

11 Características sexuais da comunidade de morcegos para os ambientes amostrados.

12 Porcentagem de indivíduos se reproduzindo na comunidade e sexo no período de levantamento na Fazenda Figueira.

13 Curva acumulada de espécies de mamíferos de médio e grande porte, referente ao período de levantamento na Fazenda Figueira.

14 Riqueza de espécies de mamíferos de médio e grande porte para os diferentes ambientes amostrados na Fazenda Figueira.

15 Abundância relativa das ordens de mamíferos não-voadores nos diferentes ambientes da Fazenda Figueira

16 Abundância de rastros para as espécies de mamíferos não-voadores. 68

17 Abundância de espécies de mamíferos não-voadores registrados através de observações. 


\section{LISTA DE TABELAS}

Página

1 Dados climáticos referente aos dias e meses de levantamento da mastofauna na Fazenda Figueira.

2 Riqueza e abundância de espécies de morcegos nos diferentes ambiente da Fazenda Figueira

3 Riqueza e abundância de espécies na Bacia do Tibagi.

4 Porcentagem de Similaridade entre as comunidades de morcegos dos ambientes da Fazenda Figueira.

5 Características de peso e tamanho do antebraço das espécies de morcegos registradas para a Fazenda Figueira.

6 Períodos reprodutivos para as espécies de morcegos registradas na Fazenda Figueira.

7 Lista dos mamíferos não-voadores da Fazenda Figueira. 


\title{
A MASTOFAUNA DA FAZENDA FIGUEIRA EM UMA ÁREA DO BAIXO TIBAGI, MUNICÍPIO DE LONDRINA - PARANÁ
}

\author{
Autora: LIZIE JATKOSKE LAZO \\ Orientador: Prof. Dr. ÁLVARO FERNANDO DE ALMEIDA
}

\section{RESUMO}

O Estado do Paraná é um bom exemplo do atual estado dos remanescentes florestais na região sul do Brasil, onde as poucas e descontínuas áreas florestais, e a presença de um ambiente constituído por pastagem, tornaram-se fatores preocupantes para a conservação da mastofauna. No presente trabalho, foi analisado o estado de conservação de mamíferos voadores e não-voadores da Fazenda Figueira, localizada em uma área do baixo Tibagi, no município de Londrina, Estado do Paraná, através de estudos da composição e da abundância das espécies em áreas de pastagem da Estação Experimental Agrozootécnica "Hildegard Georgina Von Pritzelwitz", e remanescentes florestais da Reserva Particular do Patrimônio Natural (RPPN) Estadual Mata do Barão. Para estes estudos, foram utilizados os métodos de captura com redes "neblina" para os mamíferos voadores, e, para os mamíferos não-voadores, o uso de armadilhas de captura e levantamento qualitativo através dos métodos direto e indireto. A fazenda apresentou uma riqueza alta, sendo 14 espécies de mamíferos voadores, equivalente a $31,7 \%$ das registradas na Bacia do rio Tibagi, com o acréscimo de Mesophilla macconnelli e Tonatia silvicola, e 35 espécies de mamíferos não-voadores, que representam $50 \%$ das espécies da Bacia, acrescentando-se Marmosops paulensis, Chironectes minimus, 
Conepatus chinga, Pteronura brasiliensis, e Nectomys squamipes, que ainda não haviam sido registradas. $\mathrm{O}$ uso dos ambientes de pastagens para o acesso a outros remanescentes foi verificado para todos os grupos de mamíferos, porém o fragmento florestal foi o mais representativo da diversidade de morcegos da fazenda, ocorrendo um decréscimo nos demais ambientes à medida que se distanciavam do fragmento, e, para os mamíferos não-voadores, foi responsável por uma riqueza maior de espécies. Com relação à comunidade de mamíferos voadores, foi observada uma dominância de Artibeus lituratus, Carollia perspicillata e Sturnira lilum em todos os ambientes da fazenda, uma proporção grande de indivíduos jovens, uma proporção equivalente entre machos e de fềmeas, sendo as fềmeas responsáveis por $3 / 4$ dos indivíduos reprodutivamente ativos. Dentre a comunidade de mamíferos não-voadores, a taxa de captura de pequenos mamíferos foi muito baixa, e a ordem Carnívora correspondeu a $38 \%$ do total de espécies, mostrando-se bastante abundante em todos os ambientes, principalmente os mesopredadores. O método de levantamento indireto por rastros foi o mais eficiente, porém apresentou muitos problemas em função das diferentes probabilidades de marcar rastros no solo entre as espécies. Os resultados obtidos permitem inferir que o estado de conservação da mastofauna foi satisfatório, sendo encontradas espécies indicadoras de áreas degradadas como T. silvicola, Myotis ruber, Tapirus terrestris e Tayassu tajacu, e espécies ameaçadas como M. ruber, Chrysocyon brachyurus, Leopardus pardalis, Leopardus tigrinus, Puma concolor e $P$. brasiliensis. Entretanto a riqueza elevada de espécies pode ter ocorrido em função da descaracterização do ambiente natural, sendo importante qualquer medida que vise minimizar os efeitos da fragmentação. 


\title{
THE MASTOFAUNA OF THE FIGUEIRA FARM IN LOWER TIBAGI'S AREA, MUNICIPAL DISTRICT OF THE LONDRINA - PARANÁ
}

\author{
Author: LIZIE JATKOSKE LAZO \\ Adviser: Prof. Dr. ÁLVARO FERNANDO DE ALMEIDA
}

\section{SUMMARY}

The Paraná State is a good example of forest reminiscent conditions at the south region of the Brazil, because the few and discontinued forests areas and the existence a pasture environment are factors that menaces the mammalian conservation. The flying and terrestrial mammals' conservation in the Figueira Farm, located at the region of lower Tibagi's basin, municipal district of the Londrina at Paraná State, was realized based on the species composition and abundance of pasture areas at 'Hildegard Georgina Von Pritzelwitz' Agrozootechnical Experiment Station and forest reminiscent at Mata do Barão Private Reserve of Natural Patrimony (PRNP). In this work, we utilized the mist nets capture methods for flying mammals, and live traps in order to assess direct and indirectly qualitative methods to non-flying mammals. The farm presented a high richness species, with 14 flying mammals species, equivalent to the $31,7 \%$ of the Tibagi river Basin's registers, with addition of Mesophilla macconnelli and Tonatia silvicola, and 35 terrestrial mammals species that represents $50 \%$ of the Basin's species, plus Marmosops paulensis, Chironectes minimus, Conepatus chinga, Pteronura brasiliensis and Nectomys squamipes, which were not registered before. The use of the pasture environments as a passageway to other reminiscents was verified for all mammals, but 
the forest patch was the more representative for the bats' diversity at farm, appearing a decrease in others environments with a distance addition of the fragment, and non-flying mammals were responsible for an elevated species richness. The non-flying mammals community showed a dominance of Artibeus lituratus, Carollia perspicillata and Sturnira lilum in all farm environments, and in relation to age and sex ratio, we founded a great proportion of young individuals, and an equal proportion between male and females. The females itself were responsible for $3 / 4$ of the all the individuals in reproductively cycle. Relatively to the terrestrial mammals' community, the small mammals capture rate was very low, and the Carnivore Order contributed with $38 \%$ of all species, showing a great abundance in all environments, principally the mesopredators. The indirect method of tracks was the more efficient, but also it was the more problematic due to the impossibility to differentiate some tracks between species. The encountered results allowed us to infer that the mammalian conservation status was satisfactory, with the register of species known as indicators of degraded areas being $T$. silvicola, Myotis rubber, Tapirus terrestris and Tayassu tajacu, and threatened species as M. rubber, Chrysocyon brachyurus, Leopardus pardalis, Leopardus tigrinus, Puma concolor and P. brasiliensis. However, the species elevated richness could have occurred due to the natural environment mischaracterization, being important the application of any measures that could be able to minimize the patchiness effects. 


\section{INTRODUÇÃo}

O crescente aumento populacional, acompanhado por um maior consumo de recursos, vêm exercendo constante pressão sobre os ambientes naturais, reduzindo-os progressivamente, transformando-os em fragmentos isolados (McCullough, $1996 \mathrm{e}$ Laurance, 1999b). Estes problemas, embora ocorram em todas as regiões, podem ser mais sérios em regiões tropicais e subtropicais, onde a riqueza de espécies de mamíferos é alta e a equitabilidade baixa, havendo uma desigualdade na abundância relativa das espécies. Neste contexto, as espécies pouco abundantes tornam-se extremamente vulneráveis, principalmente se este aumento no consumo de recursos naturais ocorrerem em regiões que concentram uma grande quantidade de pessoas, e onde o crescimento populacional ocorre rapidamente (Cole \& Wilson, 1996), tendendo a agravar o processo de fragmentação.

Até o início da década de 1950, a superexploração dos recursos naturais foi a principal causa das extinções de vertebrados. Nos anos recentes, a causa primária do desaparecimento das espécies continua sendo a exploração dos recursos naturais, que resultam nas perturbações ambientais (Ceballos \& Navarro, 1991), entretanto o que difere entre os períodos seria a razão entre as áreas alteradas e as áreas conservadas, que tende a aumentar com o passar do tempo. Dentre as perturbações ambientais, a mais importante é o desmatamento que ocorre pela desocupação de terras para a agricultura, pecuária e o crescimento industrial, fatores que juntos resultam em perda significativa de hábitats naturais de vida silvestre (Cole \& Wilson, 1996; Laurance, 1999a e Laurance, 1999b), principalmente se considerarmos que nos países tropicais, um mínimo de 70\% das espécies residentes de vertebrados é comumente relatado como sendo dependentes de florestas fechadas (Erwin, 1988). 
Na conservação dos ecossistemas, os aspectos das regiões como tamanho, topografia, forma dos fragmentos e conectividade entre estes, têm importantes influências sobre o número, composição, abundância e viabilidade de espécies (Wilson et al., 1996). Fragmentos que apresentem uma forma física responsável pela manutenção de uma área núcleo de maior extensão, como os fragmentos circulares e/ou quadrados, são adequados, mas, em geral, as áreas destinadas à conservação da biodiversidade apresentam-se como faixas estreitas e/ou longas, ou muito pequenas e distantes umas das outras, o que pode dificultar a manutenção da fauna.

$O$ fato de ocorrerem desmatamentos da floresta natural, transformando-a em pequenos fragmentos isolados, não é o único fator impactante sobre a fauna silvestre; o ambiente de entorno dos fragmentos florestais também exerce importantes efeitos sobre a fauna, sendo o principal agente do isolamento florestal para as comunidades de animais (Almeida, 1996 e Gascon et al., 1999). Entretanto, a falta de estudos que busquem verificar os efeitos do entorno sobre os mamíferos, ou a susceptibilidade destes em relação ao ambiente alterado após um processo de fragmentação, dificultam o entendimento do estado de conservação destas populações, e da tomada de qualquer iniciativa que procure minimizar estes efeitos visando à conservação da mastofauna.

Segundo Cosson et al. (1999a), as características de uma espécie de morcego, frugívoro ou nectarívoro, que a torne mais ou menos vulnerável à fragmentação, seriam: a abundância da espécie; as estratégias de forragem; e o tamanho corpóreo. Em geral, espécies que apresentem uma abundância alta, com estratégias de forrageio na altura da copa e grande tamanho corpóreo, são consideradas mais resistentes aos efeitos da fragmentação. Estas espécies, pouco vulneráveis à fragmentação, podem conseguir utilizar ou ultrapassar estes ambientes de entorno, dependendo do grau de "agressividade" deste ambiente, e da distância a ser transcorrida. Espécies muito sensíveis podem vir a apresentar dificuldades ao atravessar e/ou explorar o ambiente de entorno, mesmo que pouco agressivo, como os ambientes fechados.

Os ambientes fechados (florestais) devem representar importante conectividade entre os fragmentos (Gascon et al., 1999), exercendo certo grau de proteção aos animais silvestres, quando capazes de utilizar e/ou ultrapassar estes ambientes, ao contrário dos 
ambientes abertos, que expõem os animais a diversos fatores como predação, escassez de água e de alimento, falta de abrigos, entre outros, tornando-os mais vulneráveis.

Dentre os ecossistemas brasileiros, a Floresta Estacional Mesófila Semidecídua foi um dos ambientes mais degradados e destruídos do país - embora não se tenha uma estimativa de quanto restou deste tipo florestal, pelo fato de se superestimar seus remanescentes quando se considera, erroneamente, este tipo florestal como Floresta Atlântica - estando hoje representada por uma porção diminuta do que foram no passado e, em sua maioria, insuficientes para conservação da fauna (Martuscelli, 1996). Entretanto, estas áreas abrigam inúmeras formas de vida vegetais e animais, que continuam vivendo e se mantendo nestes locais, como mostram vários trabalhos de levantamento da biodiversidade (Gargaglioni et al., 1998; Chiarello, 2000; Félix et al., 2001; Gueler-Costa, 2002; Peracchi et al., 2002; Reis et al., 2002 e Reis et al., 2003). A falta de estudos em escala temporal não permite nenhuma afirmativa, entretanto, imagina-se que apesar de conservar um grande número de formas de vida, estas representem uma porção diminuta das originais e, caso isto não ocorra, é provável que esta diversidade seja muito distinta da anterior, sendo de grande importância a conservação destes remanescentes, principalmente por não sabermos em que condições estas espécies estão sobrevivendo, e por quanto tempo persistirão.

O Estado do Paraná é um bom exemplo do estado atual em que se encontram os remanescentes florestais no Brasil, principalmente nas regiões sul e sudeste, onde as poucas e descontínuas áreas destinadas à conservação da biodiversidade são fatores que preocupam do ponto de vista conservacionista. Desta maneira, a avaliação da diversidade de mamíferos em uma paisagem agropecuária (paisagem comum nestas regiões), constituída por pastagens e poucos remanescentes florestais - geralmente Reserva Legal (RL), Área de Proteção Permanente (APP) e Reserva Particular do Patrimônio Natural (RPPN) - dispersos, torna-se representativa do estado de conservação destes vertebrados, e importante para a conservação ambiental da fauna paranaense.

Na Fazenda Figueira, localizada no município de Londrina, o crescimento da agropecuária transformou o ambiente em um mosaico constituído por pastagens e remanescentes florestais, passando, estes ambientes, a representar um papel determinante 
sobre as populações de mamíferos silvestres nesta área. Esperou-se: 1) grande diversidade local em função da heterogeneidade de ambientes da fazenda; 2) uma menor freqüência de uso dos ambientes de entorno por populações de mamíferos; e 3) um grande potencial conservacionista da área, mesmo que fragmentada, na sustentação de populações da mastofauna.

Para a comprovação destas hipóteses, o estudo foi realizado com base nos seguintes objetivos: 1) a determinação da riqueza de espécies de mamíferos presentes em pastagens e fragmentos florestais; 2) a avaliação da abundância de pequenos mamíferos voadores e não-voadores; 3) e a avaliação do atual estado de conservação da fauna em conjunto com as atividades agropecuárias, inferindo-se sobre as melhores estratégias para a conservação da mastofauna. 


\section{REVISÃO DE LITERATURA}

\subsection{A mastofauna em florestas neotropicais}

A mastofauna em florestas da região neotropical - do México até o extremo sul da América do Sul - é presentemente conhecida por incluir cerca de 700 espécies (Cimardi, 1996). Estes mamíferos são muito variáveis em tamanho, apresentando desde umas poucas gramas até centenas de quilos, incluindo espécies que diferem em dieta, hábitat, locomoção, comportamento social, e atividades circadianas, esclarecendo a real complexidade em se amostrar estas populações de animais silvestres (Voss \& Emmons, 1996).

A ordem dos roedores (Rodentia) é o grupo de mamíferos de maior representatividade mundial, apresentando cerca de 2.020 espécies (Wilson \& Reeder, 1993). Na América do Sul, estão presentes $23 \%$ do total de espécies mundial (Eisenberg, 1999), correspondendo à metade das espécies de mamíferos existentes no continente (Wilson \& Reeder, 1993).

A ordem dos morcegos (Chiroptera) é considerada uma das mais importantes em florestas neotropicais, representando 39\% das espécies de mamíferos (Voss \& Emmons, 1996), e sendo composta atualmente, no mundo, por cerca de 1.000 espécies, distribuídas em duas subordens, a Megachiroptera, presente exclusivamente no velho mundo, diferindo do grupo dos Microchiroptera, por atingir peso superior a 196 gramas, além de possuírem diferenças quanto à ecolocalização, organização social, dieta, entre outras (Nowak, 1994). O grupo dos Microchiroptera contém 759 espécies, das quais cerca de 140 estão presentes no Brasil (Marinho-Filho \& Sazima, 1998 e Bredt et al., 2003). Na América do Sul, esta ordem representa $21 \%$ do total de espécies no mundo (Wilson \& 
Reeder, 1993), sendo 53\% correspondente à família Phyllostomidae e $21 \%$ à Vespertilionidae (Eisenberg, 1999).

Segundo a classificação da fauna por tipos de ambientes proposta por Ávila-Pires (1966), a mastofauna é característica de apenas três tipos de ambientes, que seriam: áreas abertas; áreas cobertas; e áreas de transição.

Diversos fatores estão intimamente relacionados à manutenção da diversidade biológica, entre tantos podemos citar a extensão de cobertura vegetal (Gargaglioni et al., 1998; Chiarello, 1999 e Lindenmayer et al., 2000b), a estrutura vertical e horizontal da vegetação (Gentile \& Fernandes, 1999 e Jorge et al., 2001), a presença de conectividade entre os fragmentos e a heterogeneidade da área (Lima \& Gascon, 1999 e Lindenmayer et al., 2000b), a presença de alimento (Suárez \& Bonaventura, 2001), abrigo (Nowak, 1994 e Trajano, 1996), e a presença de água, dentre outros fatores abióticos, são fatores determinantes na manutenção de uma alta diversidade biológica (Ávila-Pires, 1966; Wallauer et al., 2000 e Jorge et al., 2001), que juntos podem fazer com que um Bioma como o Cerrado tenha a mesma magnitude de ecossistema que um Bioma Mata Atlântica e outras florestas equatoriais, representando verdadeiros refúgios para as espécies animais (Gargaglioni et al., 1998).

A fragmentação dos ecossistemas naturais trás diversas conseqüências à mastofauna, facilmente visíveis através da grande quantidade de espécies ameaçadas de extinção em todo o Brasil, que soma 1 marsupial, 26 primatas, 10 carnívoros, 4 xenarthras, 12 roedores, 2 artiodactylas, e 5 morcegos (Fundação Biodiversistas et al., 2003).

De forma menos visível estão as alterações nos processos dos ecossistemas (Sax \& Gaine, 2003) como a predação, a dispersão de sementes, a polinização, as grandes interações competitivas, e a atuação como presa base, extremamente importantes para a funcionalidade dos ambientes (Terborgh, 1992; Cosson et al., 1999b e Coppolitto et al., 2004). Entretanto, sabe-se pouco sobre os morcegos, devido à deficiência de estudos que visem este aspecto de conservação (Marinho-Filho \& Sazima, 1998). 


\subsection{O processo de fragmentação dos hábitats}

Nas proximidades dos grandes centros urbanos, ou em continentes super populosos, a maior parte das terras naturais foi convertida para uso humano, confinando a vida biológica a pequenos fragmentos de vegetação, rodeados por cidades ou terras agricultáveis. Existem diversos estudos de campo que procuram verificar os efeitos da redução no tamanho dos remanescentes florestais sobre sua ecologia (Redford \& Robinson, 1991; Martuscelli, 1996; Phillips, 1997; Marinho-Filho \& Sazima, 1998; Chiarello, 1999; Cosson et al., 1999a; Cosson et al., 1999b; Gascon et al., 1999; Lindenmayer et al., 2000b; Wallauer et al., 2000; Félix et al., 2001; Harrington et al., 2001; Quesada et al., 2003; Reis et al., 2003 e Timo, 2003), mas, em geral, demonstra-se que quanto menor forem os fragmentos florestais, maiores são as mudanças ecológicas em relação às formações florestais extensas e contínuas, independentemente das interferências humanas adicionais ao desmatamento (Martuscelli, 1996 e Phillips, 1997).

A fragmentação florestal é caracterizada por diversas alterações que, direta ou indiretamente, estão associadas ao processo de destruição da característica original de um ecossistema natural. Dentre estas alterações, podemos citar as mudanças na composição vegetal e animal, a amplificação dos efeitos de borda, o isolamento genético e demográfico, além de alterações na dinâmica dos pequenos fragmentos, como ocorre, por exemplo, com a proporção de árvores que apresentam seus frutos dispersos por aves e mamíferos, que em geral, diminui, refletindo posteriormente no desaparecimento de muitos vertebrados nestes locais (Laurance, 1999a e Tabarelli, 1999). À medida que ocorre uma amplificação dos efeitos de borda como resultado direto da fragmentação, há uma elevação da luminosidade e do vento no sub-bosque, resultando na alteração da composição das espécies e na estrutura da vegetação (Tabarelli, 1999).

O tamanho do remanescente florestal é de suma importância para o suporte da mastofauna, sendo que quanto maior o fragmento florestal maior o número de espécies presentes (Chiarello, 1999 e Reis et al., 2003). Este fator deixa em dúvida a viabilidade de grande parte das unidades destinadas à conservação da fauna, principalmente se consideradas as áreas necessárias para suportar populações viáveis de espécies como a 
Onça-pintada (Panthera onca), e a Anta (Tapirus terrestris), poucas Unidades de Conservação seriam capazes de manter populações de grandes predadores, de grandes frugívoros e de grandes herbívoros por um longo prazo de tempo (Redford \& Robinson, 1991; Terborgh, 1992; Martuscelli, 1996 e Elmhagen \& Angerbjorn, 2001). Entretanto, a influência do tamanho de um fragmento florestal sobre a fauna nativa pode variar enormemente, considerando-se que nem todas as espécies são igualmente sensiveis, como será mostrado adiante, podendo uma mesma área florestal ser suficiente para a manutenção de uma espécie e, ao mesmo tempo, insuficiente para outra (Terborgh, 1992).

Para Reis et al. (2003), um grande fragmento é mais significante para a conservação de morcegos do que vários fragmentos pequenos. A mesma importância às áreas grandes é dada por Timo (2003), com relação aos grandes mamíferos terrestres, onde a constituição do ambiente de entorno passa a ser secundária. Neste caso, o autor cita que o impacto de um ambiente de entorno constituído por capoeira, desde que haja uma área contínua próxima a fragmentos florestais, seria preferível a qualquer outro tipo de ambiente de entorno, mesmo que menos hostil, em um local onde haja apenas pequenos fragmentos.

Outro fator de extrema importância na manutenção de populações animais em hábitats fragmentados são os corredores florestais (remanescentes lineares), que podem facilitar a passagem e/ou mesmo o uso por espécies comuns como Didelphis marsupialis e Metachirus nudicaudatus, que podem apresentar os mesmos índices de riqueza e abundância em corredores e floresta contínua (Lima \& Gascon, 1999). Segundo Laurance \& Laurance (1999), os corredores são geralmente degradados, sendo as espécies de mamíferos arbóreos, que forrageiam em espécie vegetais de sucessão, adaptados a utilizar estes remanescentes lineares.

Para Lidicker (1999), os corredores são ambientes não sustentáveis e atuam como bordas, sendo sua funcionalidade dependente da resposta das espécies aos efeitos de borda. Desta forma, um remanescente linear pode ao mesmo tempo em que atuar como corredor para muitas espécies, atuar como barreira para outras. 
A destruição dos hábitats naturais, de uma forma geral, resulta em uma queda da diversidade em escala global, podendo ocorrer, ao contrário, um aumento da diversidade em escala regional e/ou local. Em escala global, esta destruição dos hábitats é caracterizada por uma série de mudanças ocasionando, eventualmente, em processos de especiação; em escala regional, pode levar à especiação, extinção, extirpação ou imigração; e, em escala local, pode causar grandes alterações nos processos dos ecossistemas, incluindo produtividade, ciclo de nutrientes, e retenção de nutrientes, onde o aumento da diversidade pode ser mais comum do que o decréscimo (Sax \& Gaine, 2003).

A fragmentação pode ser diretamente responsável por uma drástica redução no tamanho efetivo de muitas populações animais e de suas viabilidade genética, fato desencadeado a partir dos efeitos indiretos da alteração na estrutura vegetal sobre os mamíferos não-voadores. Como exemplo, está a diminuição da disponibilidade de grandes frutos, que leva a uma redução das populações de grandes presas e subseqüente exclusão dos grandes predadores, interferindo na regulação das populações de presas. Consequentemente, no processo de competição por espaço, os vegetais que produzem pequenos frutos aumentam em abundância, aumentando, assim, as populações de pequenas presas e pequenos predadores, que passam a ser mais comuns em ambientes alterados (Terborgh, 1992). Para morcegos, parece ocorrer exatamente o oposto, ocorrendo um acréscimo de espécies vegetais que produzem grandes frutos, consumidos por espécies de maior porte (Schulze et al., 2000), embora isto não tenha sido observado por outros autores (Cosson et al., 1999a e Bernard \& Fenton, 2003).

Segundo Almeida (1996), a fragmentação e/ou simplificação dos ecossistemas pode provocar alterações significativas sobre as comunidades bióticas, causando reduções populacionais, mudanças na razão sexual e isolamento de metapopulações. $O$ processo de fragmentação florestal pode, ainda, resultar em um acréscimo na riqueza de espécies coexistentes, em decorrência das alterações ecológicas ao longo do tempo, que podem levar à especiação (Phillips, 1997). Este padrão não é observado para as comunidades de quirópteros, pois este grupo de mamíferos apresenta alta capacidade de locomoção (Nowak, 1994; Trajano, 1996 e Cosson et al., 1999a), podendo ultrapassar 
com grande facilidade ambientes de entorno entre remanescentes florestais (Nowak, 1994; Bernard \& Fenton, 2003).

Com relação à área de uso das espécies, os ambientes simplificados exigem dos animais grandes gastos de energia na procura de alimento (Almeida, 1996 e Bernard \& Fenton, 2003), além de um maior risco de sobrevivência dos indivíduos adultos e de suas proles, pela maior exposição a predadores. Entretanto, o maior risco da fragmentação estaria na dificuldade de sustentação genética das populações animal, principalmente de espécies do interior das matas, ocorrendo a "erosão" genética proporcionada pelo endocruzamento em populações muito reduzidas, que podem levar a extinção local (Almeida, 1996).

Segundo Laurance (1999b), pelo fato dos desmatamentos constituírem um processo não-randômico, nem todos os tipos florestais são igualmente fragmentados, sendo mais vulneráveis as áreas de fácil acesso e de relativo potencial produtivo, que apresentem solos com boa drenagem e topografia moderada.

Devido à escassez de estudos que busquem compreender o processo de fragmentação sobre a Mata Estacional Semidecídua, não se pode desconsiderar que a Floresta Atlântica - com a extensão a que a ela vem sendo atribuída - representa um sistema ideal para se medir os efeitos do desmatamento na extinção de espécies (Brown Jr. \& Brown, 1992). Segundo os autores, a persistência de espécies raras em áreas fragmentadas da Floresta Atlântica deve-se: à presença de numerosos microhábitats, entre os quais pequenas populações se movem; às respostas adaptativas ao alto grau de alterações naturais do hábitat; e à rápida adaptação às mudanças, pela "plasticidade" de muitas espécies de plantas e animais em alterarem seus padrões de comportamento, resultando em um melhor aproveitamento das novas características do ambiente.

A floresta de encosta da Serra do Mar, que representa a maior extensão contínua de Floresta Atlântica do Sul e Sudeste brasileiro, ainda vem se mantendo em função de seu relevo altamente acidentado, embora seja, atualmente, um ecossistema bastante fragmentado, sendo na verdade formada por vários bolsões de florestas fragmentadas e circunvizinhas por áreas particulares (Martuscelli, 1996). Além disso, este estado de fragmentação do Bioma torna a diversidade e a densidade de muitas populações animais 
baixa e variável, devido ao fato dos remanescentes apresentarem uma grande área periférica, se comparado a áreas núcleo, passando os fragmentos a comportarem-se como borda (Jorge et al., 2001).

Atualmente, a maior parte dos fragmentos florestais no Estado de São Paulo (o que restou das florestas originais), e de outras regiões do país que se encontram na mesma situação, são considerados inviáveis para a conservação de animais que necessitam de extensa área de vida. Cerca de 50\% das Unidades de Conservação (UC) do Estado (excluindo as APA), são menores de 500 ha; 12,9\% estão entre 500 e 1.000 ha; $19,4 \%$ entre 1.000 e 5.000 ha; $9,0 \%$ entre 5.000 e 10.000 ha; $9,0 \%$ entre 10.000 e 40.000 ha; e apenas 3,8\% são maiores que 40.000 ha (E. E. Juréia/Itatins, P. E. Jacupiranga e o P. E. Serra do Mar), podendo garantir a manutenção de populações viáveis a um médio prazo de tempo, o que torna essencial o manejo destas unidades de conservação (Martuscelli, 1996).

\subsection{O processo de fragmentação na Bacia do rio Tibagi}

A ocupação da Bacia do rio Tibagi, no Estado do Paraná, deu-se em três etapas: a primeira foi caracterizada pelas reduções jesuíticas espanholas (1610-1631); a segunda foi o ciclo do ouro no Paraná, que se iniciou em 1640, estendendo-se até o final do século XIX; e a terceira etapa foi o ciclo da madeira e o do café, que ocorreu nas primeiras décadas do século XX (Soares \& Medri, 2002). Segundo os autores, o ciclo da madeira e do café no baixo Tibagi se iniciou pelo leste e oeste do rio, tornando os processos de desmatamento, ocupação e alteração, rápidos, e sendo esta frente cafeeira a principal força de desmatamento no norte da Bacia (baixo Tibagi), que hoje se encontra quase totalmente sem cobertura vegetal.

No passado, a vegetação presente na região pertencente à Bacia Hidrográfica do rio Tibagi, fazia parte de uma área contínua que vinha desde o sul do Estado de Minas Gerais até o Rio Grande do Sul, passando pelos Estados de São Paulo, Paraná e Santa Catarina. Hoje, este tipo florestal foi quase totalmente destruído, sendo sua fauna drasticamente reduzida (Reis et al., 2002). Segundo Soares \& Medri (2002), o Paraná 
preserva hoje apenas $9 \%$ de suas florestas, sendo apenas $3,8 \%$ o que restou da cobertura vegetal original na Bacia do rio Tibagi.

Com relação aos possíveis impactos de matrizes constituídas por gramíneas sobre os remanescentes florestais, White et al. (1999) consideram que as pequenas propriedades rurais são as principais responsáveis pela fragmentação. Para os autores, as tecnologias atualmente disponíveis na área pecuária possibilitam uma criação intensiva, porém, pelo alto custo desta tecnologia, apenas grandes proprietários rurais têm acesso a estas tecnologias. Por outro lado estão os pequenos proprietários que, por não terem condições de investir em uma tecnologia avançada, optam pelo uso de suas terras de forma extensiva, em busca da ampliação de suas fronteiras e de seus capitais. É neste ponto que as pequenas propriedades rurais avançam sobre os remanescentes florestais, causando a fragmentação florestal.

Segundo Fearnside ${ }^{1}$ as pequenas propriedades rurais destinadas à produção de leite e carne bovina apresentam um grande impacto sobre as florestas. Na Amazônia, por exemplo, estas pequenas propriedades rurais (com menos de 60 ha.), correspondem a apenas $10 \%$ das propriedades rurais da região, porém são responsáveis por $30 \%$ de todo o desmatamento.

\subsection{O ambiente entre os fragmentos florestais}

A acelerada destruição das florestas reduz estas a remanescentes que, em muitos casos, são imersos em um ambiente de vegetação alterada, como as pastagens e culturas (Chiarello, 2000). O ambiente que rodeia os fragmentos florestais exerce grandes efeitos sobre as comunidades de vertebrados. Primeiro, por que muitas espécies (originalmente presentes em florestas contínuas) invadem este ambiente, passando a constituir uma espécie comum ao ambiente modificado. Segundo, por estas espécies poderem usar este ambiente de entorno, e poderem providenciar recursos potenciais próximos, principalmente em casos onde há grandes extensões de floresta (Gascon et al., 1999). Além destes fatores, a matriz pode atuar sobre o fragmento florestal intensificando ou

\footnotetext{
${ }^{1}$ FEARNSIDE foi citado por White et al. (1999).
} 
diminuindo os efeitos de borda, dependendo apenas do tipo vegetal pôr que o ambiente de entorno é constituído (Laurance, 1999a).

Para Almeida (1996), a homogeneidade da vegetação é inversamente proporcional à diversidade da fauna em áreas florestadas, que distantes de florestas naturais e sem sub-bosque, representam um ambiente pobre, onde os animais gastam mais energia para encontrar alimento, do que a energia necessária para sua alimentação e de seus filhotes, tornando esta prole inviável e sua existência difícil. Assim, estes ambientes passam a apresentar apenas populações muito reduzidas, compostas praticamente por indivíduos transitórios.

Segundo Cosson et al. (1999b) e Gascon et al. (1999), o entorno atua como um filtro seletivo, mas que muitas espécies de floresta primária podem utilizar este ambiente para movimentação e/ou reprodução, como observado também por Chiarello (2000) e Bernard \& Fenton (2003). Os autores ainda sugerem que este ambiente seria de grande importância para a dinâmica dos remanescentes florestais, possibilitando a conservação das populações dos fragmentos.

Para pequenos mamíferos de hábito arborícola a fragmentação pode não resultar em diferenças significativas na diversidade, dependendo do ambiente presente entre os remanescentes florestais (Laurance, 1999a). Lindenmayer (2000a) sugere que em um florestamento de Pinus spp, por apresentar uma estrutura caulinar rugosa, pode ao invés de atuar como uma barreira, facilitar o movimento destas espécies entre os fragmentos. Entretanto, esta pode ser uma conclusão precipitada se considerarmos que muitos outros fatores podem estimular ou desestimular um animal a atravessar um plantio comercial como o de Pinus spp., sendo a estrutura morfológica das espécies vegetais do plantio, apenas um dos prováveis fatores.

Os ambientes abertos, como as pastagens, causam alterações mais sérias na composição vegetal dos fragmentos florestais, sendo a grande mortandade de árvores um resultado dos efeitos de borda em função destas alterações, que pode provocar, direta e/ou indiretamente, mudanças drásticas na fauna, principalmente sobre espécies pouco tolerantes aos ambientes abetos (Laurance, 1999a). 


\subsection{A susceptibilidade das espécies às alterações ambientais}

De uma forma geral, existe um consenso entre diversos autores (Emmons \& Feer, 1997; Cosson et al., 1999b; Harrington et al., 2001 e Coppolitto et al., 2004), com relação a grande parte das características que tornam uma espécie mais ou menos vulnerável à fragmentação.

Os mamíferos em ambientes fragmentados são submetidos a três pressões: a caça, a introdução de espécies exóticas, e a destruição dos hábitats. A caça atua mais sobre espécies grandes (dependendo de sua importância econômica), conspícuas, expostas a local de fácil acesso, e que apresentam baixa taxa de reprodução. A introdução de espécies exóticas pode afetar as espécies silvestres através da introdução de patógenos e competição. Por fim, a destruição do hábitat, que afeta, principalmente, as espécies com pequena distribuição geográfica e/ou pouco flexíveis (Emmons \& Feer, 1997). Entretanto, o processo de adaptação das espécies (alta flexibilidade) associado aos diversos fatores antropogênicos é mais norma do que exceção (Brown Jr. \& Brown, 1992 e Stockwell \& Ashley, 2004).

As espécies de determinada comunidade podem se distinguir por três categorias: 1) espécies residentes; 2) espécies com grande habilidade de dispersão entre fragmentos, mas que não são residentes; 3) e aquelas que exploram os novos hábitats criados (Cosson et al., 1999b). Porém, a tolerância da fauna à fragmentação (Julia \& Richard, 1999) está fortemente ligada a diversos fatores como: a qualidade do hábitat (Brooks \& Eisenberg, 1999); a disponibilidade de alimentos e abrigos no novo ambiente, e a competição interespecífica por estes; o tamanho e a dinâmica das metapopulações; e às mudanças no risco de predação (Harrington et al., 2001). Além destes fatores, as próprias características morfofisiológicas como regulação térmica, sistema locomotor e a capacidade de criar microclimas estáveis, podem definir o grau de tolerância dos mamíferos às mudanças ambientais resultantes da fragmentação (Ávila-Pires, 1966).

A mobilidade dos animais é um determinante na ultrapassagem de ambientes de entorno (Wiens, 1996), e esta mobilidade está intimamente ligada às características biológicas das espécies. Para os grandes mamíferos terrestres (Tozetti, 2002 e Timo, 
2003) e voadores, foi observado um uso freqüente de pequenos fragmentos, bem como a dispersão entre estes, demonstrando a alta mobilidade destes grupos, ao contrário de grupos como o dos primatas e de pequenos mamíferos, que apresentaram uma limitada habilidade de dispersão (Cosson et al., 1999b). Entre os morcegos, muitas espécies apresentam pouca fidelidade ao ninho deslocando-se frequentemente para outros locais, enquanto que espécies da subfamília Phyllostominae são mais sedentárias (Trajano, 1996).

Coppolitto et al. (2004) definem o grau de sensibilidade de uma espécie às alterações dos ecossistemas naturais através de uma série de critérios: 1) o tamanho da área em que as espécies vivem (blocos de hábitats podem não ser grandes o suficiente para suportar as populações de forma viável e/ou ecologicamente funcional), as distâncias de dispersão entre os blocos, a proporção da área ocupada, e a capacidade desta área de suprir os requerimentos de toda a população; 2) o requerimento de uma heterogeneidade de hábitats durante seu ciclo de vida torna-se uma vantagem, sendo que apenas um pequeno número de espécies requer hábitats homogêneos ou de menor diversidade que uma paisagem de mesmo tamanho; 3) a exposição a um grande número de locais de uso humano aumenta as chances de conflito com os seres humanos, aumentando frequentemente as taxas de mortandade, dependendo, logicamente, da severidade das ameaças, urgência, probabilidade de ocorrência e a área afetada, além da área de uso da espécie, o tempo de recuperação e a proporção do hábitat afetada; 4) a funcionalidade da espécie no ecossistema; e 5) a importância econômica da espécie para o homem.

Para Cosson et al. (1999b) as espécies mais tolerantes são as de grande tamanho corpóreo, naturalmente abundante, generalista em hábitats e requerimentos alimentares, com grande habilidade locomotora, e de ampla distribuição geográfica. Entretanto, há uma contrariedade quanto às espécies grandes, pois estas, geralmente, requerem grandes territórios, o que as torna bastante vulnerável à fragmentação.

Em geral, as espécies de vertebrados mais tolerantes e capazes de utilizar o ambiente de entorno apresentam uma maior probabilidade em persistirem em ambientes fragmentados, devido à possibilidade de movimento entre os fragmentos, fato este que 
torna possível a redução dos efeitos deletérios que agem sobre as pequenas populações em fragmentos. Para as espécies pouco tolerantes, como os primatas, a presença de remanescentes lineares unindo os fragmentos pode ajudar a minimizar, em certo grau, os efeitos do entorno (Laurance \& Laurance, 1999), principalmente se este for constituído por pastagem.

\subsection{A fragmentação sobre comunidades de morcegos}

A intensificação das técnicas agrícolas - como o aumento do uso de fertilizantes sintéticos, pesticidas e reguladores de crescimento - pode ser um fator determinante na presença ou ausência de muitas espécies de quirópteros em um ecossistema natural. Segundo Wickramasinghe et al. (2003), o declínio de insetos, resultante desta intensificação agrícola, afeta seriamente as atividades de forragem de muitas espécies de morcegos insetívoros.

Dentro do grupo dos morcegos, a família Phyllostomidae parece ser uma boa indicadora de ambientes alterados, devido ao fato de apresentar uma alta diversidade de espécies alimentando-se em guildas diferentes, e dentre estas espécies, um grande número associado às áreas florestais (Wilson et al., 1996). Dentre suas subfamílias, a Phyllostominae é considerada como a mais sensível às degradações ambientais, sendo a presença de espécies desta subfamília, como Tonatia silvicola, é um excelente indicador de degradação ambiental (Falcão et al., 2003), também por esta espécie utilizar áreas pequenas de vida (Trajano, 1996 e Bernard \& Fenton, 2003).

Dados apresentados por diversos autores (Marinho-Filho \& Sazima, 1998; Félix et al., 2001; Pedro et al., 2001; Reis et al., 2002 e Falcão et al., 2003), demonstram que as comunidades de morcegos em diversas regiões do Brasil são heterogêneas, com poucas espécies dominantes, tanto em ambientes alterados como em ambientes conservados, para um número relativamente grande de espécies raras.

Segundo Felix et al. (2001), Reis et al. (2002), e Reis et al. (2003), as espécies

mais abundantes em pequenos fragmentos no município de Londrina são Artibeus lituratus, Carollia perspicillata e Sturnira lilium. Além destes, outros autores (Baptista \& 
Mello, 2001 e Pedro et al., 2001), também encontraram estas espécies como sendo as mais abundantes em remanescentes florestais na região sudeste, e em florestas degradadas de áreas urbanas (Marinho-Filho \& Sazima, 1998), ressaltando a importância destas espécies generalistas e extremamente versáteis na dinâmica destas comunidades, $\mathrm{e}$ o fato destas não serem bons indicadores de degradação ambiental (Reis et al., 2003).

A presença de Artibeus lituratus, C. perspicillata e Sturnira lilium como espécies dominantes em qualquer tipo de ambiente, pode estar relacionada com o habito generalista em relação ao ambiente utilizado, e ao fato de se reproduzirem-se durante todo o ano, mesmo que apresentem alguns picos de maior reprodução (Nowak, 1994).

A fragmentação dos ecossistemas naturais pode resultar em uma grande alteração da riqueza e abundância de espécies (Bernard et al., 2001), e na estrutura das guildas, sendo estas alterações mais pronunciadas em pequenos fragmentos. Neste processo de fragmentação, a distância de isolamento entre os fragmentos foi uma variável importante, impedindo a dispersão dos morcegos para outros locais favoráveis, afetando principalmente os pequenos morcegos frugívoros de sub-bosque, que passaram a constituir espécies escassas nestes fragmentos. Para os grandes morcegos frugívoros de copa foi observada uma baixa sensibilidade à fragmentação, fato este que pode estar relacionado à maior facilidade de percorrer longas distâncias, e à maior disponibilidade de alimento nas copas (Cosson et al., 1999a; Cosson et al., 1999b). Entretanto, segundo outros autores (Nowak, 1994; Trajano, 1996 e Bernard \& Fenton, 2003), as espécies de sub-bosque não se mostraram muito sensíveis à fragmentação, sendo freqüente percorrerem grandes distâncias em busca de alimento e abrigo.

Comparando-se os fragmentos florestais e as áreas contínuas, o aumento da luz e do vento no sub-bosque dos fragmentos altera sua estrutura vegetal e horizontal, passando esta a apresentar um maior número de espécies pioneiras. Muitas destas espécies vegetais pioneiras, assim como Piper spp, produzem frutos relativamente grandes que, em geral, são consumidos por morcegos de tamanho corpóreo relativamente grande dentro do grupo dos Microchiroptera (Schulze et al., 2000), sendo de se esperar que estas espécies maiores sejam mais comuns nos pequenos fragmentos, pois grande parte dos morcegos menores não se alimenta de grandes frutos. C. perspicillata, 
entretanto, é uma espécie relativamente pequena que se alimenta preferencialmente de Piper spp e Solanum spp., o que torna esta espécie comum em ambientes degradados, devido à maior densidade de piperáceas e solanáceas nestes ambientes, e exige uma maior movimentação, considerando que, geralmente, estas espécies vegetais não se distribuem uniformemente no ambiente (Bernard \& Fenton, 2003).

$\mathrm{O}$ grau de degradação de um ecossistema pode afetar negativamente os processos de polinização e de dispersão, realizados através dos morcegos. Segundo Stoner et al. (2002) e Quesada et al. (2003), uma espécie vegetal pode deixar drasticamente de ser visitada por morcegos se estiver em um ambiente degradado, fato que não ocorreria em uma área conservada. Entretanto, muitas espécies de morcegos foram relatadas em áreas alteradas, sendo comuns e abundantes inclusive em áreas urbanas (Reis et al., 2002).

Moreno \& Malffter (2001), estudando as diversidades $\boldsymbol{\alpha}, \boldsymbol{\beta}$ e $\boldsymbol{\gamma}$ de morcegos em sete tipos de hábitats (paisagem heterogênea), concluíram que os ambientes estudados atuam como uma área homogênea para as espécies de morcegos generalistas, sendo estes não sensíveis às mudanças ambientais em escala espacial. Além da característica generalista, a escassez de cavidades utilizadas como abrigo diurno e/ou noturno nos pequenos fragmentos, pode ser outro fator determinante sobre a baixa abundância de muitas espécies nestes ambientes, tornando-se necessária a locomoção entre os fragmentos, o forrageio nestes pequenos fragmentos, e o abrigo em áreas contínuas próximas para alimentarem-se e/ou descansarem (Schulze et al., 2000).

$\mathrm{O}$ tamanho de um fragmento florestal influi sobre a disponibilidade de alimento para os diferentes grupos de morcegos, sendo menor a abundância de morcegos insetívoros quanto menor o tamanho do remanescente florestal (Pedro et al., 2001).

Segundo Lim \& Engstrom (2001), os quirópteros são considerados um táxon chave no desenvolvimento dos sistemas de monitoramento, por compreenderem uma grande porção da fauna total, serem facilmente inventariados, e pela sua diversidade e composição, além de algumas espécies poderem ser utilizadas como indicadoras de distúrbios ambientais.

A conservação de grandes fragmentos é necessária, devido à maior estruturação destes, capaz de sustentar uma maior riqueza de espécies (Félix et al., 2001 e Reis et al., 
2003). De fato, o tamanho de fragmento, bem como seu estado de conservação, mostra-se importante na manutenção da biodiversidade, mas isto não elimina o potencial conservacionista de pequenos fragmentos, principalmente para espécies pouco sensíveis à fragmentação e que se movem facilmente entre áreas distantes (Wickramasinghe et al., 2003), como é o caso de Syconycteris australis, que em uma paisagem altamente fragmentada apresenta um deslocamento de até $5,8 \mathrm{~km}$, fator este que a torna capaz de manter certa variabilidade genética e maior conectividade demográfica entre os fragmentos florestais (Law \& Lean, 1999).

No município de Londrina, foram realizados estudos sobre morcegos em áreas fragmentadas pertencentes à Bacia do rio Tibagi (Félix et al., 2001; Reis et al., $2002 \mathrm{e}$ Reis et al., 2003). Destes estudos, destaca-se o de Reis et al. (2002), onde foram registradas 39 espécies de morcegos, que corresponde a $28 \%$ das espécies do país. Os autores sugerem que esta alta diversidade só foi possivelmente mantida devido à presença dos remanescentes florestais, que propiciam abrigo e alimento para estas espécies. Porém, o que pode ter ocorrido é um aumento da diversidade em escala local ou regional que nem sempre pode ser benéfico (Sax \& Gaine, 2003), sendo resultado de uma descaracterização da diversidade original, e que pode resultar em alterações nos processos do ecossistema.

\subsection{A mastofauna terrestre em hábitats fragmentados}

As pesquisas relativas à fauna no Estado de São Paulo, desde o descobrimento até meados do séc. XVIII (após mais de 300 anos de exploração dos recursos naturais), resultaram em pouco ou nada de registros ou documentos, deixando basicamente descrições sobre o meio ambiente e sua composição. A partir de 1800 , iniciou-se uma fase de explorações para a coleta de material científico, ou com o intuito de conhecimento e catalogação (Martuscelli, 1996), que passam a ser considerados trabalhos muito importantes, principalmente para a tomada de qualquer decisão efetiva sobre a conservação dos recursos naturais. 
As populações de pequenos mamíferos em agroecossistemas têm sido pouco estudadas na região tropical (Engel \& Mello, 1933). Segundo Laurance (1999a), as comunidades de mamíferos em ambientes recentemente fragmentados podem mudar rapidamente em composição, havendo uma substituição de grande parte da fauna local dominante, por espécies generalistas e/ou exóticas. Estas/mudanças foram observadas por Carey \& Harrington (2001), que encontraram diversas alterações nas comunidades de mamíferos, caracterizadas por um decréscimo na abundância das espécies de pequenos mamíferos, principalmente de espécies locais e comuns, e pelo aumento de espécies raras (que antes não estavam nesta categoria), correndo o risco de uma extinção local.

A composição estrutural da vegetação influencia substancialmente a diversidade e a abundância de pequenos mamíferos terrestres (Gentile \& Fernandes, 1999 e Jorge et al., 2001), que acabam por sofrer mudanças em suas populações em decorrência, não apenas de mudanças no ecossistema, mas também por alterações sazonais (Alho et al., 1986), que podem definir a distribuição geográfica de uma espécie em determinada localidade (Lindenmayer et al., 2000b). Com o aumento da idade de um fragmento e, consequentemente, de sua complexidade estrutural e da matéria em decomposição no solo, alguns membros da comunidade passam a apresentar uma menor abundância em relação a outros membros da comunidade, concordando com os dados encontrados por Jorge et al. (2001), que observaram que a riqueza e abundância de espécies de pequenos mamíferos esta relacionada com a complexidade estrutural do ambiente.

A disponibilidade sazonal de insetos em um fragmento não influi sobre as populações de espécies de pequenos mamíferos insetívoros, sendo a estrutura da vegetação uma variável de maior magnitude do que o alimento, assim como as condições climáticas (Suárez \& Bonaventura, 2001), onde se observa um maior padrão de atividade em condições climáticas favoráveis.

Lindenmayer et al. (2000b), encontraram uma diferença significativa entre o tamanho de um remanescente e a diversidade de pequenos mamíferos, onde se constatou uma redução da diversidade em remanescentes, se comparado a áreas contínuas ou fragmentos de maior extensão, que são capazes de suportar populações maiores e mais resistentes aos processos de extinção local. 
O fato de um grupo de mamíferos aumentarem ou diminuir em abundância dentro de um fragmento florestal, dependerá do grupo taxonômico considerado. Os marsupiais, por exemplo, apresentam um hábito preferencialmente arborícola, sendo relatados mais sobre o estrato arbóreo em ambientes florestais que apresentem uma estrutura vertical bem desenvolvida, padrão este que pode resultar na diminuição da diversidade destes mamíferos em ambientes onde a composição vegetal original encontra-se descaracterizada, com um predomínio de espécies herbáceas e arbustivas, que podem favorecer a proliferação de algumas espécies de roedores, mais comuns neste estrato (Gentile \& Fernandes, 1999).

Em função da importância ecológica desempenhada pelos mesopredadores em uma comunidade, através do controle da abundância das espécies presa (Wang, 2002), é normal ocorrer um acréscimo na pressão de predação por parte destes predadores de médio porte, levando a um decréscimo da abundância de pequenos mamíferos nos fragmentos (Cosson et al., 1999b).

Segundo Harrington et al. (2001), quase todas as espécies de pequenos mamíferos foram possivelmente afetadas, positiva ou negativamente, pela fragmentação da floresta, sendo forçadas a forragear no ambiente entre os fragmentos, a alterar suas preferências alimentares durante o ano e a busca por abrigo, e a tornarem-se mais susceptíveis a predação (Tozetti, 2002). É lógico que estas alterações comportamentais devem, com o passar do tempo, resultar em custos adaptativos a estes animais, ocorrendo uma de duas possibilidades: ou a espécie pode se adaptar as novas condições, ou pode ser excluída do ambiente modificado, neste último caso, o espaço logo passa a ser ocupado por outra espécie mais hábil (Harrington et al., 2001).

$O$ uso de diferentes tipos de ambientes pela fauna foi verificado por Gheler-Costa (2002), que observou espécies de pequenos mamíferos utilizando diversos ambientes em áreas agrícolas com intensa alteração do uso do solo, sendo maior a diversidade e abundância em plantios de Pinus kesyia na presença de sub-bosque com espécies nativas.

Grandes mamiferos utilizam mais florestas naturais, evitando ambientes muito alterados como reflorestamentos e locais abertos como estradas e aceiros, que em sua maioria seriam freqüentados por animais silvestres, principalmente para translocação 
(Wallauer et al., 2000 e Tozetti, 2002). De fato, são freqüentes espécies generalistas como a Onça Parda (Puma concolor) e o Mão-pelada (Procyon cancrivorus), forragearem em diferentes tipos de ambientes, desde que haja ambientes fechados próximos para se abrigarem (Chiarello, 1999).

Em uma área de Pilar do Sul (SP), as espécies de mamíferos não voadores utilizam os plantios de Eucaliptus saligna, demonstrando que estes plantios intercalados às florestas nativas, formando mosaicos, diminuem os impactos da fragmentação sobre as espécies de mamíferos (Silva, 2001). A autora observou, também, que espécies arborícolas como Cebus apella não utilizaram estes florestamentos, apesar de serem comuns relatos sobre a presença desta espécie em florestas de eucaliptos.

A maior estruturação vertical e horizontal da vegetação resultou em uma maior diversidade e em uma menor dominância de mamíferos de médio e grande porte em comparação às áreas de cerrado e campo sujo, demonstrando o uso diferencial destes ambientes por estas populações (Tozetti, 2002).

Uma cobertura vegetal secundária disponibiliza menos recursos alimentares para grandes mamíferos frugívoros e herbívoros, sendo, o uso destas áreas, menos freqüente (Timo, 2003). Segundo o autor, algumas espécies generalistas como Tapirus terrestris e Mazama spp., se beneficiem com as características destes ambientes, composta por uma grande abundância de plantas herbáceas e arbustivas. O primata $C$. apella normalmente apresenta-se em alta densidade em fragmentos florestais em função de sua dieta variada $\mathrm{e}$ seu comportamento generalista (Cosson et al., 1999b).

Para a Bacia do rio Tibagi, já foram registradas 60 espécies de mamíferos de médio e grande porte (Peracchi et al., 2002), demonstrando que a região conserva uma grande diversidade. Isto torna visível a importância de maiores estudos sobre a fauna desta região, para se tomar medidas adequadas no desenvolvimento das atividades humanas sem prejuízos para a mastofauna local e o ecossistema.

Para os grandes mamíferos, Elmhagen \& Angesbjörn (2001), consideram difícil a definição de uma área ideal para a manutenção de sub-populações de mamíferos, devido a esta manutenção depender de vários fatores, dentre os quais, a taxa de migrações entre as sub-populações, a longevidade das gerações, e a densidade populacional (Phillips, 
1997). Como citado anteriormente para a mastofauna em geral, o requerimento de uma heterogeneidade de hábitats durante seu ciclo de vida torna-se uma vantagem, sendo que apenas um pequeno número de espécies requer hábitats homogêneos (Coppolitto et al., 2004), entretanto, estes hábitats não podem ser desprezados do ponto de vista conservacionista, em função dos diferentes requerimentos das espécies.

\subsection{A conservação da mastofauna em ambientes fragmentados}

A conservação da mastofauna, em parte, depende de estudos do ambiente heterogêneo (paisagem) formado pelos fragmentos, corredores e entorno (Selman \& Doar, 1992 e Wiens, 1996). De uma forma geral, qualquer estratégia a ser tomada necessita antes passar por uma seqüência de ações: a identificação da estrutura interna e forma dos fragmentos; o arranjo espacial dos remanescentes, corredores e entorno (aspectos como proximidade, densidade e conectividade); e, a heterogeneidade de ambientes. A partir destes procedimentos inicia-se o estabelecimento de áreas para a conservação, de acordo com objetivos que devem ser pré-definidos. Pode ocorrer a necessidade de estabelecer estas estratégias de conservação sobre espécies "chave" ou espécies “alvo" (Selman \& Doar, 1992), sendo necessário, então, a identificação destas.

A escolha de espécies indicadoras depende do conhecimento de quais espécies estão presentes no ambiente, onde estão, e como respondem ao distúrbio produzido. Os indicadores de diversidade podem ser divididos em dois grupos: 1- indicadores baseados no táxon (espécie ou guilda), que depende do conhecimento da presença ou ausência de outras espécies a elas associadas, dos efeitos de sua retirada ou inclusão, seu significado no ambiente, sua abundância, sua capacidade para indicar mudanças ambientais, se são passíveis de manejo e, nos casos de considerar uma guilda, se todos os membros desta guilda respondem da mesma forma a um mesmo distúrbio; 2- indicadores baseados na estrutura, atuam no nível local e de paisagem, através da complexidade estrutural de um local, composição de espécies vegetais, conectividade e heterogeneidade (Lindenmayer et al., 2000a). 
A utilização de espécies de médio e grande mamíferos como espécie "alvo" é válida desde que se considere a utilização de grandes áreas, não isoladas, e contendo razoável variedade de hábitats disponíveis para a espécie poder realizar todas as suas atividades, referentes ao ciclo de vida e manutenção de populações viáveis (Timo, 2003).

Como estratégia para a conservação dos ecossistemas naturais, Lindenmayer et al. (2000a) sugerem: o estabelecimento de um grupo adequado de áreas prioritárias e representativas da biodiversidade; uma melhora da estrutura vertical e horizontal, na conectividade e heterogeneidade da área; uma diminuição dos impactos das atividades humanas; e o monitoramento das estratégias aplicadas. Sugere, ainda, que considerar a estrutura, ao invés das espécies indicadoras, pode ser mais efetivo na conservação de uma maior diversidade, pois a escolha de uma espécie ou táxon pode não resultar na conservação de outros táxons.

Roberge \& Angelstam (2003) apontam para o uso de espécies "guarda-chuva" (espécies as quais sua conservação proporciona a proteção de espécies co-ocorrentes), em estratégias que visem à conservação dos ecossistemas naturais. Os autores também sugerem que estas espécies devam apresentar grandes áreas de vida, como os grandes carnívoros, por exemplo, o que envolveria a proteção de diversas outras espécies com áreas menores. Entretanto, estratégias de conservação baseadas exclusivamente nos requerimentos de área podem ser pouco efetivas se não incorporarem os requerimentos de espécies mais sensíveis, que necessitam de hábitats específicos. Assim como o uso de espécie "bandeira", que não é uma ferramenta muito efetiva de conservação por não ter ligação com a diversidade e abundância de pequenos vertebrados (Caro et al., 2004).

Devido à subjetividade de se usar uma espécie focal para conservação, Coppolitto et al. (2004) e Roberge \& Angelstam (2003), recomendam a adoção de todas as espécies selecionadas para conservação, desde que considere as dificuldades associadas com esta estratégia, e o fato da improbabilidade de uma ou poucas espécies "guarda-chuva" englobarem todas as outras espécies. Assim, as estratégias a serem tomadas devem seguir uma seqüência de etapas, que inicia com a seleção de todas as espécies que apresentem as características "guarda-chuva", e depois a escolha da(s) melhor(es) espécies em função da área que se pretende conservar (Roberge \& Angelstam, 2003). 


\section{MATERIAL E MÉTODOS}

\section{1 Área de estudo}

A Bacia do rio Tibagi cruza o Estado do Paraná de norte a sul, e é dividida em três áreas: alto, médio e baixo Tibagi. Esta classificação foi baseada em diferenças geológicas e de solo (Stipp, 2002 e Torezan, 2002), climática (Mendonça \& DanniOliveira, 2002), e vegetativa (Torezan, 2002).

A Fazenda Figueira localiza-se no município de Londrina (PR), no baixo Tibagi (Figura 1), sendo propriedade da Fundação de Estudos Agrários Luiz de Queiroz (FEALQ) desde o ano de 2000, quando adquirida por meio de doação de seu antigo proprietário Alexandre Von Pritzelwitz, e ex-aluno da Escola Superior de Agricultura "Luiz de Queiroz" (ESALQ).

A Fazenda Figueira possui uma área total de 3.670,29 hectares, sendo que aproximadamente mil hectares estão representados por mata natural ou em regeneração pertencentes à Reserva Particular do Patrimônio Natural (RPPN) Estadual Mata do Barão, e 2.670 hectares por pastagens destinadas às atividades pecuárias de exploração extensiva, principalmente de gado bovino (cria, recria e engorda), e secundariamente eqüino, muar e ovino, pertencentes à Estação Experimental Agrozootécnica "Hildegard Georgina Von Pritzelwitz". 

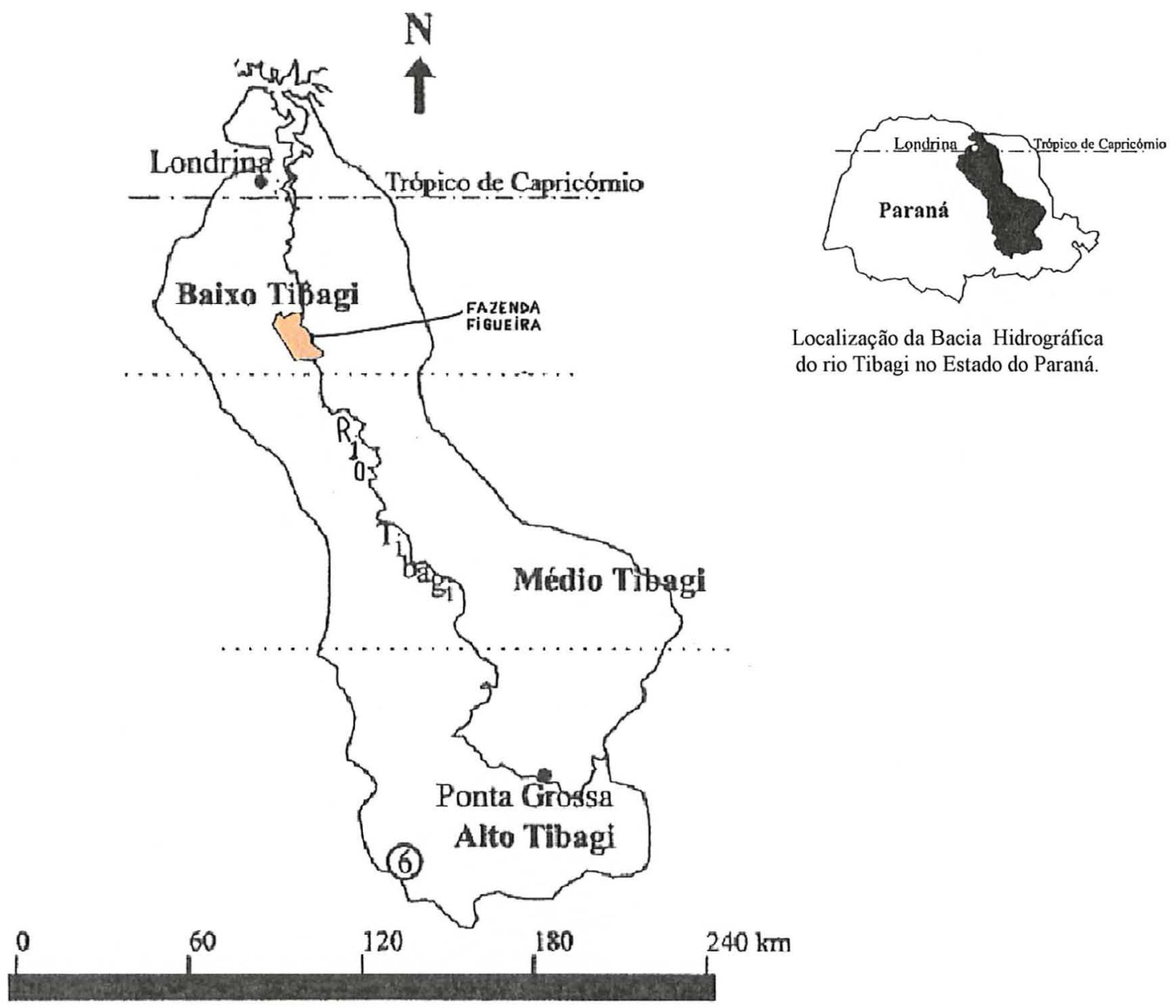

Localização da Bacia Hidrográfica do rio Tibagi no Estado do Paraná.

Figura 1 - Localização geográfica da Fazenda Figueira dentro da Bacia Hidrográfica do rio Tibagi. O mapa do Estado e da Bacia Hidrográfica foram extraídos de Medri et al. (2002)

\subsubsection{Características climáticas e geológicas}

A propriedade esta situada a $23^{\circ} 32^{\prime} 22^{\prime \prime} \mathrm{S}$ latitude e $50^{\circ} 58^{\prime} 23^{\prime \prime} \mathrm{W}$ longitude, em zona de tipo climático Cfa. subtropical úmido com verão quente, sendo a temperatura média anual de $21^{\circ} \mathrm{C}$ (méd.máx. $28^{\circ} \mathrm{C}$ e méd.min. $16^{\circ} \mathrm{C}$ ). A média pluviométrica anual é 
de $1.600 \mathrm{~mm}$, atingindo, no período de estiagem (julho e agosto), a média mensal de 50 $\mathrm{mm}$ (Mendonça \& Danni-Oliveira, 2002).

O levantamento da mastofauna na Fazenda Figueira ocorreu dos dias 14-28 de julho de 2003, de 7 de janeiro a 18 de fevereiro, 6-15 de julho e 7-11 de agosto de 2004 . As características climáticas de temperatura e precipitação para estes períodos foram apresentadas na Tabela 1 .

Tabela 1. Dados climáticos referente aos dias e meses de levantamento da mastofauna na Fazenda Figueira

\begin{tabular}{cccccc}
\hline Ano & Mês & Temp. Máx. & Temp. Mín. & Temp. Méd. & Precipitação (mm) \\
\hline 2003 & Julho & 29,4 & 11,6 & 19,1 & 0,0 \\
2004 & Janeiro & 32,8 & 16,7 & 24,0 & 151,0 \\
& Fevereiro & 32,8 & 14,2 & 23,9 & 59,8 \\
& Julho & 25,2 & 6,4 & 16,9 & 53,8 \\
& Agosto & 26,0 & 5,8 & 14,7 & 0,0 \\
\hline
\end{tabular}

Fonte: Instituto Agronômico do Paraná, Estação Agrometereológica de Londrina.

Quanto às características de solo, a fazenda encontra-se na zona fisiográfica conhecida como terceiro planalto, sendo este, talhado sobre rochas eruptivas básicas (Stipp, 2002), e onde as altitudes médias não ultrapassam os 800 metros (Torezan, 2002). O solo é, em sua maior parte, dos tipos Terra Roxa Estruturada Eutrófica (TEr) e Solos Litólicos Eutróficos (Re). O primeiro tipo de solo apresenta uma textura muito argilosa (cerca de $60 \%$ na maior parte dos horizontes), principalmente no horizonte superficial, cerosidade, grande saturação de bases e alta capacidade de drenagem; o segundo tipo é um solo jovem e raso, sendo horizonte A diretamente sobre a rocha consolidada (Stipp, 2002). 


\subsubsection{Vegetação da Fazenda Figueira}

A Fazenda Figueira é composta principalmente por pastagens de capim colonião (Panicum maximum), apresentando locais onde a pastagem apresenta um início de sucessão secundária, além de vários fragmentos de Floresta Estacional Semidecídua e Floresta Estacional Semidecídua Ribeirinha ou mata ciliar.

Em toda a região do baixo Tibagi, no qual se encontra a Fazenda Figueira, o tipo vegetacional dominante é a Floresta Estacional Semidecídua, sendo esta um prolongamento da Mata Atlântica para o interior (Torezan, 2002; Rodrigues et al., dados não publicados ${ }^{2}$ ).

Para a área da Fazenda Figueira foram registrados um total de 279 espécies vegetais pertencentes a 60 famílias, das quais as de maior riqueza foram LeguminosaePapilionoideae (18), Solanaceae (14) e Euphorbiaceae (13). Além disto, espécies pouco comuns à Bacia do rio Tibagi como Didymopanax angustissimum foram encontradas na fazenda (Rodrigues et al., dados não publicados). Resultado semelhante foi obtido por Dias et al. (2002), que encontrou Leguminosae como a mais importante no baixo Tibagi, depois de Myrtacea.

A diversidade vegetal da Bacia do Tibagi $(3,08)$ mostrou que esta não apresenta uma riqueza de espécies muito grande (média de 94,8 espécies), tendo valores muito semelhantes às florestas ribeirinhas do sul e sudeste, e inferiores às florestas da Amazônia e da Mata Atlântica. O norte da Bacia do Tibagi, onde se localiza a Fazenda Figueira, foi a área de maior diversidade (Torezan \& Silveira, 2002).

Segundo Torezan (2002) e Rodrigues et al. (Dados não publicados), a vegetação do baixo Tibagi e da Fazenda Figueira foram determinadas pela profundidade do solo, sendo que os remanescentes florestais em locais onde os solos são profundos e bem drenados apresentaram um sub-bosque menos denso composto, principalmente, por

\footnotetext{
${ }^{2}$ RODRIGUES, R.R.; GANDOLFI, S.; VIEIRA, A.O.S.; NAVE, A.G.; VIANI, R.A.G.; ESTEVAM, D.; LOVATO, M.C.; MOTA,T.D.; CAMPOS,V.E.; KITAYAMA, L.; KOGA, L.J.; ZUKOWSKI, W.
} Programa de adequação ambiental da Fazenda Figueira. Relatório Técnico. (Em elaboração) 
laranjeira-do-mato (Actinostemon concolor) e catiguá (Trichilia spp), e um dossel mais alto, caracterizado pela presença de poucas interrupções, e emergentes acima dos $35 \mathrm{~m}$, como a Peroba-rosa (Aspidosperma polyneuron) e o pau-d'alho (Gallesia integrifolia). Já, nos locais da fazenda onde ocorreram encostas com solos rasos, as clareiras foram mais freqüentes e maiores, com um dossel freqüentemente interrompido, onde foram comuns: a canelinha (Nectandra megapotamica), a canjarana (Cabralea canjarana) e a gurucaia (Parapiptadenia rigida). Nos locais com este tipo de vegetação houve também uma abundância de cipós. Nos locais onde os solos foram ainda mais rasos (Neossolos) foi possível encontrar cactáceas arborescentes como o mandacaru (Cereus peruvianus).

Segundo Rodrigues et al. (dados não publicados), os fragmentos florestais estavam bastante perturbados, sem um dossel definido, e com predomínio de espécies em estágio inicial de sucessão, como, pau-pólvora (Trema micrantha), guaçatonga (Casearia sylvestris), embaúba (Cecropia spp.), fumo bravo (Solanum erianthum e $S$. granuloso leprosum), grão-de-galo (Celtis spinosa e C. ferruginea), açoita-cavalo (Luehea divaricata), candeia (Gochnatia polymorpha), garajú (Bacharis tridentata), erva-dejaboti (Piper gaudichaudianum.), coerana (Cestrum spp.), chal-chal (Allophylus guaraniticus), maria-mole (Guapira opposita), entre outras, com apenas alguns indivíduos remanescentes das espécies dos estágios finais da sucessão.

O bom estado de conservação do maior fragmento florestal foi verificado através das características das manchas de fases de clareira, madura e de preenchimento, que estão permitindo a manutenção dos processos ecológicos, onde foi registrada uma densidade arbórea de 1569 indivíduos/ha, uma área basal total de $50,53 \mathrm{~m} 2$, uma freqüência total de 965.0, sendo a família Meliaceae a de maior IVI, correspondente a $36,7 \%$ do total de indivíduos (Estevan, 2004).

A mata ciliar foi representada por todos os tipos florestais da região situados às margens dos cursos de água, independentemente do grau de influência pluvial sobre a vegetação. Do ponto de vista ecológico, este tipo florestal (zonas ripárias) tem sido considerado como corredor extremamente importante para o desenvolvimento da fauna ao longo da paisagem, assim como para a dispersão vegetal, além de outras funções extremamente importantes na dinâmica hidrológica. A maioria das espécies dessa 
formação não apresenta queda de folhas na estação seca, e a superposição das copas das árvores em áreas pouco degradadas estabelece uma cobertura arbórea espessa, possibilitando que a umidade relativa em seu interior seja alta mesmo na época mais seca do ano (Torezan, 2002; Rodrigues et al., dados não publicados). Na Fazenda Figueira, o tipo florestal foi representado por um dossel baixo, composto principalmente por canelinha ( $N$. megapotamica) e guabiroba (Campomanesia xanthocarpa), e um subbosque dominado por $A$. concolor (Rodrigues et al., dados não publicados).

Além de fragmentos de Mata Estacional Semidecídua e Floresta Estacional Semidecídua Ribeirinha, a fazenda apresenta alguns locais com campo úmido de origem antrópica (Rodrigues et al., dados não publicados), também chamados de banhados ou "varjões", que se desenvolveram em áreas onde se envolveu a retirada da floresta ribeirinha com influência fluvial ou alterou-se a dinâmica hídrica do solo. Esses locais, atualmente, estão infestados de plantas herbáceas e ou arbustivas, adaptadas às condições de alta umidade do solo. Muitas das espécies dominantes nestes locais foram exóticas com destaque para a africana lírio-do-brejo (Hedychium coronarium) e a asiática taboa (Typha dominguensis) (Torezan, 2002; Rodrigues et al., dados não publicados).

Os campos úmidos encontraram-se nas cotas mais baixas da propriedade, próximo aos cursos de água e estão, geralmente, associados às florestas ribeirinhas. Trata-se de uma vegetação hidrófila, adaptada à saturação hídrica do solo, permanente ou sazonal, onde existe baixa drenagem natural. Esses tipos vegetacionais foram geralmente destituídos de formas arbóreas, sendo constituído, essencialmente, por espécies com formas herbáceas e/ou subarbustivas, principalmente pertencentes às familias Poaceae e Cyperaceae. Entre os principais gêneros destas duas famílias estão Bulbostylis, Cyperus, Fimbristylis, Heliocharis e Rhynchospora (Cyperaceae); Paspalum, Axonopus e Syngonanthus (Poaceae). Em meio a essas herbáceas podem ocorrer arbustos das famílias Asteraceae, (Baccharis spp), Onagraceae (Ludwigia spp), entre outras, formando brejos arbustivos. A leguminosa Sesbania virgata às vezes ocupou os diques marginais e as áreas situadas entre banhados e rios (Rodrigues et al., dados não publicados). 


\subsection{O estudo da mastofauna na Fazenda Figueira}

O estudo da mastofauna (mamíferos voadores e não-voadores) concentrou-se nos fragmentos florestais e nas pastagens, que foram os ambientes que constituem a Fazenda Figueira.

Em função das diferenças entre os grupos, optou-se por concentrar o levantamento de mamíferos voadores e de pequenos mamíferos não-voadores a uma área restrita da fazenda, de forma que se englobaram quatro tipos de ambientes, e para os mamíferos não-voadores de médio e grande porte, o levantamento ocorreu em toda a área da fazenda, distinguindo-se apenas três ambientes.

Os levantamentos dos pequenos mamíferos não-voadores e voadores foram realizados nos mesmos quatro ambientes da Fazenda Figueira (Figura 2), sendo:

1) Fragmento florestal ou FR (Figura 3);

2) Mata ciliar do rio Taquara ou MC (Figura 4);

3) Pastagem com início de sucessão secundária ou PS (Figura 5);

4) Pastagem ou PA (Figura 6).

Os locais amostrados foram demarcados com círculo na Figura 2, sendo os traços dentro dos círculos referentes aos trajetos onde foram capturados os pequenos mamíferos não voadores.

A escolha dos ambientes seguiu os seguintes critérios: para os remanescentes florestais, optou-se pelas áreas mais preservadas da Fazenda Figueira, ou seja, o fragmento mais estruturado e de maior extensão, e o maior trecho de mata ciliar (em função do trecho pertencente à fazenda vizinha); para as áreas de pastagem, optou-se pela escolha de locais próximos aos fragmentos florestais e que fossem característicos da grande maioria das pastagens presentes na área da fazenda, além de locais sem a presença de gado, pelo fato destes destruírem as redes e armadilhas. 


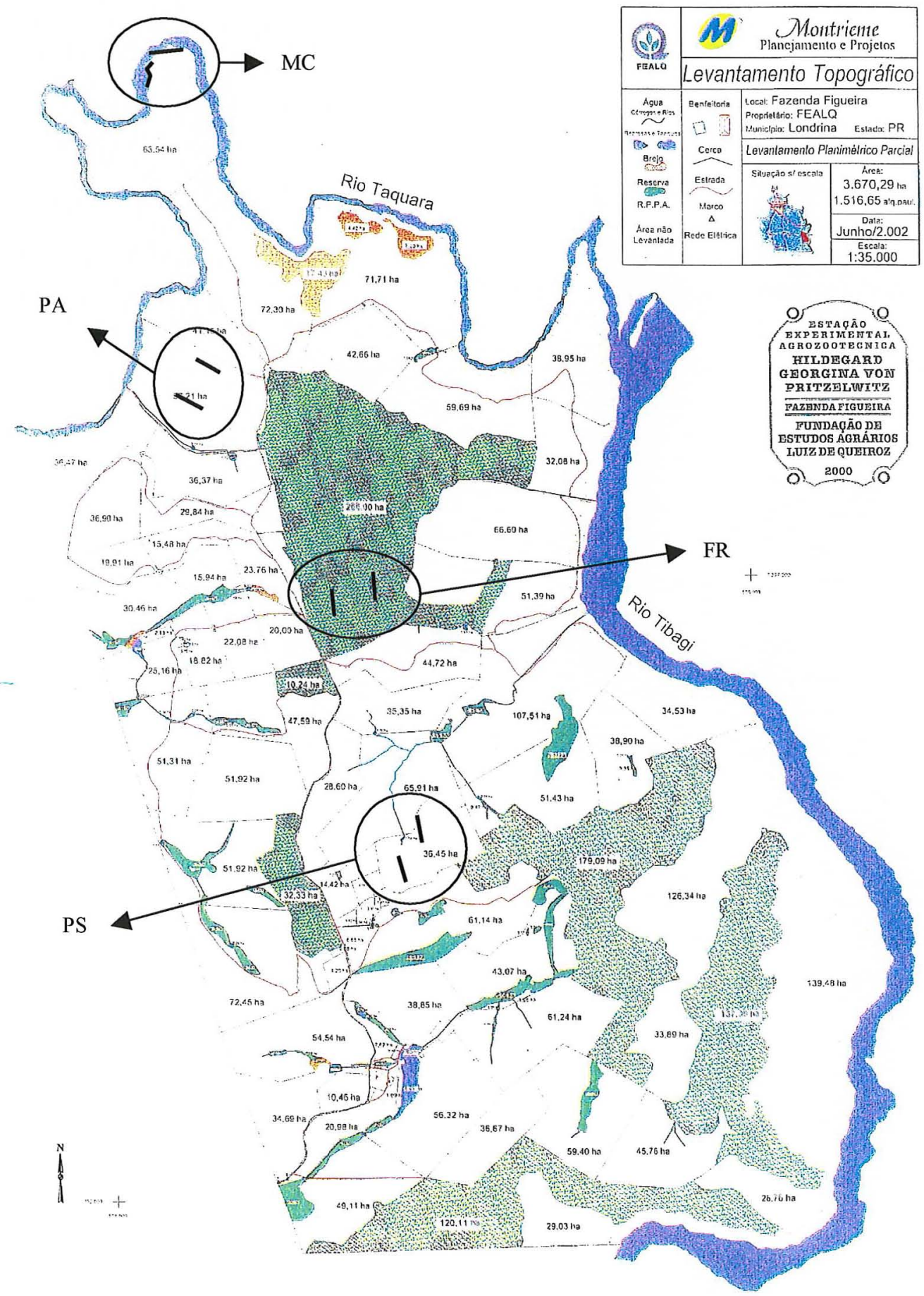

Figura 2 - Área da Fazenda Figueira, contendo os remanescentes florestais que fazem parte da RPPN Estadual Mata do Barão. MC, mata ciliar; PA, pastagem; FR, fragmento; e PS, pastagem com início de sucessão secundária. Fonte: Projeto de Readequação Ambiental da Fazenda Figueira (FEALQ) 


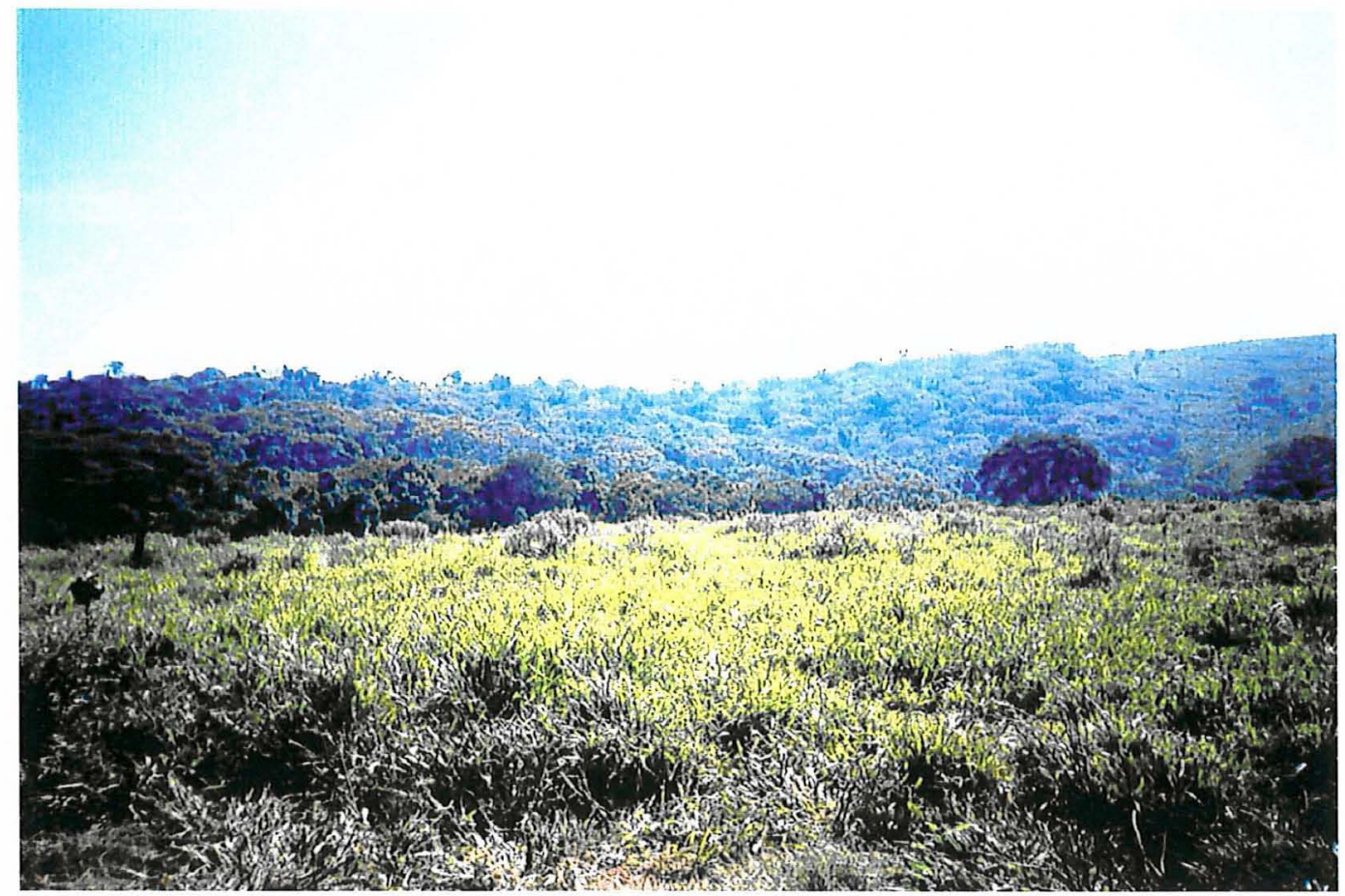

Figura 3 - Parte do fragmento de Floresta Estacional Semidecídua (FR) de 266 ha. Foto:

Lazo, L. J

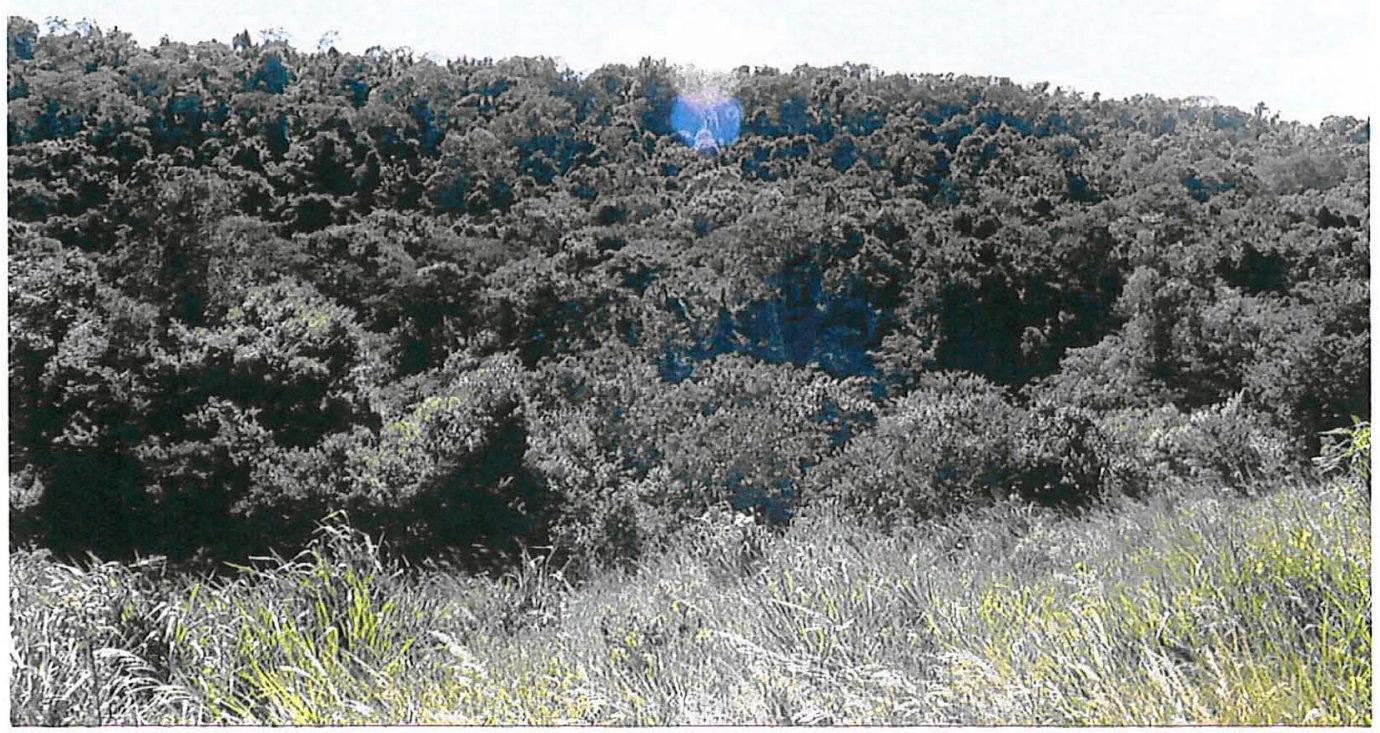

Figura 4 - Porção do maior trecho de mata ciliar (MC) do rio Taquara. Foto: Lazo, L.J 


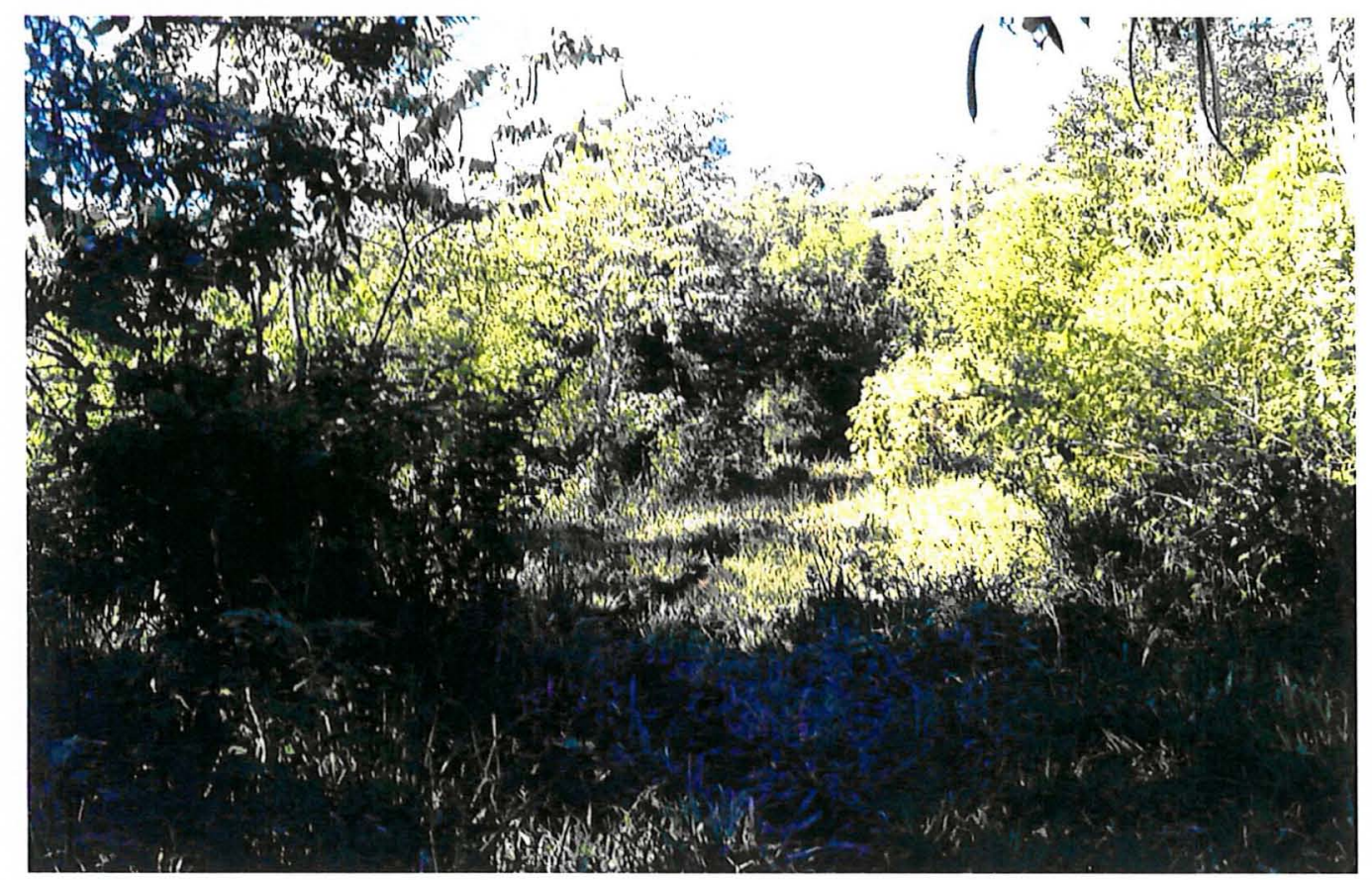

Figura 5 - Pastagem com início de sucessão secundária (PS), pouco manejada. Foto: Lazo, L.J

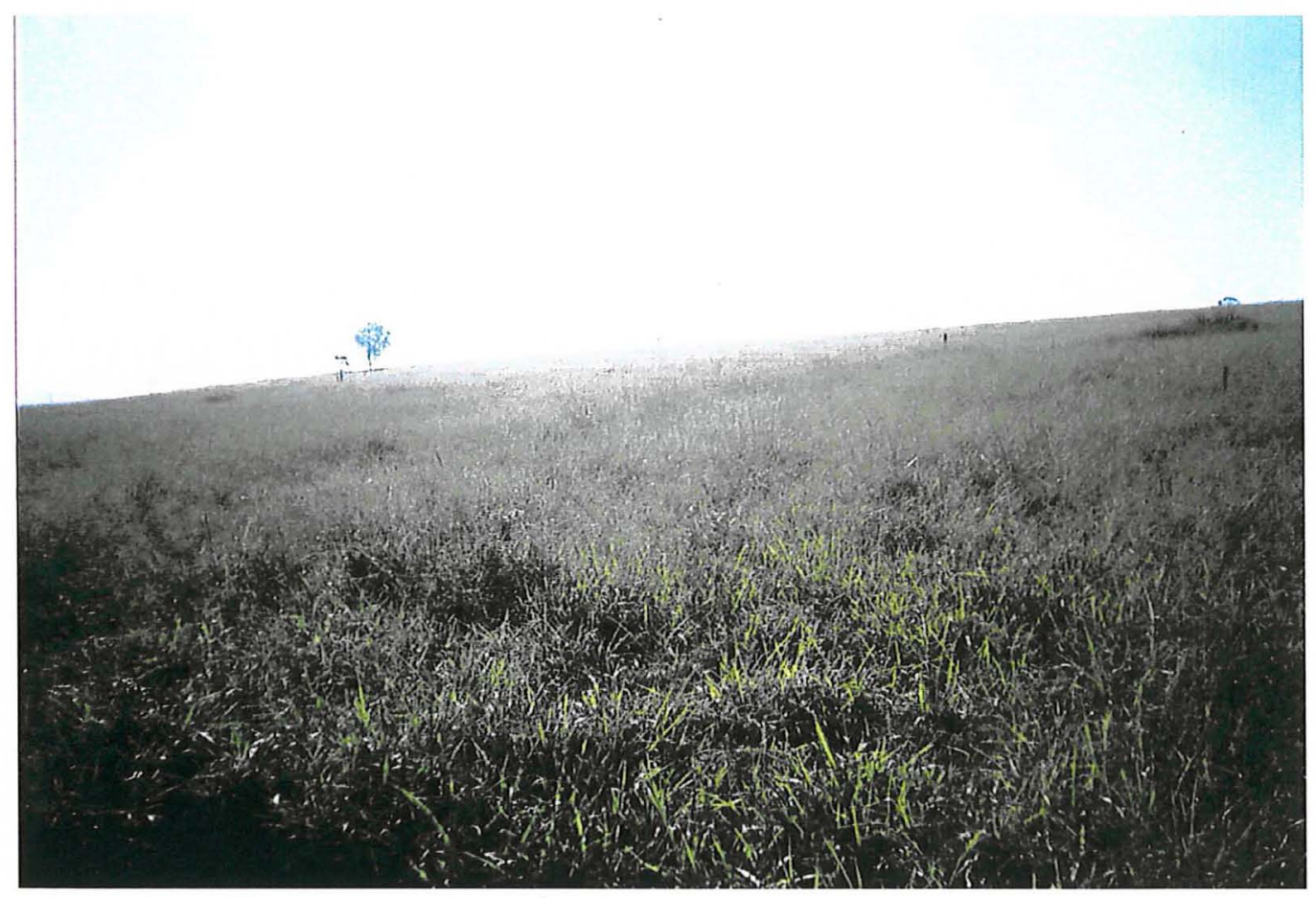

Figura 6 - Pastagem (PA) intensamente utilizada para a criação de gado bovino. Foto: Silveira, P.B 
O censo de grandes e médios mamíferos foi realizado em todas as áreas dentro dos limites da Fazenda Figueira e entorno (eventualmente), que foi subdividida em três ambientes distintos, dependendo do tipo vegetal predominante:

1) área florestal (FR), caracterizada por quaisquer fragmentos de Floresta Estacional Semidecídua, independente do tamanho, forma e estado de conservação;

2) área florestal ribeirinha (MC), sendo quaisquer trechos de mata ao longo dos rios Taquara e Tibagi, e ao longo dos pequenos cursos de água, independente de sua extensão e estado de conservação, e incluído também os campos úmidos de origem antrópica, caracterizado por todas as vegetações em ambiente permanentemente alagado com ou sem porte arbóreo, e áreas de taboa (T. dominguensis);

3) matriz formada com pastagem do tipo colonião (P. maximum) (PA), caracterizado por áreas abertas destinadas à pecuária, até o limite de 50 metros de ambientes florestais, estando ou não em algum estágio de regeneração da Floresta Estacional Semidecídua.

Para o estudo de mamíferos de médio e grande porte é importante destacar que a faixa de 50 metros (distância estimada aleatoriamente), entre as pastagens e ambientes florestais, apesar de ser constituída por pastagem (capim colonião), foram consideradas como parte do ambiente florestal em que estavam em contato. Isto se deve ao fato de que os animais das áreas florestais poderiam, eventualmente, sair nestas faixas sem cobertura vegetal, sem estarem utilizando este ambiente. É difícil de estimar, com alto grau de certeza, se um animal que se deslocou para fora de um ambiente florestal, utilizou ou não este ambiente de entorno; ele pode ter simplesmente saído, voltando para a mata assim que verificou que o ambiente externo não apresentou condições favoráveis para seu deslocamento e/ou sobrevivência.

\subsection{Estudo dos mamíferos voadores}

O levantamento foi realizado utilizando-se o método de captura, marcação e recaptura com redes de "neblina", constituída de malha de nylon preto, contendo 14 metros de comprimento por 3 metros de altura, e apresentando 3 conchas. 
Os levantamentos ocorreram em quatro meses do ano, que foram: janeiro, fevereiro, julho e agosto de 2004, sendo as coletas por ambiente ocorridas em uma média de 4 dias não consecutivos, distribuídos em dois meses, fora do período de lua cheia.

As redes, em cada um dos ambientes amostrados, foram abertas ao escurecer (por volta das 20:00 h em janeiro - fevereiro, e 18:00 h em julho - agosto), até completar 36 horas de captura por ambiente, que correspondeu a uma média de duas noites. $\mathrm{O}$ término das capturas foi por volta das 05:00 h em janeiro - fevereiro, e 03:00 h em julho - agosto. Destas redes, metade apresentou malha de $25 \mathrm{~mm}$ e metade malha de $35 \mathrm{~mm}$, buscandose ampliar o número de espécies capturadas (captura de espécies com tamanhos diferentes). $\mathrm{Na}$ área de pastagem, as redes ficaram distanciadas por cerca de 350 metros da borda do fragmento, de forma a ser caracterizando como pastagem e não como borda.

Em campo foram coletados dados biométricos, peso, sexo dos animais, estado reprodutivo, idade estimada, entre outros. Os morcegos capturados foram marcados com anilhas de alumínio numeradas em baixo relevo, e posteriormente soltos. A marcação foi feita no antebraço sem a realização de cortes no patágio (membrana que se estende entre os dedos).

A identificação foi realizada em campo com a ajuda de bibliografia especializada como Visoto \& Taddei (1973), Nowak (1994) e Emmons \& Feer (1997), e fora de campo através de bibliografia especializada, como Bredt et al. (2002) e/ou através de comparações com exemplares taxidermizados ou fixados. Os animais não identificados em campo foram levados para o Museu de Zoologia da Universidade de São Paulo, para identificação e deposito.

\subsection{Estudo dos mamíferos não-voadores}

\subsubsection{Estudo de mamíferos de pequeno porte por meio de captura}

Os pequenos mamíferos foram levantados através do método direto de captura e marcação, utilizando-se de armadilhas do tipo de gaiola ("live-trapping"), de arame 
galvanizado e com tamanhos pequeno $(11 \times 11 \times 20 \mathrm{~cm})$ e médio $(25 \times 25 \times 40 \mathrm{~cm})$, dispostas nos ambientes através de dois trajetos irregulares (Figura 2). As armadilhas receberam isca suspensa variada como atrativos para os animais. A isca utilizada foi constituída por banana, óleo de fígado de bacalhau e pasta de amendoim (alimentos com odor forte, altamente calórico, e de grande aceitação pelos grupos de pequenos mamíferos).

Foram utilizadas 15 armadilhas de tamanho pequeno e 15 armadilhas de tamanho médio nas áreas de pastagem (PA e PS), totalizando 30 armadilhas em cada uma dos dois ambientes, que ficaram posicionadas diretamente sobre o solo. Nas áreas florestais (FR e $\mathrm{MC}$ ), além das 15 armadilhas pequenas e 15 médias sobre o solo, foram utilizadas outras 15 armadilhas de tamanho pequeno suspensas em árvores a uma altitude que variou de 1 a 2 metros do solo, destinadas à captura de espécies arborícolas de pequeno porte, totalizando 45 armadilhas em cada ambiente florestal.

Os trajetos apresentaram uma distância de 375 metros, onde foram demarcados 8 pontos com armadilhas. Em cada ponto foi colocada uma armadilha no solo, pequena ou média, que foram intercalando-se ao longo do trajeto a cada 25 metros. Já nas áreas de mata, além de intercalar as armądilhas pequenas e médias no solo, foi colocada uma armadilha pequena de sub-bosque no mesmo ponto das armadilhas de tamanho médio de solo.

As capturas foram realizadas com duração de 15 dias consecutivos entre os meses de janeiro e fevereiro, e antes de serem iscadas e armadas, as armadilhas permaneceram fechadas no trajeto, por um período de quatro dias, nos quais receberam ceva, constituída por milho e amendoim, que atuaram como atrativo para os animais.

Os animais capturados foram pesados, medidos, marcados com etiquetas de alumínio numeradas em baixo relevo, colocadas na orelha do animal ("Tags"), e posteriormente soltos. Dados de sexo e idade estimada também foram coletados. A identificação foi realizada em campo com a ajuda de bibliografia especializada como Wilson \& Reeder (1993), Cimardi (1996), Emmons \& Feer (1997) e Eisenberg \& Redford (1998). Os animais não identificados em campo foram levados para o Museu de Zoologia da Universidade de São Paulo, para identificação e depósito. 


\subsubsection{Estudo qualitativo de mamíferos}

Este estudo foi realizado através dos métodos qualitativos com: observações indiretas de indícios, como fezes $(\mathrm{Fe})$, rastros $(\mathrm{Ra})$, questionário $(\mathrm{Qu})$, presença de abrigos e tocas $(\mathrm{Ab})$, carcaças $(\mathrm{Ca})$, pêlos $(\mathrm{Pe})$; e através de observações diretas $(\mathrm{Ob})$ e/ou vocalizações dos animais (Vo), odor (Od), registro por câmera "Trap" digital (Ct), e capturas (para pequenos mamíferos) através de armadilhas (Cp).

O levantamento foi realizado em horários variados entre as 08:00 horas e 21:00 horas, nos meses de julho de 2003, janeiro, fevereiro, julho e agosto de 2004, sendo as observações feitas nos três tipos de ambientes descritos anteriormente, a partir de trajetos irregulares realizados por meio de caminhadas, com veículo, e através de pontos fixos dentro dos ambientes. $\mathrm{O}$ tempo foi determinado em cada trajeto realizado somando-se as horas de observações em cada ambiente.

Dos indícios, foram tiradas informações como dia, hora, local, espécie, número de indícios. As fezes foram coletadas para futura análise dos pêlos, para a identificação das espécies de presas e/ou predadores, buscando-se complementar os dados de médios e grandes mamíferos, e os dados de pequenos mamíferos, encontrados a partir dos levantamentos com armadilhas.

As fezes, depois de coletadas, foram lavadas e secas. Os pêlos nas amostras fecais foram separados e enviados, para identificação, ao Laboratório de Ecologia de Predadores, no Centro de Estudos Ambientais da Universidade Estadual Paulista "Júlio de Mesquita Filho" - Campus de Rio Claro.

Os questionários foram aplicados através de perguntas direcionadas a moradores locais e/ou das proximidades, a fim de identificar as espécies existentes atualmente na área. Os animais citados por moradores locais e funcionários da Fazenda Figueira, através de questionário, foram considerados tomando-se o cuidado para registrar apenas espécies de possível ocorrência no local e/ou condizentes com as características locais.

A câmera "trap" foi posicionada em locais de possível passagem de grandes mamíferos (carreiros) nos ambientes florestais, onde ficou presa em uma árvore a uma altura média de 0,5 metros, e com uma inclinação média de $45^{\circ}$. Foi utilizada, 
eventualmente, ceva (milho, amendoim e carne) dentro do campo de alcance da câmera, buscando-se ampliar a probabilidade de um animal ser fotografado.

A identificação dos animais observados e dos indícios foi realizada em campo através da utilização de bibliografia especializada como Cimardi (1996), Emmons \& Feer (1997), Becker \& Dalponte (1999), Oliveira \& Cassaro (1999) e Pitman et al. (2002), e fora de campo através de bibliografia especializada como Ramos et al. (2003).

\subsection{Análise dos Dados}

\subsubsection{Estudo de mamíferos voadores}

A partir dos dados coletados na Fazenda Figueira, foi aplicado o Índice de Riqueza de espécies (S), que nos proporciona uma expressão compreensível e instantânea da diversidade (Magurran, 1989); a Abundância Relativa das espécies (A); e a Diversidade das espécies nos diferentes ambientes amostrados.

As análises dos dados de morcegos foram baseadas em três tipos de medidas de diversidade: a Diversidade $\alpha$ (alfa) representou a diversidade em cada um dos ambientes amostrados; a Diversidade $\boldsymbol{\beta}$ (beta) representou a similaridade ou dissimilaridade entre o nível de diversidade $\alpha$; e a Diversidade $\gamma$ (gama), foi o conjunto de todos os ambientes em nível $\alpha$, sendo representativa da região.

Para demonstrar a riqueza de espécies, foram utilizadas tabelas comparativas entre o número de espécies e os ambientes. $\mathrm{O}$ mesmo foi feito para demonstrar as diferenças da riqueza com outras áreas dentro do baixo Tibagi.

O esforço de captura foi apresentado através da curva acumulada de espécies, onde o método de Cain (Mueller-Dombóis \& Ellenberg, 1974), foi utilizado para estimar os tempos mínimos de captura. Este método foi aplicado traçando uma reta do ponto de origem ao ponto correspondente a $100 \%$ dos valores do eixo $\mathrm{x}$ e $\mathrm{y}$, a partir da qual se traçou outra reta de forma paralela e em contato com a curva acumulada de espécies, a partir do ponto de contato em contato com a curva, foi então projetada uma reta 
tangencial em direção ao eixo $\mathrm{x}$, indicando o tempo mínimo calculado sobre $10 \%$ do aumento de espécies. O mesmo procedimento foi realizado sobre $5 \%$ do aumento de espécies, sendo a primeira reta traçada do ponto de origem ao ponto correspondente a $50 \%$ dos valores do eixo $\mathrm{x}$ e $\mathrm{y}$.

A Abundância Relativa (A) das espécies em nível $\alpha$ foi determinada somando-se os indivíduos capturados e dividindo-se o valor pelo total de indivíduos capturados no ambiente. Em nível $\gamma$, foram considerados os animais capturados em todos os ambientes, dividindo-se o valor total de indivíduos capturados entre todos os ambientes, através da equação:

$$
\mathrm{A}=\Sigma \mathrm{n} / \mathrm{N}
$$

onde, $\mathbf{A}$ foi a abundância relativa de pequenos mamíferos não voadores; $\mathbf{n}$ representou $\mathbf{o}$ número de indivíduos capturados; e N, o total de indivíduos capturados.

O Índice de Shannon-Wiener (H') (Krebs, 1989), conforme o Modelo 1.1, foi adotado como índice de diversidade $\alpha$ e $\gamma$ por apresentar uma boa capacidade discriminatória entre diferentes localidades, e uma relativa sensibilidade ao tamanho amostral, além de ser amplamente utilizado como índice de diversidade, o que tornou os dados passíveis de serem comparados com os valores encontrados em outros trabalhos.

$$
H^{\prime}=-\Sigma p_{i} \log _{2} p_{i}
$$

onde, H', a diversidade de espécies; $\mathbf{p}_{\mathbf{i}}$ a proporção de indivíduos de espécies capturadas.

Outra medida de diversidade utilizada em $\alpha$ e $\gamma$ foi o Índice de Equitabilidade de Simpson (1.2), baseado no Índice de Heterogeneidade Recíproca de Simpson (1/D).

$$
\mathrm{E}_{1 / \mathrm{D}}=1 /\left(1 / \Sigma \mathrm{p}_{\mathrm{i}}{ }^{2}\right)
$$


onde, $\mathbf{E}_{\mathbf{1} / \mathbf{D}}$ representou a equitabilidade; $\mathbf{p}_{\mathbf{i}}$ foi a proporção de indivíduos da espécie $\mathbf{i}$ na comunidade.

Para a diversidade $\beta$ (análise de similaridade ou dissimilaridade entre as amostras da diversidade $\alpha$ ), foi utilizado a Porcentagem de Similaridade (P) ou Índice de Renkonem (Krebs, 1989). Para obter o valor de similaridade, utilizou-se o Modelo 1.3. Esta medida foi escolhida pela simplicidade e por ser pouco afetada pelo tamanho amostral e pela diversidade de espécies.

$$
\mathrm{P}=\sum \text { mínima }\left(\mathrm{p}_{1 \mathrm{i}}, \mathrm{p}_{2 \mathrm{i}}\right)
$$

onde, $\mathbf{P}$ foi a similaridade entre os pares de ambientes; $\mathbf{p}_{\mathbf{1 i}}$ foi a porcentagem da espécie $\mathbf{i}$ no ambiente amostrado $1 ; \mathbf{p}_{\mathrm{i} 2}$ foi a porcentagem da espécie $\mathbf{i}$ no ambiente amostrado 2 ;

A análise de variância para valores de abundância entre espécies e ambientes foi realizada através de ANOVA (fator duplo), que consiste em uma técnica boa para verificar as relações entre grupos de dados (Fowler \& Coher, 1999). ANOVA (fator único) foi utilizada para verificar se houve diferença nas abundâncias relativa entre as espécies, nas medidas de comprimento do antebraço e no peso médio das espécies entre espécies e dentro das populações, e se ocorreu dominância na comunidade.

O Teste do Qui-quadrado $\left(\chi^{2}\right)$, através da Equação 1.4, foi aplicado sobre os dados populacionais como idade, sexo e estado reprodutivos das espécies. Para este teste foram excluídas todas as espécies que apresentaram valores esperados $<3$ (Krebs, 1989).

$$
\chi^{2}=(\mathrm{O}-\mathrm{E})^{2} / \mathrm{E}
$$

onde, $\chi^{2}$ foi o valor do Qui-quadrado; $\mathbf{O}$ foi o número de individuos observado; e $\mathbf{E}, \mathrm{o}$ número esperado de individuos. 


\subsubsection{Estudo de mamíferos não-voadores}

O método qualitativo para o levantamento de mamíferos não-voadores foi realizado através do Índice de Riqueza de espécies (S), agrupando-se os valores pelas ordens e famílias às quais as espécies pertencem, e pelos ambientes amostrados.

O esforço de captura foi apresentado através da curva acumulada de espécies, utilizando-se o mesmo procedimento de Cain (Mueller-Dombóis \& Ellenberg, 1974), da mesma forma como descrita para mamíferos voadores, diferindo, porém, por ter considerado o esforço em dias, ao invés de horas. Assim, para estimar os tempos mínimos de levantamento, traçou-se uma reta do ponto de origem ao ponto correspondente a $100 \%$ e $50 \%$ dos valores do eixo x e y, a partir da qual se traçou outra reta de forma paralela e em contato com a curva acumulada de espécies. Do ponto de contato em contato com a curva, foi então projetada uma reta tangencial em direção ao eixo $\mathrm{x}$, indicando o tempo mínimo calculado sobre $10 \%$ e $5 \%$ do aumento de espécies.

Para as populações de médios e grandes mamíferos, amostradas pelo método direto de observação e indireto por rastros, a Abundância Relativa das espécies (A) foi estimada, foi através da Equação 1.0, descrita anteriormente para mamíferos voadores (capítulo 3.5.1.).

As comparações entre a riqueza de espécies por ordem e ambientes foram realizadas através da análise de variância ANOVA, fator duplo.

Os dados amostrados através do método de captura, para pequenos mamíferos terrestres, foram avaliados qualitativamente, junto aos dados de médios e grandes mamíferos. 


\section{RESULTADOS E DISCUSSÕES}

\subsection{Estudo de mamíferos voadores}

O levantamento de morcegos na Fazenda Figueira foi realizado nos períodos de janeiro-fevereiro e julho-agosto de 2004, resultando em um esforço total de 2.160 horas/rede, divididas em 540 horas/rede para cada um dos quatro ambientes considerados. $O$ levantamento resultou na captura total de 162 indivíduos (10 recapturas), pertencentes a 2 famílias e 14 espécies (Tabela 2).

Fora do período de levantamento foi capturado um Vespertilionidae, possivelmente Myotis ruber, que foi considerada, porém com certa cautela (Reis \& Lima; comunicação pessoal ${ }^{3}$ ), pelo fato da identificação ter ocorrido por meio de registro fotográfico, sendo necessária a realização de novas coletas para uma identificação segura (Aires; comunicação pessoal ${ }^{4}$ ). A espécie foi considerada apenas nos dados de riqueza de espécies e nas conclusões, sendo excluída das demais análises.

A família Phyllostomidae representou 78,6\% do total de espécies capturadas. Os resultados mostraram uma predominância de espécies primariamente frugívoras (50\%), talvez pela maior probabilidade destas em serem capturadas em rede na altura de subbosque, considerando que espécies de outras famílias voam principalmente na altura das copas. O segundo grupo de maior riqueza foi o das espécies insetívoras, ou que incluem grande quantidade de insetos em sua dieta $(28,6 \%)$. As outras guildas, juntas, corresponderam a $21,4 \%$ do total de espécies (carnívora, nectarívora e hematófaga).

\footnotetext{
${ }^{3}$ REIS, N.R.; LIMA. I.P. Universidade Estadual de Londrina. Informação obtida através de comunicação pessoal.

${ }^{4}$ AIRES, C. Museu de Zoologia da Universidade de São Paulo. Informação obtida através de comunicação pessoal.
} 
Estas proporções são similares à obtida por Falcão et al. (2003), na Reserva da Serra do Caraça (MG), e à obtida por Estrada \& Coates-Estrada (2002) em fragmentos florestais de Veracruz (México), sendo que estes últimos autores encontraram em florestas contínuas uma proporção de $86 \%$ de frugívoros para 3\% de insetívoros. Estes dados mostram que esta proporção maior de frugívoros é comum mesmo em diferentes regiões climáticas.

Tabela 2. Riqueza e abundância de espécies de morcegos nos diferentes ambientes da Fazenda Figueira. Legenda: FR, fragmento; MC, mata ciliar; PS, pastagem com início de sucessão secundária; PA, pastagem

\begin{tabular}{|c|c|c|c|c|c|}
\hline Famílias & Espécies & FR (\%) & MC (\%) & PS (\%) & PA (\%) \\
\hline \multirow[t]{11}{*}{ Phyllostomidae } & 01 - Anoura caudifera & - & $1(3,1)$ & - & - \\
\hline & $\begin{array}{l}02 \text { - Artibeus } \\
\text { jamaicencis }\end{array}$ & $1(1,9)$ & - & $1(5,6)$ & $7(11,9)$ \\
\hline & 03 - Artibeus lituratus & $11(20,8)$ & $10(31,3)$ & $8(44,4)$ & $29(49,2)$ \\
\hline & $\begin{array}{l}04 \text { - Carollia } \\
\text { perspicillata }\end{array}$ & $11(20,8)$ & $6(18,8)$ & $3(16,7)$ & $3(5,1)$ \\
\hline & $\begin{array}{l}05-\text { - Chrotopterus } \\
\text { auritus }\end{array}$ & $2(3,8)$ & - & - & $1(1,7)$ \\
\hline & 06 - Desmodus rotundus & $3(5,7)$ & - & - & $1(1,7)$ \\
\hline & $\begin{array}{l}07 \text { - Mesophylla } \\
\text { macconnelli }\end{array}$ & - & - & - & $1(1,7)$ \\
\hline & $\begin{array}{l}08 \text { - Platyrrhinus } \\
\text { lineatus }\end{array}$ & $2(3,8)$ & - & $2(11,1)$ & $1(1,7)$ \\
\hline & $\begin{array}{l}09 \text { - Pygoderma } \\
\text { bilabiatum }\end{array}$ & $4(7,5)$ & - & $3(16,7)$ & $1(1,7)$ \\
\hline & 10 - Sturnira lilium & $16(30,2)$ & $14(43,8)$ & $1(5,6)$ & $15(25,4)$ \\
\hline & 11 - Tonatia silvicola & $1(1,9)$ & - & - & - \\
\hline \multirow[t]{4}{*}{ Vespertilionidae } & 12 - Lasiurus blossevillii & - & $1(3,1)$ & - & - \\
\hline & 13 - Myotis nigricans & $2(3,8)$ & - & - & - \\
\hline & 14 - Myotis ruber* & - & - & - & - \\
\hline & & $53(100)$ & $32(100)$ & $18(100)$ & $59(100)$ \\
\hline
\end{tabular}

* Espécie não capturada nos quatro ambientes amostrados. O Dado de abundância não foi considerado.

Das espécies registradas: 7 foram frugívoras (Sturnira lilium, Artibeus lituratus, A. jamaicensis, Carollia perspicillata, Mesophylla macconnelli, Platyrrhinus lineatus e Pygoderma bilabiatum), e com exceção da primeira, todas se alimentam eventualmente ou frequentemente de outros itens como insetos, néctar, pólen e/ou partes florais; 4 foram insetívoras (Lasiurus blossevillii, Myotis nigricans, M. ruber e Tonatia silvicola); Chrotopterus auritus é carnívora, alimentando-se de pequenos vertebrados como 
morcegos, marsupiais, camundongos, aves, répteis e anfibios, embora se alimente também de insetos; Anoura caudifera é nectarívora; e Desmodus rotundus é hematófaga (Nowak, 1994; Emmons \& Feer, 1997 e Bredt et al., 2002).

A riqueza de morcegos na Fazenda Figueira correspondeu a 82,3\% do número máximo de espécies registradas no Parque Municipal Arthur Tomas (PR), a 50\% das espécies registradas por Reis et al. (2003) no Parque Estadual Mata dos Godoy (PR), e a $34,1 \%$ da riqueza total observada para a Bacia Hidrográfica do Tibagi (Reis et al., $2002 \mathrm{e}$ Reis et al., 2003). A diferença na riqueza de espécies das áreas dentro da Bacia do Tibagi, e nesta como um todo, foram apresentada na Tabela 3.

A baixa diversidade da fazenda, quando tomamos toda a Bacia como referência, pode ser melhor compreendida se comparada às outras áreas do médio e do alto Tibagi, que apresentam extensão de 3.571 ha e 11.116 ha de vegetação primitiva, sendo certamente as responsáveis pela grande diversidade de morcegos da Bacia (Reis et al., 2002), devido à extensão destas áreas destinadas a conservação (Cosson et al. 1999).

$\mathrm{O}$ tamanho das áreas não deve ter sido o único fator determinante sobre a diversidade de morcegos, pois somente o fragmento de Floresta Estacional Semidecídua amostrado na Fazenda Figueira, apresentou um tamanho superior ao do Parque Municipal Arthur Tomas (PR), mas sua diversidade correspondeu a apenas 58,8\% da diversidade deste parque. Neste caso, a riqueza de espécies registradas para a fazenda, inferior às outras áreas já estudadas na Bacia do Tibagi, certamente foi resultado de uma coleta em período muito reduzido, ao ser comparado ao Parque Estadual Mata dos Godoy (PR) que vem sendo estudado desde 1982, e ao Parque Municipal Arthur Thomas (PR), onde coletas de morcegos foram realizadas de 1992 até 2000 (Reis et al., 2003).

Como era esperada para a fazenda, a maior parte das espécies foi "generalista" com relação ao ambiente que utilizam independentemente da forma de uso destes ambientes, como ocorre principalmente com A. lituratus, C. perspicillata e S. lilium. Estando esta característica de acordo com a descrita por Nowak (1994), que cita $A$. lituratus e $S$. lilium como espécies que utilizam tanto áreas florestais como abertas, e mesmo para $C$. perspicillata, que pode apresentar até 6 locais para forragear, exigindo um grande deslocamento. 
Tabela 3. Riqueza e abundância de espécies na Bacia do Tibagi. Re, registro efetuado

\begin{tabular}{|c|c|c|c|c|c|c|}
\hline \multirow[t]{2}{*}{$\begin{array}{l}\text { Espécies registradas para a Bacia do Tibagi } \\
\qquad(29 \text { gêneros, } 41 \text { espécies) }\end{array}$} & \multicolumn{2}{|c|}{$\begin{array}{l}\text { Fazenda Figueira } \\
550 \mathrm{ha}^{*}\end{array}$} & \multicolumn{2}{|c|}{$\begin{array}{c}\text { PE Mata dos Godoy } \\
680 \text { ha }\end{array}$} & \multicolumn{2}{|c|}{$\begin{array}{c}\text { PM Arthur Thomas } \\
85,47 \text { ha }\end{array}$} \\
\hline & $\mathrm{N}$ & $\%$ & $\mathrm{~N}$ & $\%$ & $\mathrm{~N}$ & $\%$ \\
\hline Noctilionidae (1 gênero, 2 espécies) & - & - & - & - & - & - \\
\hline Noctilio albiventris (Desmarest, 1818) & - & - & 1 & 0,1 & - & - \\
\hline Noctilio leporinus (Linnaeus, 1758) & - & - & - & - & - & - \\
\hline Phyllostomidae (18 gêneros, 22 espécies) & - & - & - & - & - & - \\
\hline Anoura caudifera (E. Geoffroy, 1818) & 1 & 0,6 & 12 & 1,1 & 4 & 0,2 \\
\hline Artibeus fimbriatus (Gray, 1838) & - & - & 21 & 1,9 & 79 & 3,8 \\
\hline Artibeus jamaicencis (Leach, 1821) & 9 & 5,6 & 30 & 2,7 & 10 & 0,5 \\
\hline Artibeus linuranus (Olfers, 1818) & 58 & 35,8 & 353 & 31,9 & 1326 & 63,1 \\
\hline Carollia perspicillata (Linnaeus, 1758) & 23 & 14,2 & 332 & 30,0 & 257 & 12,2 \\
\hline Chiroderma doriae (Thomas, 1891) & - & - & 1 & 0,1 & - & - \\
\hline Chiroderma villosum (Peters, 1860) & - & - & - & - & - & - \\
\hline Chrotopterus auritus (Peters, 1856) & 3 & 1,9 & 36 & 3,3 & 21 & 1,0 \\
\hline Desmodus rotundus (E. Geoffroy, 1810) & 4 & 2,5 & 23 & 2,1 & - & - \\
\hline Diaemus youngi (Jentink, 1893) & - & - & 1 & 0,1 & - & - \\
\hline Diphylla ecaudata (Spix, 1823) & - & - & 1 & 0,1 & - & - \\
\hline Glossophaga soricina (Pallas, 1766) & - & - & 3 & 0,3 & - & - \\
\hline Micronycteris megalostis (Gray, 1842) & $\cdot$ & - & 19 & 1,7 & 12 & 0,6 \\
\hline Mesophylla macconnelli (Thomas, 1901)** & 1 & 0,6 & - & - & - & - \\
\hline Phyllostomus discolor (Wagner, 1843) & - & - & - & - & - & - \\
\hline Phyllostomus hastatus (Pallas, 1767) & - & - & 6 & 0,5 & 16 & 0,8 \\
\hline Platyrrhinus lineatus (E. Geoffroy, 1810) & 5 & 3,1 & 4 & 0,4 & 89 & 4,2 \\
\hline Pygoderma bilabiatum (Wagner, 1843) & 8 & 4,9 & 19 & 1,7 & 7 & 0,3 \\
\hline Stumira lilium (E. Geoffroy, 1810) & 46 & 28,4 & 156 & 14,1 & 219 & 10,4 \\
\hline Tonatia silvicola (Gray, 1827)* & 1 & 0,6 & - & - & - & - \\
\hline Uroderma bilobatum (Peters, 1866) & - & - & 1 & 0,1 & - & - \\
\hline Vampyressa pusilla (Wagner, 1843) & - & - & 2 & 0,2 & - & - \\
\hline Vespertilionidae ( 5 gêneros, 10 espécies) & - & - & - & - & - & - \\
\hline Eptesicus brasiliensis (Desmarest, 1819) & - & - & 1 & 0,1 & 1 & 0,0 \\
\hline Eptesicus diminutus (Osgood, 1915) & - & - & 3 & 0,3 & 2 & 0,1 \\
\hline Eptesicus furinalis (d'Orbigny, 1847) & - & - & 7 & 0,6 & - & - \\
\hline Histiotus velatus (I. Geoffroy, 1824) & - & - & 12 & 1,1 & - & - \\
\hline Lasiurus blossevillii (Muller, 1776) & 1 & 0,6 & 5 & 0,5 & 3 & 0,1 \\
\hline Lasiurus ega (Gervais, 1856) & - & - & 1 & 0,1 & - & - \\
\hline Myotis levis (1. Geoffroy, 1824) & - & - & 2 & 0,2 & - & - \\
\hline Myotis nigricans (Schinz, 1821) & 2 & 1,2 & 43 & 3,9 & 51 & 2,4 \\
\hline Myotis ruber (E. Geoffroy, 1806) & $\operatorname{Re}$ & - & 11 & 1,0 & 3 & 0,1 \\
\hline Rogheessa humida (Allen, 1866) & - & - & - & - & - & - \\
\hline Molossidae (5 gêneros, 7 espécies) ${ }^{* * *}$ & - & - & - & - & - & - \\
\hline Eumops gloucinus (Wagner, 1843) & - & - & - & - & - & - \\
\hline Molossops abrasus (Temminck, 1827) & - & - & - & - & - & - \\
\hline Molossus rufus (E. Geoffroy, 1805) & - & - & - & - & - & - \\
\hline Molossus molossus (Pallas, 1766) & - & - & - & - & - & - \\
\hline Nyctinomops laticaudatus (E. Geoffroy, 1805) & - & - & - & - & - & - \\
\hline Nyctinomops macrotis (Gray, 1840) & - & - & - & - & - & - \\
\hline Tadarida brasiliensis (I. Geoffroy, 1824) & - & - & - & - & - & - \\
\hline Total de individuos & 162 & 100 & 1106 & 100 & 2100 & 100 \\
\hline Total de espécies (\% do total) & $14(34,1)$ & & $28(68)$ & & $17(41)$ & \\
\hline
\end{tabular}

* Área aproximada amostrada dentro da Fazenda Figueira.

** Espécies que ainda não haviam sido registradas para a Bacia do rio Tibagi.

*** Espécies de molossídeos presentes na região (não considerados neste trabalho). Os dados referentes à Bacia do rio Tibagi, o PE Mata dos Godoy e PM Arthur Thomas foram extraídos do trabalho de Reis et al. (2003). 
Ao contrário das espécies "generalistas", foi verificada também a presença de espécies exclusivas a um ou mais tipos de ambiente. Quatro espécies $(30,8 \%)$ foram exclusivas aos remanescentes florestais (A. caudifera, T. silvicola, Lasiurus blossevillii, e Myotis nigricans). Quanto aos vespertilionídeos, a ausência em ambientes abertos pode ter ocorrido em função do tipo de metodologia utilizada, pela estratificação vertical dessas espécies. $\mathrm{O}$ declínio de $A$. caudifera em pequenas áreas foi registrado por Cosson et al. (1999), enquanto que T. silvicola - pertencente à subfamília Phyllostominae - vem sendo descrita como sensível às modificações do hábitat natural, e característica de florestas primárias (Faria, 2002). Esta última espécie não havia sido registrada até o momento para a Bacia do rio Tibagi, o que pode indicar que o fragmento em questão apresenta-se, ainda ou pelo menos presentemente, em um bom estado de conservação. Estado este relativo, pois não se sabe se esta espécie chegou recentemente à área ou mesmo se irá persistir por longo tempo.

M. macconnelli, que também não havia sido registrada até o momento para a Bacia do rio Tibagi, foi a única espécie capturada exclusivamente em área aberta. Entretanto, foi verificado que tanto esta como todas as outras espécies capturadas, principalmente as generalistas, em áreas abertas $(69,2 \%)$ e quase todos os indivíduos destas espécies $(90,9 \%)$ estavam saindo de um remanescente florestal ou dirigindo-se a este, mostrando a pouca sensibilidade às alterações no ambiente pela presença das áreas de pastagens, de acordo com os dados de Moreno \& Malffter (2001), que verificaram que as espécies generalistas são pouco sensíveis às mudanças em escala espacial.

M. ruber não foi registrada em nenhuma das áreas amostradas, sendo sua captura ocorrida no segundo maior fragmento florestal da Fazenda Figueira.

Embora o levantamento da população de morcegos da Fazenda Figueira tenha ocorrido em um período extremamente curto, a riqueza de espécies registrada foi considerável. A curva do coletor (Figura 7) apresentou uma tendência à estabilização, sugerindo que o número de espécies capturadas não teria um grande acréscimo, mesmo com o aumento das horas de captura. Porém, este fato não exclui a possibilidade de novas espécies serem capturadas a partir de um maior esforço amostral. 


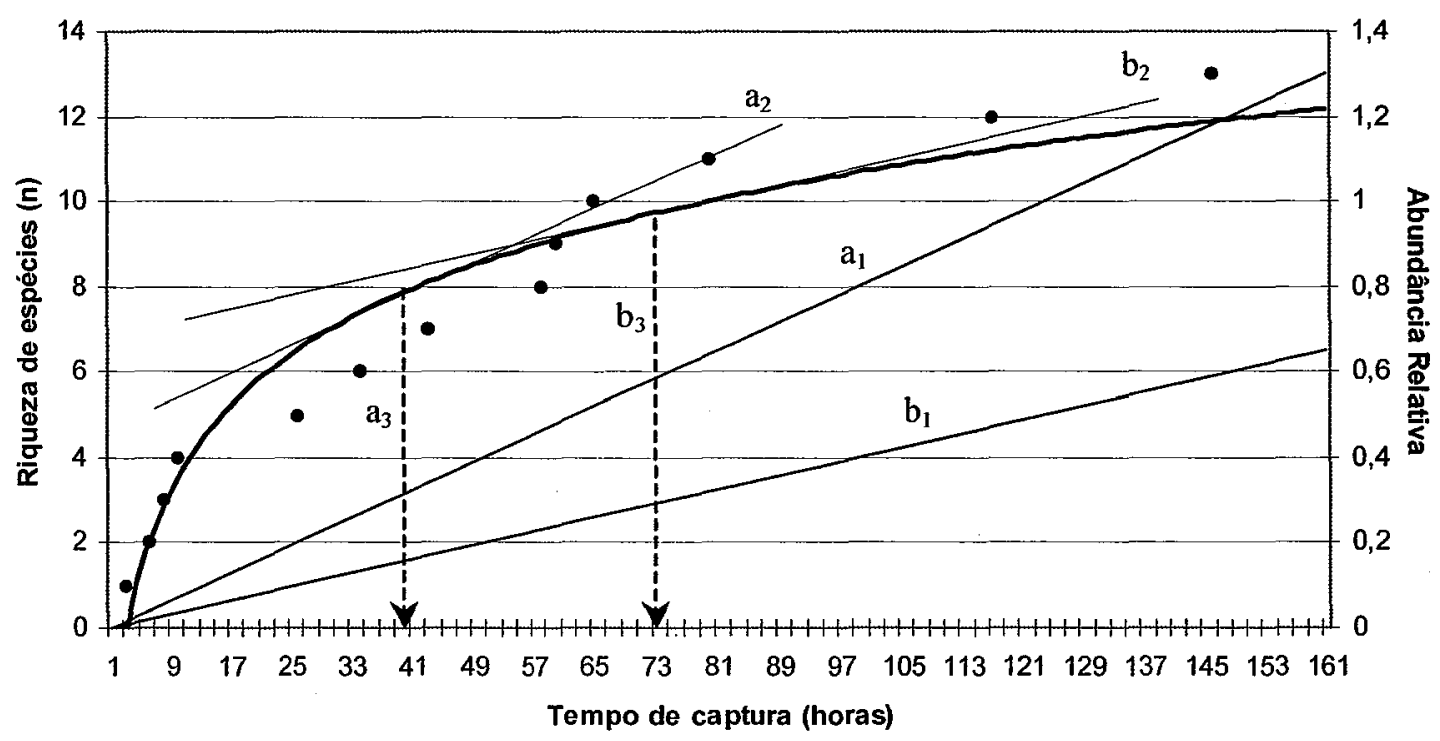

Figura 7 - Curva de tendência para o número acumulado de espécies de morcegos em função do tempo de captura com rede "neblina". Legenda: $\mathbf{a}_{\mathbf{1}}$ e $\mathbf{b}_{\mathbf{1}}$, linhas sobre $10 \%$ e $5 \%$ do total de espécies; $\mathbf{a}_{2}$ e $\mathbf{b}_{2}$, retas paralelas às linhas dos $10 \%$ e $5 \% ; \mathbf{a}_{3}$ e $\mathbf{b}_{3}$, tangentes sobre o tempo mínimo baseado no aumento de $10 \%$ e $5 \%$ das espécies

Utilizando o conceito de área mínima proposto por Cain (Krebs, 1989), e aplicando este conceito para tempo mínimo, foram verificadas que ao menos 39 horas (a) ou 73 horas (b) seriam necessárias para que o registro de $90 \%$ ou $95 \%$ das espécies, respectivamente, fosse efetuado (Figura 7), podendo indicar que o total de 160 horas de captura foi satisfatório para o estudo da área em questão. De fato, o maior acréscimo na riqueza de espécies ocorreu com um tempo compreendido no intervalo dos valores de tempo mínimo.

Os ambientes de maior abundância foram o de pastagem (36\%) e o fragmento florestal (33\%), seguido pela mata ciliar (20\%), e a pastagem com início de sucessão secundária, que representou apenas $11 \%$ do total observado (Figura 8), entretanto, estes valores não diferiram significativamente entre si $(\mathrm{F}=2,198707 ; \mathrm{P}>0,05)$. A explicação 
mais plausível para a área de pastagem igualar-se com o fragmento pareceu ser a pequena distância entre o fragmento e a mata ciliar, possibilitando a passagem entre estes dois ambientes. A pastagem com início de sucessão secundária não se encontrava em local propício à passagem entre remanescentes florestais, e os poucos indivíduos capturados neste local foram frugívoros, que talvez estivessem forrageando neste ambiente.

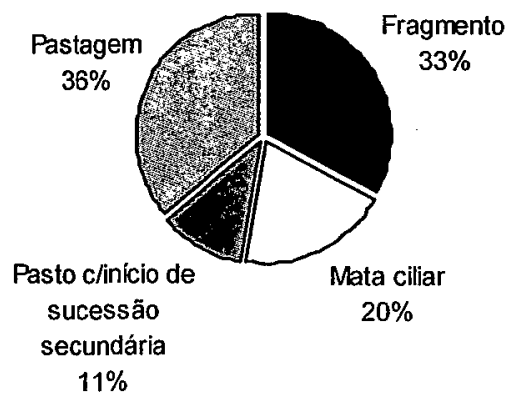

Figura 8 - Porcentagem da abundância de morcegos nos diferentes ambientes da Fazenda Figueira

No total foram recapturados 10 indivíduos $(3 \mathrm{~S}$. lilium, $3 \mathrm{~A}$. lituratus, $2 \mathrm{C}$. perspicillata e 2 D. rotundus), resultando em uma taxa de recaptura de $6,2 \%$, sendo que a maioria das recapturas ocorreu no mesmo ambiente em que o indivíduo havia sido capturado (60\%). As exceções foram para um $D$. rotundus, recapturado na pastagem quatro dias após sua captura no fragmento; um $A$. lituratus, recapturado no fragmento cinco meses depois de capturado na pastagem; um $S$. lilium, que foi recapturado na pastagem também após cinco meses de ser capturado no fragmento; e um $C$. perspicillata, recapturado no fragmento após quatro meses de sua captura na mata ciliar.

$\mathrm{O}$ deslocamento observado para os indivíduos, entre os ambientes, pode estar indicando que estas espécies possivelmente utilizam os remanescentes florestais como refúgio e local para alimentarem-se, mas ultrapassam áreas abertas a fim de ampliarem 
sua área de forrageio e busca de abrigo, fato observado principalmente para $C$. perspicillata e $D$. rotundus, e que está de acordo com os dados de Trajano (1996), Schulze et al. (2000), Estrada \& Coates-Estrada (2002) e Bernard \& Fenton (2003).

$\mathrm{O}$ ambiente de maior diversidade $\alpha$ (2.731) foi o fragmento florestal, sendo este, também, o ambiente mais representativo da diversidade $\gamma$ (2.545). Em outros estudos (Pedro et al., 2001 e Estrada \& Coates-Estrada, 2002), os valores de Shannon (H') indicaram uma diversidade muito próxima à diversidade observada, porém inferior à observada na Fazenda Figueira. Todos os valores ficaram próximos a 2.3, mostrando a mesma dominância de poucas espécies abundantes, e especificamente, das mesmas espécies dominantes.

As duas áreas de pastagem apresentaram uma diversidade $\alpha$ inferior ao fragmento, porém maior em relação à mata ciliar (1.811). Este fato pode ter ocorrido na pastagem (2.088), pela área representar um local de transito de animais entre a mata ciliar e o fragmento, fato observado também por Bernard \& Fenton (2003), exceto pelas espécies exclusivas dos ambientes florestais, e por ter apresentado uma espécie ( $M$. macconnelli) capturada exclusivamente em área aberta, e no caso da pastagem com início de sucessão secundária (2.197), por terem sido capturados indivíduos de diversas espécies, apesar de poucos.

$\mathrm{O}$ índice de diversidade $\alpha$, quando aplicado para áreas fechadas (remanescentes florestais) e abertas (pastagens em geral), indicou que a diversidade no primeiro (2.554) foi superior ao segundo (2.254), mostrando que, como eram esperados, os remanescentes florestais foram responsáveis por uma maior diversidade de espécies, em função das características destes ambientes, capazes de providenciar refúgio e alimento para os morcegos.

A pastagem com início de sucessão secundária, foi o ambiente de maior equitabilidade (0.614), junto com a mata ciliar (0.613), o que indicou que estas espécies apresentaram valores de abundância mais próximos entre si, do que as espécies encontradas nos demais ambientes da Fazenda Figueira. $O$ ambiente de menor equitabilidade, e mais próximo do valor encontrado em $\gamma(0.325)$, foi a pastagem $(0.343)$. 
Este ambiente, provavelmente, apresentou um valor baixo devido ao fato de que nem todas as espécies apresentam a mesma facilidade para o uso dos ambientes abertos.

$\mathrm{O}$ Índice de Similaridade de Sorenson foi aplicado aos dados, porém, a Porcentagem de Similaridade entre os pares de ambientes (Tabela 4) foi o que melhor se ajustou aos dados. Este índice demonstrou que os ambientes florestais foram os de maior similaridade, seguido pelas áreas abertas. A mata ciliar e a pastagem com início de sucessão secundária foram as duas áreas de menor similaridade, provavelmente por serem as áreas mais distantes entre si. Os valores de similaridade não foram muito alto, possivelmente pela presença de poucas espécies comuns entre os quatro ambientes (3 espécies), e entre os pares de ambientes (média de 5 espécies), o que nem sempre ocorre em outras localidades (Estrada \& Coates-Estrada, 2002).

Tabela 4. Porcentagem de Similaridade entre as comunidades de morcegos dos ambientes da Fazenda Figueira. Legenda: FR, fragmento; MC, mata ciliar; PS, pastagem com início de sucessão secundária; PA, pastagem

\begin{tabular}{ccccc}
\hline & FR & MC & PS & PA \\
\hline FR & 100 & & & \\
MC & 69,69 & 100 & & \\
PS & 56,18 & 53,47 & 100 & \\
PA & 59,93 & 61,73 & 64,03 & 100 \\
\hline
\end{tabular}

O número de indivíduos entre as espécies diferiu significativamente $(\mathrm{F}=6,955427$; $\mathrm{P}<0,01$ ), demonstrando uma heterogeneidade na comunidade de morcegos nas áreas amostradas. Esta heterogeneidade foi observada também por outros autores (Cosson et al., 1999; Berbard \& Magnusson, 2001; Reis et al., 2002; Bernard \& Feton, 2003; Falcão et al., 2003 e Reis et al., 2003).

No gráfico de abundância relativa das espécies (Figura 9a), foi possível observar a heterogeneidade na comunidade de morcegos da Fazenda Figueira, com uma 
dominância de apenas três espécies $(\mathrm{F}=53,62628 ; \mathrm{P}<0,001)$, responsáveis por $78,4 \%$ do total de indivíduos capturados (A. lituratus, 35,8\%; S. lilium, 28,4\%; e C. perspicillata, $14,2 \%)$. As outras oito espécies juntas corresponderam a $21,6 \%$ do total das capturas, podendo, estas espécies, serem consideradas como raras na Fazenda Figueira. MarinhoFilho \& Sazima (1998) demonstraram esta mesma heterogeneidade nas comunidades de diferentes tamanhos de fragmentos florestais, Félix et al. (2001) e Reis et al. (2002), observaram este fato para as unidades de conservação da Bacia do Tibagi, Pedro et al. (2001) para a Estação Ecológica dos Caetetus (SP), e Falcão et al. (2003) para a Reserva da Serra do Caraça (SP).

Este padrão de dominância foi observado também para os dois ambientes florestais (Figura 9bc), diferindo nos ambientes de pastagem com início de sucessão, onde apenas $A$. lituratus (Figura 9d) destaca-se como dominante $(\mathrm{F}=29,9596 ; \mathrm{P}<0,01)$, e o ambiente de pastagem, onde A. jamaicensis (Figura 9e) destaca-se como uma das espécies dominantes $(\mathrm{F}=13,69519 ; \mathrm{P}<0,01)$.

A abundância das três espécies frugivoras dominantes, além de ser uma característica própria destas espécies, observada em diversos trabalhos (Cosson et al., 1999a; Schulze et al., 2000; Baptista \& Mello, 2001; Félix et al., 2001; Pedro et al., 2001; Estrada \& Coates-Estrada, 2002; Reis et al., 2002 e Reis et al., 2003), pode estar relacionada à presença de frutos que apresentam uma maior densidade em áreas degradadas, como Piper spp, relatado por Schulze et al. (2000), que foi um gênero aparentemente muito freqüente nas áreas estudadas, assim como a espécie $P$. gaudichaudianum ou erva-de-jaboti (Rodrigues et al., dados não publicados).

Dentre as espécies dominantes na comunidade de morcegos da Fazenda Figueira, parece ter ocorrido uma diferenciação na forma de uso dos ambientes, sendo $S$. lilium a mais abundante em remanescentes florestais, seguida de $A$. lituratus e $C$. perspicillata (Figura 9bc). Quando observado as áreas de pastagem, percebeu-se que $S$. lilium passou a apresentar uma abundância relativa menor do que A. lituratus (Figura 9de), podendo indicar uma maior facilidade da segunda espécie em ultrapassar áreas abertas, embora todas estas espécies utilizem áreas abertas e/ou degradas, como observado neste estudo e descrito por Falcão et al. (2003). C. perspicillata também apresentou um declínio na área 
de pastagem, mostrando-se menos favorecida por esta condição, fato este, citado por Marinho-Filho \& Sazima (1998).

a) Total

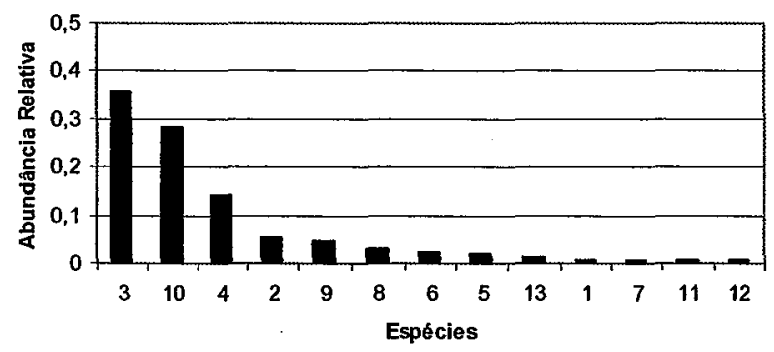

b) Fragmento

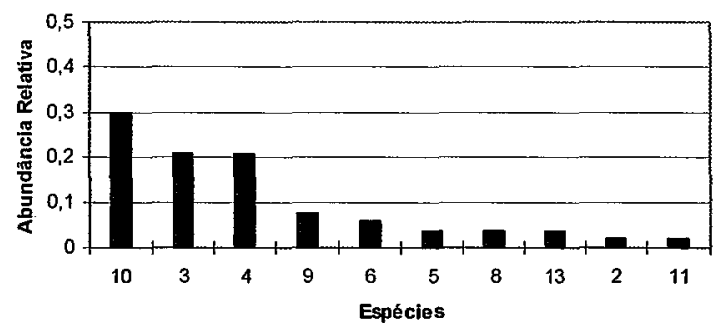

d) Pastagem c/ início sucessão secundária

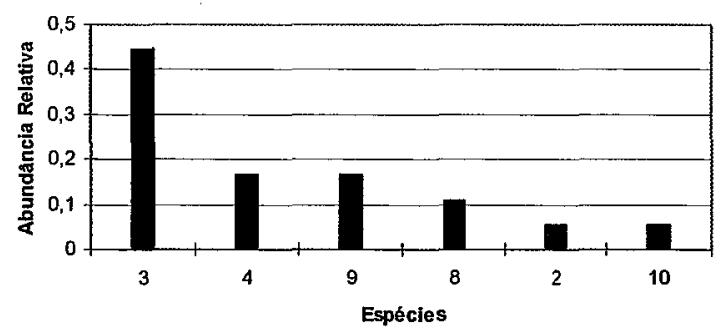

c) Mata ciliar

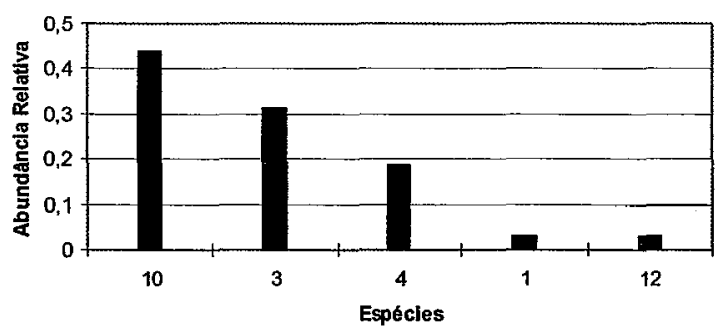

e) Pastagem

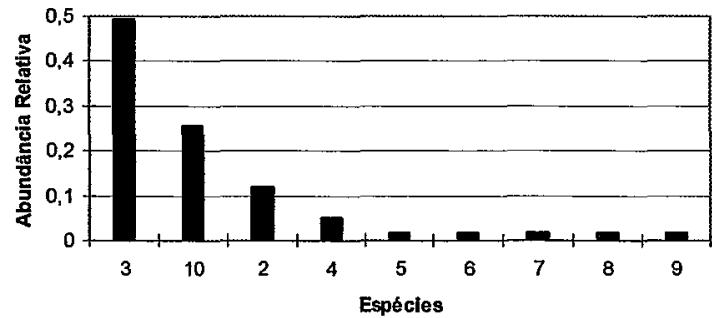

Figura 9 - Abundância das espécies de morcegos nos diferentes ambientes da Fazenda Figueira. Legenda: 1, A. caudifera; 2, A. jamaicensis; 3, A.lituratus; 4, C. perspicillata; 5, C. auritus; 6, D. rotundus; 7, M. macconnelli; 8, P. lineatus; 9, P. bilabiatum; 10, S. lilium; 11, T. silvicola; 12, L. blossevillii; 13, M. nigricans 
A abundância das espécies raras esteve de acordo com o observado em outros estudos realizados no baixo Tibagi (Félix et al., 2001; Reis et al., 2002; Reis et al., 2003), com exceção de $M$. nigricans que apresentou uma porcentagem inferior ao observado nestes estudos, e P. bilabiatum, que ao contrário, apresentou uma porcentagem superior.

A. caudifera apresentou uma abundância relativamente baixa $(0,6 \%)$, e de acordo com o observado por outros autores (Cosson et al., 1999a; Bernard et al., 2001; Félix et al., 2001; Quesada \& Stoner, 2003; Reis et al., 2002 e Reis et al., 2003), para esta e outras espécies nectarívoras em ambientes fragmentados. Esta baixa abundância, além de característico da espécie, deve ter sido influenciada pelo estado de fragmentação da área e conservação dos remanescentes, considerando o fato desta espécie declinar em áreas alteradas, como mostram os dados de Cosson et al. (1999a).

Outro fato importante com relação às espécies raras é que poucos casos de ataque de $D$. rotundus em gado bovino e/ou eqüino foram relatados, e em visita a chiqueiros destinados a criação de suínos para o consumo de moradores da fazenda, não foi verificado nenhum indício destes ataques. Os poucos casos relatados foram principalmente sobre muares, portanto, acredita-se que os $D$. rotundus esteja em uma abundância relativamente e densidade relativa baixa na área, estando de acordo com o esperado para a espécie, demonstrado por Trajano (1996), que verificou uma densidade média de 3,5 indivíduos por $\mathrm{Km}^{2}$.

C. auritus, foi outra espécie pouco abundante na área, mas manteve uma porcentagem similar às outras áreas estudadas no baixo Tibagi, e por ser uma espécie predadora, primeiramente afetada pela fragmentação como indicado por Schulze et al. (2000), pode estar indicando um bom estado de conservação das áreas quanto à disponibilidade de alimento.

Baseado nas características populacionais das espécies, e não desconsiderando que a amostragem foi temporalmente e espacialmente pequena, a comunidade de morcegos da Fazenda Figueira pode apresentar uma composição próxima à registrada, onde os indivíduos jovens representaram $45 \%$ e os adultos $55 \%$, diferindo dos dados observados por Estrada \& Coates-Estrada (2002), onde a abundância de adultos na comunidade foi extremamente superior ao número de jovens. Uma população constituída 
por um número relativamente alto de indivíduos jovens pode estar indicando uma alta taxa de imigração ou colonização, fato este que, se estiver ocorrendo, pode estar influenciando na alta diversidade do local.

$O$ teste Qui-quadrado $\left(\chi^{2}\right)$ demonstrou que não houve diferença entre a abundância de jovens e adultos entre os ambientes, mas sim entre as espécies $(\mathrm{P}<0,01)$, sendo S. lilium responsável por $47 \%$ das espécies jovens (Figura 10a), e A. lituratus por $65 \%$ das espécies adultas (Figura 10b). A. jamaicensis foi a espécie que apresentou a menor diferença com relação à idade.

a). Jovens

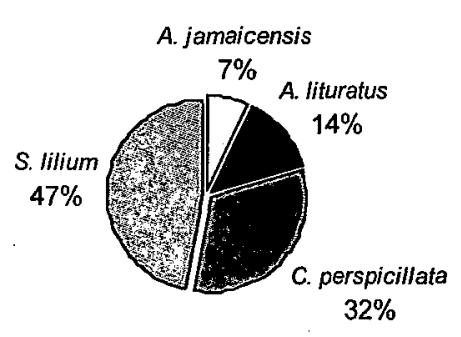

b) Adultos

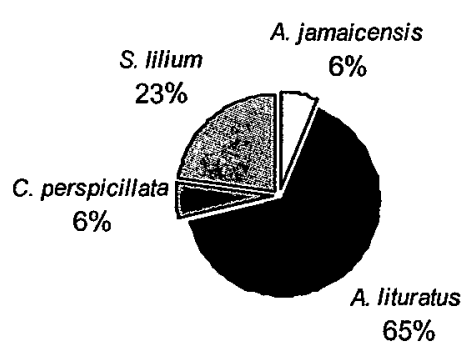

Figura 10 - Porcentagem de indivíduos jovens e adultos entre as cinco espécies mais abundantes

Dados de peso e comprimento do antebraço foram coletados (Tabela 5), sendo observado a predominância de duas classes de peso na comunidade, uma entre 11 e 30 gramas (oito espécies), na qual estavam presentes $50 \%$ dos indivíduos; e outra classe entre 51 e 80 gramas (duas espécies), com $32 \%$ da comunidade. A. caudifera, $M$. macconnelli e $S$. lilium (66\%), apresentaram-se acima do peso médio da espécie, referido por Nowak (1994). Apesar da diferença de peso entre as espécies ter sido altamente significativa ( $\mathrm{F}=115,1151 ; \mathrm{P}<0,001$ ), as medidas de comprimento do antebraço entre as espécies não foram significativas $(\mathrm{F}=0,304673 ; \mathrm{P}>0,05)$, embora os valores diferissem entre si. 
Tabela 5. Características de peso e tamanho do antebraço das espécies de morcegos registradas para a Fazenda Figueira

\begin{tabular}{lccc}
\hline \multicolumn{1}{c}{ Espécies } & Peso $(\mathbf{g})$ & Comprimento do Antebraço $(\mathbf{m m})$ & Tamanho* \\
\hline 01 - Anoura caudifera & 12,0 & $39,5 \pm 0,5$ & PEQ \\
02 - Artibeus jamaicencis & $55,4 \pm 6,5$ & $64,5 \pm 9,0$ & GR \\
03 - Artibeus lituratus & $71,4 \pm 12,8$ & $70,8 \pm 2,8$ & GR \\
04 - Carollia perspicillata & $16,2 \pm 3,4$ & $40,7 \pm 1,2$ & PEQ \\
05 - Chrotopterus auritus & $85,0 \pm 3,6$ & $84,4 \pm 1,2$ & GR \\
06 - Desmodus rotundus & $43,9 \pm 8,0$ & $63,0 \pm 3,5$ & GR \\
07 - Mesophylla macconnelli & 11,0 & $36,4 \pm 2,2$ & PEQ \\
08 - Platyrrhinus lineatus & $19,8 \pm 2,9$ & $44,5 \pm 3,0$ & PEQ \\
09 - Pygoderma bilabiatum & $19,4 \pm 6,1$ & $39,0 \pm 1,1$ & PEQ \\
10 - Sturnira lilium & $22,5 \pm 3,5$ & $43,3 \pm 1,1$ & PEQ \\
11 - Tonatia silvicola & 28,0 & $54,1 \pm 0,1$ & GR \\
12 - Lasiurus blossevillii & 11,0 & $45,9 \pm 1,2$ & PEQ \\
13 - Myotis nigricans & $3,5 \pm 0,7$ & $32,7 \pm 1,4$ & PEQ \\
\hline
\end{tabular}

* Espécies pequenas foram as que apresentaram antebraço $<45 \mathrm{~mm}$; e grandes as de antebraço $>50 \mathrm{~mm}$.

A partir das características de peso e tamanho das espécies (Tabela 5), percebeuse um predomínio de animais pequenos $(61,5 \%)$ e, dentre os frugívoros, esta proporção foi de cinco espécies pequenas ( 83 indivíduos) para apenas duas grandes (67 indivíduos), proporção esta equivalente às obtidas por outros autores (Schulze et al., 2000 e Pedro, 2001).

Os dados discordaram de Cosson et al. (1999a), que verificaram que as pequenas espécies frugívoras de sub-bosque foram mais sensiveis à fragmentação em relação às espécies de dossel. Na Fazenda Figueira não foi observada esta relação e, estatisticamente, não houve diferença entre a abundância destas espécies de sub-bosque como $C$. perspicillata e $S$. lilium $(\mathrm{F}=1,319718 ; \mathrm{P}>0,05)$, fato este que pode estar indicando que estas espécies foram pouco sensíveis à fragmentação, estando, estes resultados, de acordo com os observados por Trajano (1996) e Bernard \& Fenton (2003).

Dentro do período em que foi realizado o levantamento de morcegos, quase todas as espécies registradas apresentavam-se no período reprodutivo ou parte deste (Tabela 6), com exceção de 3 espécies (A. caudifera, L. blossevillii e $M$. nigricans). Estes períodos de reprodução, ou parte destes, corresponderam ao descrito por Nowak (1994), para 
quase todas as espécies de morcegos da família Phyllostomidae, com exceção para $D$. rotundus.

Tabela 6. Períodos reprodutivos para as espécies de morcegos registradas na Fazenda Figueira

\begin{tabular}{lc}
\hline \multicolumn{1}{c}{ Espécies } & Período reprodutivo* \\
\hline 01 - Anoura caudifera & SR $^{* *}$ \\
02 - Artibeus jamaicencis & Fev e Ago \\
03 - Artibeus lituratus & Jan, Fev, Jul e Ago \\
04 - Carollia perspicillata & Jan, Fev e Jul \\
$05-$ Chrotopterus auritus & Ago \\
$06-$ Desmodus rotundus & Fev e Jul \\
$07-$ Mesophylla macconnelli & Fev \\
08 - Platyrrhinus lineatus & Fev \\
$09-$ Pygoderma bilabiatum & Fev e Jul \\
$10-$ Sturnira lilium & Jan, Fev, Jul e Ago \\
11 - Tonatia silvicola & Fev \\
12 - Lasiurus blossevillii & SR $^{* *}$ \\
13 - Myotis nigricans & SR $^{* *}$ \\
\hline
\end{tabular}

* Corresponde aos meses de levantamento de morcegos na Fazenda Figueira.

** SR, sem registro para o período de levantamento.

A comunidade de morcegos na área estudada foi constituída por uma maior proporção de fêmeas (Figura 11). $\mathrm{O}$ teste Qui-quadrado $\left(\chi^{2}\right)$ demonstrou que não houve diferença significativa entre a abundância de indivíduos do sexo masculino e feminino $(\mathrm{P}>0,5)$, indicando que estas espécies foram constituídas de cerca de $1 / 2$ machos e $1 / 2$ fêmeas, e provando que a maior proporção de indivíduos na comunidade do sexo feminino ocorreu, não em função de uma maior abundância de fêmeas, mas sim por diferenças dentro dos grupos de machos e de fềmeas. Desta forma, considerou-se os sexos separadamente (Figura 11), foi onde a porcentagem de machos em período reprodutivo apresentou-se consideravelmente inferior (22\%) ao número de machos não reprodutivos $\left(\chi^{2} ; \mathrm{P}<0,05\right)$. Esta relação não foi observada para o grupo das fêmeas $\left(\chi^{2}\right.$; $\mathrm{P}>0,05)$, que apresentaram uma proporção de 1:1. 
Fêmeas

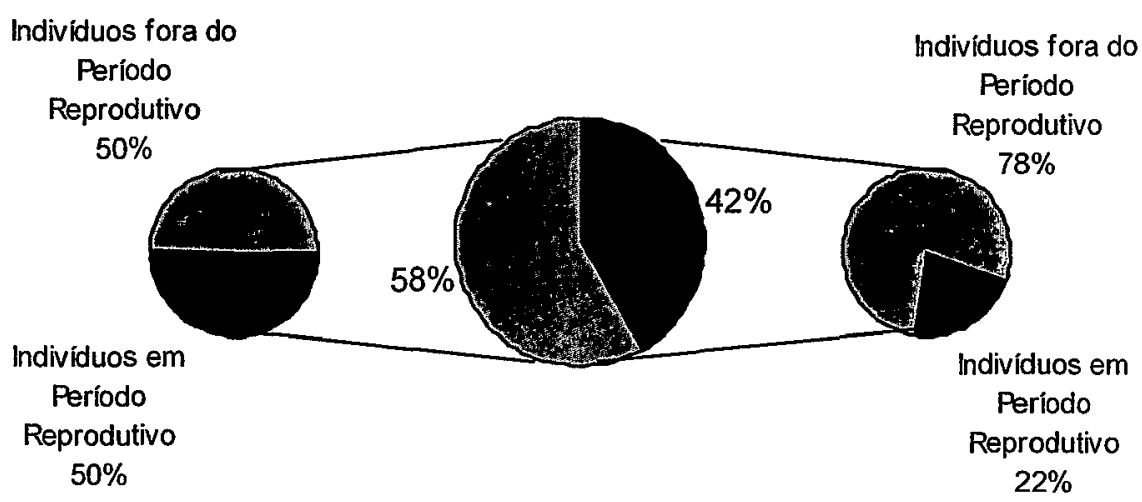

Figura 11 - Características sexuais da comunidade de morcegos para os ambientes amostrados

$\mathrm{O}$ número de machos reprodutivos não ocorreu em função da idade dos indivíduos $\left(\chi^{2} ; \mathrm{P}>0,05\right)$, reforçando o fato da razão sexual deste grupo ser de 1 indivíduo reprodutivo para 3 não reprodutivos. Considerando as espécies separadamente, apenas $A$. jamaicensis e $A$. lituratus apresentaram uma relação de machos de 1:3 (25\%), apenas $D$. rotundus apresentou $100 \%$ de indivíduos machos reprodutivos, e na maior parte das espécies $(62,5 \%)$ não houve nenhum indivíduo reprodutivo.

$\mathrm{Na}$ Figura 12, foi possível verificar que a maior parte da comunidade encontrouse fora do período reprodutivo (60\%), sendo que destes indivíduos houve uma proporção equivalente de machos e de fêmeas. Os indivíduos da comunidade em período reprodutivo (machos escrotados, fêmeas lactantes e/ou grávidas), resultaram em uma proporção de 3 fêmeas para 1 macho, razão esta que difere dos dados de Estrada \& Coates-Estrada (2002).

A razão sexual de 3 fêmeas para cada macho manteve-se em $57 \%$ das espécies (excluindo as espécies em que foram capturados indivíduos de um único sexo), para $D$. rotundus e $P$. bilabiatum a razão foi igual, porém inversa. S. lilum foi a única espécie que apresentou a razão de 1:1. Esta razão de 3 para 1 pode ter predominado nas populações 
pelo fato da maioria das fềmeas, por estarem grávidas, apresentarem um maior deslocamento em busca de alimento, sendo maior a probabilidade de serem capturadas e/ou por um macho copular com diversas fêmeas (formando ou não haréns).

Indivíduos fora do período reprodutivo
Individuos em Periodo Reprodutivo

\section{Comunidade}

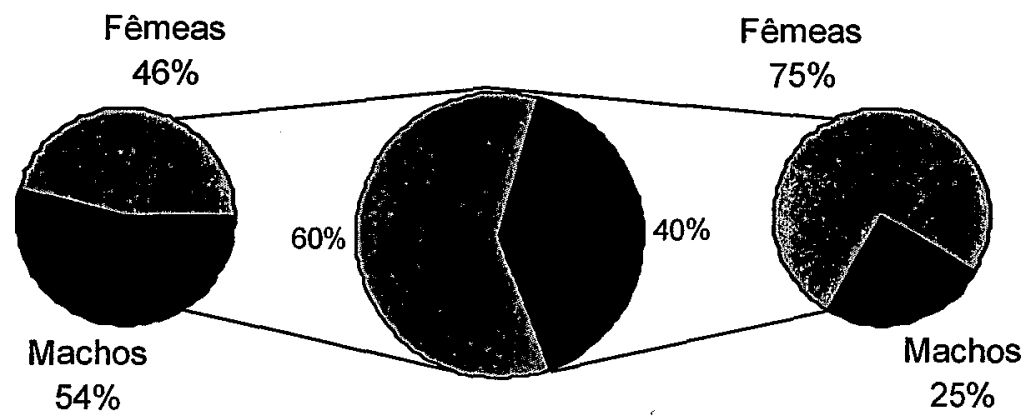

Figura 12 - Porcentagem de indivíduos se reproduzindo na comunidade e sexo no período de levantamento na Fazenda Figueira

A alternativa encontrada para avaliar o estado de conservação da comunidade de morcegos na Fazenda Figueira foi verificar todos os dados observados junto às características apresentadas pelas espécies, onde se verificou que a fazenda apresenta uma diversidade alta de espécies em função, provavelmente, da heterogeneidade de ambientes, responsáveis por suportar espécies com as mais variadas exigências ecológicas, fato verificado através da presença de $T$. silvicola (não-generalista) e $A$. lituratus (generalista). $\mathrm{O}$ fato da heterogeneidade de um determinado local ser responsável por um acréscimo de diversidade foi observado por outros autores (Sax \& Gaines, 2003 e Coppolitto et al., 2004), porém, cuidado deve ser tomado ao considerar esta diversidade elevada como benéfica, pois possivelmente as espécies que requerem ambientes homogêneos sofreram um declínio ou mesmo extinção local, restando apenas espécies mais adaptáveis às alterações do hábitat (Coppolitto et al., 2004). 
A sensibilidade à fragmentação foi um fato de difícil julgamento, pois a distância entre os remanescentes foi relativamente pequena nas áreas estudadas. C. perspicillata $\mathrm{e}$ S. lilium, assim como todas as outras (exceto $T$. silvicola) são espécies que apresentam grandes áreas de vida, podendo percorrer grandes distâncias em uma noite (Nowak, 1994 e Bernard \& Fenton, 2003), sendo muito subjetivo considerar simplesmente o uso de ambientes abertos e alterados como indicativo de sensibilidade.

Utilizar espécies que apresentem área de vida pequena, como T. silvicola, parece uma melhor alternativa, pois esta espécie restringe suas atividades para uma área pequena ao redor do ninho (Bernard \& Fenton, 2003), sendo improvável que percorra as distancias, mesmo que pequenas, entre os remanescentes. Neste caso, presença de $T$. silvicola, dentre as 14 espécies capturadas, atuou como indicadora para o estado de conservação do fragmento florestal em função de sua sensibilidade à fragmentação, que é uma característica citada por Lindenmayer et al. (2000a), como condicional para espécies indicadoras. M. ruber por ser a única espécie ameaçada (Fundação Biodiversistas et al., 2003), registrada para a Fazenda Figueira, também pode ser uma boa indicadora de degradação.

Uma boa espécie "guarda-chuva" na conservação da comunidade de morcegos em remanescentes florestais teria que apresentar os requisitos atribuídos a estas espécies, como grande tamanho corpóreo, grande área de vida, e ambiente bem estruturado como sugerido por Roberge \& Angelstam (2003). Porém, no caso dos morcegos, faltam estudos no sentido de encontrar espécies "guarda-chuva", podendo ser mais efetivo o uso das espécies indicadoras e/ou ameaçadas em estratégias de conservação, através da proteção de toda a área na qual há registro para a espécie. 


\subsection{Estudo de mamíferos não-voadores}

\subsubsection{Estudo de mamíferos de pequeno porte por meio de captura}

O levantamento de pequenos mamíferos não-voadores foi realizado em janeirofevereiro de 2004, e resultou em um esforço total de 2.250 armadilhas/noite. Em áreas de pastagem, com e sem início de sucessão secundária, o esforço foi de 450 armadilhas/noite, e em as áreas florestais o esforço foi de 675 armadilhas/noite, incluindo as armadilhas colocadas no sub-bosque.

No total foram capturados apenas sete indivíduos de pequenos mamíferos nãovoadores, pertencentes à pelo menos três espécies, das quais: uma espécie de marsupial (Marmosops paulensis), e quatro roedores, sendo uma da família Dasyproctidae (Dasyprocta azarae) e 3 roedores não identificados.

Apesar do esforço, a porcentagem de captura de pequenos mamíferos terrestres foi muito baixa $(0,31 \%)$. Para as duas áreas compostas por pastagem, a baixa taxa de captura $(0,33 \%)$ foi esperada, porém no fragmento de Floresta Estacional Semidecídua, onde era esperada uma maior taxa de captura, apenas um indivíduo foi capturado $(0,15 \%)$. Poucos indícios de aproximações dos animais das armadilhas foram verificados. Já na mata ciliar, a presença de Lontra (Lontra longicaudis) atraída pela isca, e o desarme das armadilhas, podem ter sido alguns dos fatores responsáveis pela baixa taxa de captura $(0,44 \%)$ neste ambiente.

\subsubsection{Estudo qualitativo de mamíferos}

Com o período de levantamento realizado na Fazenda Figueira, foram registradas 7 ordens, 17 famílias, 35 espécies e um gênero de mamífero entre pequeno, médio e grande porte, nos três tipos de ambientes avaliados (Tabela 07), considerando-se todos os tipos de registros, diretos e/ou indiretos. 
Tabela 7. Lista dos mamíferos não-voadores da Fazenda Figueira. FR, fragmentos; MC, matas ciliares; PA, pastagens; TR, tipo de registro; Ob, observação direta; Ra, rastros; Vo, vocalizações; $\mathrm{Ct}$, registro por câmera digital; Re, relato; $\mathrm{Ab}$, abrigo ou toca; Fe, fezes; Cp, captura; Pe, pêlos; Od, odor

\begin{tabular}{|c|c|c|c|c|c|}
\hline Ordem & Família & Espécies & Nome Popular & Ambiente & TR \\
\hline \multirow[t]{4}{*}{ Didelphimorphia } & Didelphidae & 01 - Didelphis albiventris & Gambá & PA & $\mathrm{Ob} ; \mathrm{Ra}(?)$ \\
\hline & & 02 - Didelphis aurita & Gambá & FR & $\operatorname{Re} ; \operatorname{Ra}(?)$ \\
\hline & & 03 - Chironectes minimus & Cuíca d'água & $\mathrm{MC}$ & $\mathrm{Ra}$ \\
\hline & & $04-$ Marmosops paulensis & Cuíca & PA & $\mathrm{Cp}$ \\
\hline \multirow[t]{4}{*}{ Xenarthra } & Myrmecophagidae & 05 - Tamandua tetradactyla & Tamanduá mirim & PA & $\mathrm{Ra} ; \operatorname{Re}$ \\
\hline & Dasypodidae & 06 - Euphractus sexcinctus & Tatu peba & FR & $\operatorname{Re}$ \\
\hline & & $07-$ Dasypus novemcinctus & Tatu galinha & FR; MC; PA & $\mathrm{Ob} ; \mathrm{Ra} ; \mathrm{Re} ; \mathrm{Ab}$ \\
\hline & & 08 - Dasypus septemcinctus & Tatu mulita & FR; PA & $\operatorname{Ra}(?) ; \operatorname{Re}$ \\
\hline Primates & Cebidae & $09-$ Cebus apella & Macaco Prego & FR; PA & $\mathrm{Ob} ; \mathrm{Vo} ; \mathrm{Re} ; \mathrm{Ra}$ \\
\hline \multirow[t]{14}{*}{ Carnivora } & Canidae & $10-$ Cerdocyon thous & Cachorro do mato & $\mathrm{FR} ; \mathrm{MC} ; \mathrm{PA}$ & $\mathrm{Ob} ; \mathrm{Ra} ; \mathrm{Re}$ \\
\hline & & 11 - Pseudalopex gymnocercus & Raposinha & $\mathrm{FR} ; \mathrm{MC} ; \mathrm{PA}$ & $\mathrm{Fe} ; \mathrm{Ra}$ \\
\hline & & 12 - Chrysocyon brachyurus & Lobo guará & PA & $\operatorname{Re}$ \\
\hline & Procyonidae & 13 - Nasua nasua & Coati & $\mathrm{MC} ; \mathrm{PA}$ & $\mathrm{Ob} ; \mathrm{Ra} ; \mathrm{Re}$ \\
\hline & & 14 - Procyon cancrivorus & Mão pelada & $\mathrm{FR} ; \mathrm{MC} ; \mathrm{PA}$ & $\mathrm{Ra}$ \\
\hline & Mustelidae & 15 - Conepatus chinga & Cangambá & FR; MC & $\mathrm{Ra}$ \\
\hline & & 16-Galictis vittata & Furão & $\mathrm{MC}$ & $\mathrm{Ra}$ \\
\hline & & 17 - Lontra longicaudis & Lontra & MC & $\mathrm{Ra} ; \mathrm{Re}$ \\
\hline & & 18 - Pteronura brasiliensis & Ariranha & MC & $\mathrm{Ra}$ \\
\hline & Felidae* & $19-$ Leopardus pardalis & Jaquatirica & FR; MC & $\mathrm{Ra} ; \operatorname{Re}$ \\
\hline & & 20 - Leopardus tigrinus & Gato do mato & FR; MC & $\mathbf{R a}$ \\
\hline & & 21 - Leopardus wiedii & Gato maracajá & FR & $\mathbf{R a}$ \\
\hline & & 22 - Herpailurus yagouaroundi & Gato mourisco & $\mathrm{MC}$ & $\mathbf{R a}$ \\
\hline & & 23 - Puma concolor & Onça parda & FR & $\mathrm{Re} ; \mathrm{Ra} ; \mathrm{Ob}$ \\
\hline Perissodactyla & Tapiridae & $24-$ Tapirus terrestris & Anta & $\mathrm{FR} ; \mathrm{MC} ; \mathrm{PA}$ & $\mathrm{Ra} ; \mathrm{Re} ; \mathrm{Fe} ; \mathrm{Ct}$ \\
\hline \multirow[t]{3}{*}{ Artiodactyla } & Cervidae & 25 - Mazama americana & Veado mateiro & FR & $\mathrm{Ra}$ \\
\hline & & 26 -Ozotocerus bezoarticus & Veado campeiro & FR; PA & $\mathrm{Ra} ; \operatorname{Re}$ \\
\hline & Tayassuidae & 27 - Tayassu tajacu & Cateto & FR & $\mathrm{Ra} ; \mathrm{Re} ; \mathrm{Ct} ; \mathrm{Od}$ \\
\hline \multirow[t]{9}{*}{ Rodentia } & Agoutidae & 28 - Agouti paca & Paca & $\mathrm{FR} ; \mathrm{MC}$ & $\mathrm{Ra} ; \mathrm{Re}$ \\
\hline & Caviidae & 29-Cavia aparea & Preá & MC & $\mathrm{Ob} ; \mathrm{Ra} ; \mathrm{Re}$ \\
\hline & Dasyproctidae & 30 - Dasyprocta azarae & Cutia & FR; MC; PA & $\mathrm{Cp} ; \mathrm{Ra} ; \mathrm{Re} ; \mathrm{Ct}$ \\
\hline & Hydrochaeridae & 31 - Hydrochaeris hydrochaeris & Capivara & $\mathrm{MC}$ & $\mathrm{Ra} ; \mathrm{Fe} ; \mathrm{Re}$ \\
\hline & Muridae & $32-$ Akodon spp. & Rato & FR; MC; PA & $\mathrm{Pe} ; \mathrm{Cp}$ \\
\hline & & 33 - Myocastor coypus & Ratão do banhado & $\mathrm{MC}$ & Ra \\
\hline & & 34 - Nectomys squamipes & Rato d'água & $\mathrm{MC}$ & Ra \\
\hline & Leporidae & 35 - Sylvilagus brasiliensis & Tapiti & FR; MC; PA & $\mathrm{Ob} ; \mathrm{Fe} ; \mathrm{Re}$ \\
\hline & & 36 - Lepus europaeus & Lebre européia & PA & $\mathrm{Ob} ; \mathrm{Fe} ; \mathrm{Re} ; \mathrm{Ra}$ \\
\hline
\end{tabular}

\footnotetext{
* A identificação foi realizada a partir das características métricas de vários rastros observados na fazenda.
} 
O levantamento resultou em $50 \%$ das espécies (60) de mamíferos não-voadores registrados até o momento na Bacia do rio Tibagi (Peracchi et al., 2002), e mais 5 espécies (M. paulensis, Chironectes minimus, Conepatus chinga, Pteronura brasiliensis, e Nectomys squamipes) e um gênero (Akodon spp.) que ainda não haviam sido registradas na Bacia, provavelmente em função da falta de estudos de pequenos mamíferos não-voadores, totalizando 65 espécies de mamíferos não-voadores para a Bacia do rio Tibagi (PR). Esta riqueza de espécies foi considerada alta, em função da extensão da área da fazenda, muito inferior à área total da Bacia do Tibagi.

Através da curva acumulada de espécies (excluindo M. paulensis) para o total de dias de levantamento (Figura 13), pode ser observado que, apesar de uma alta riqueza de espécies, a curva acumulada não se estabilizou em um total de 45 dias de levantamento, embora houvesse tendência, mostrando que o tempo de levantamento foi insuficiente, e que um período maior teria sido necessário para se atingir a estabilização da curva nesta área.

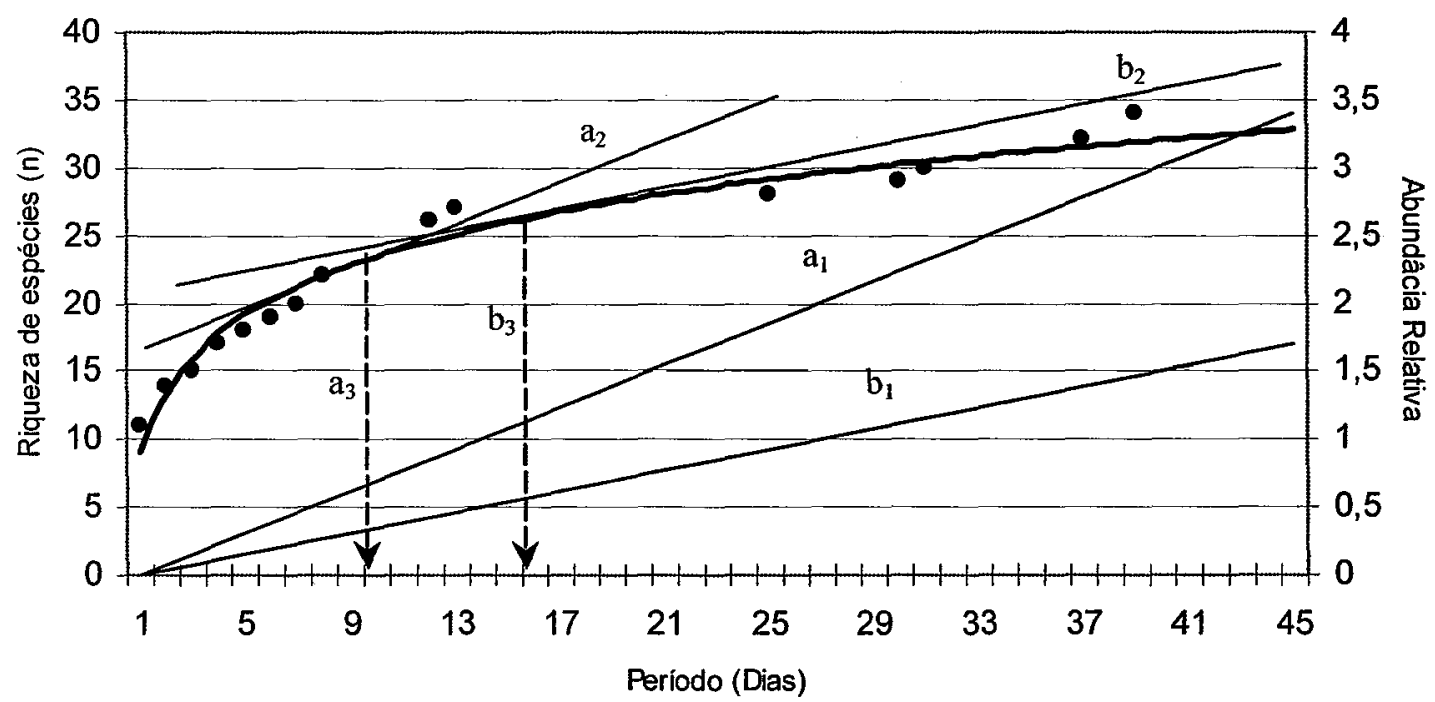

Figura 13 - Curva acumulada de espécies de mamíferos de médio e grande porte, referente ao período de levantamento na Fazenda Figueira 
O tempo mínimo de levantamento na área para que $90 \%$ ou $95 \%$ das espécies fossem registradas seria de aproximadamente 9 e 15 dias, segundo o método proposto por Cain (Krebs), sugerindo que um total de 45 dias de levantamento foi um tempo satisfatório.

Considerando-se os ambientes separadamente, as pastagens apresentaram a menor riqueza de espécies de mamíferos (Tabela 4; Figura 14), que correspondeu a 48,6\% (17 espécies) da riqueza total observada para a fazenda, enquanto que os fragmentos florestais e as matas ciliares representaram 60\% (21 espécies) e 62,8\% (22 espécies) da riqueza total, respectivamente.

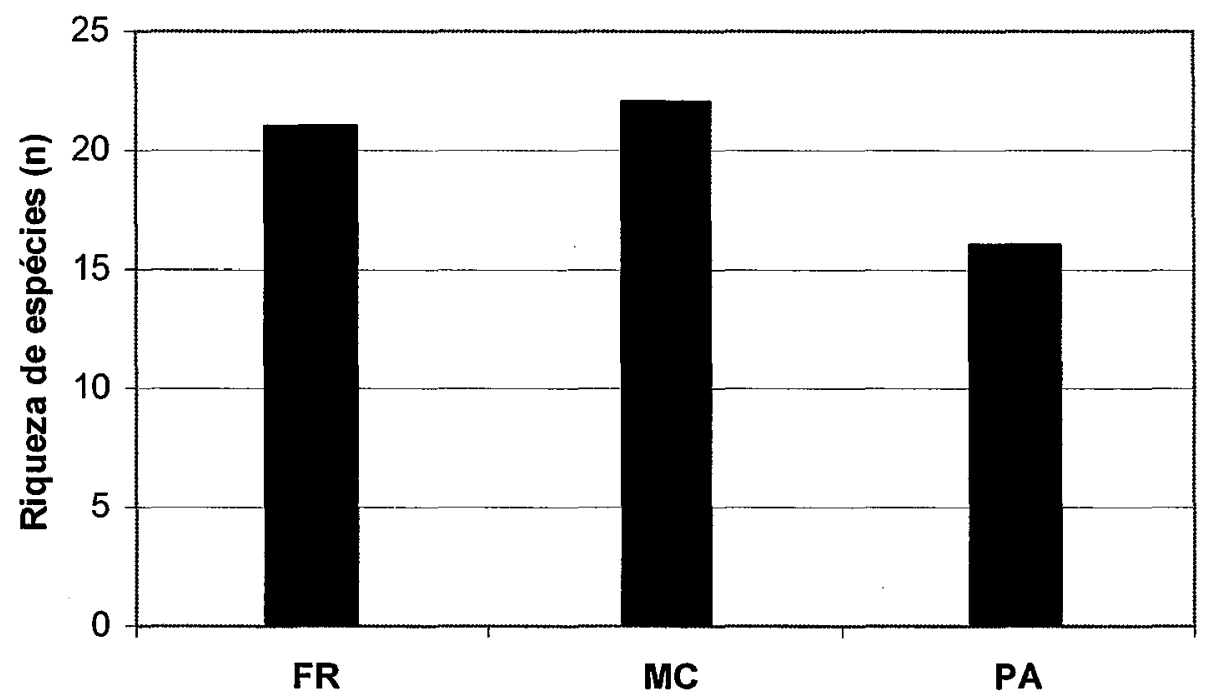

Figura 14 - Riqueza de espécies de mamíferos de médio e grande porte para os diferentes ambientes amostrados na Fazenda Figueira

$\mathrm{O}$ ambiente constituído por pastagem foi o de menor riqueza de espécies, provavelmente em função da escassez de alimento para os grandes mamíferos neste ambiente e, para os pequenos e médios mamíferos, pela falta de abrigo, sombra e, em segundo lugar, pela maior exposição dos animais aos predadores. Também, o fato deste ambientes serem mais secos do que os ambientes florestais deve ter dificultado a marcação de rastros pelas espécies, principalmente as de pequeno porte. Entretanto, este 
ambiente foi frequentemente utilizado por diversas populações, sugerindo que estes espécies o utilizam para passagem entre os remanescentes florestais, de acordo com os dados obtidos por Chiarello (1999), Wallauer et al. (2000) e Tozetti (2002), que observaram o uso de aceiros para translocação.

O valor de riqueza de espécies obtido para as matas ciliares foi igual ao valor encontrado no fragmento. Em composição de espécies, foi observada a presença de 13 espécies em comum entre o fragmento e a mata ciliar, 10 entre o fragmento e a pastagem, e 9 entre a mata ciliar e a pastagem. Das espécies encontradas, 20 (56\%) foram exclusivas a um único ambiente, sendo $30 \%$ pertencente aos fragmentos, $45 \%$ às matas ciliares e $25 \%$ às pastagens. Estes resultados indicaram, provavelmente, o papel dos grandes cursos de água na manutenção de uma alta riqueza de espécies, através da presença de espécies semi-aquáticas como C. minimus, L. longicaudis, $P$. brasiliensis, Hydrochaeris hydrochaeris, N. squamipes e Myocastor coypus.

Todas as espécies que ocorreram exclusivamente na pastagem, dependem de áreas florestais, com exceção de Lepus aeuropeus, para viverem, sugerindo que a maior parte das espécies está vivendo nos remanescentes florestais, e utilizando as pastagens para se translocarem entre estes remanescentes. Isto demonstrou também, que estas espécies foram pouco sensíveis ou tolerantes à fragmentação, e altamente flexíveis, concordando com Stockwell \& Ashley (2004).

M. paulensis foi capturada exclusivamente em área de pastagem, discordando dos dados de Gentile \& Fernandes (1999), que descrevem os marsupiais como espécies arbóreas e dependentes de um ambiente florestal bem estruturado, sendo, assim, espécies pouco tolerantes à fragmentação. Este comportamento pode ter indicado que esta espécie estava sendo afetada negativamente pela fragmentação, sendo forçada a forragear no ambiente entre os fragmentos, o que pode estar afetando também suas preferências alimentares e a busca por abrigo, tornando-se mais susceptíveis a predação, como sugerido por Harrington et al. (2001) e Tozetti (2002).

O método qualitativo, como ferramenta para o levantamento de populações de mamíferos não-voadores, apresenta diversos problemas, que podem ter ocorrido em função das diferentes probabilidades de encontro de vestígios entre as populações de 
mamíferos, seja por características morfológicas e/ou pelos hábitos ecológicos das espécies, seja pelas características do solo nos diferentes ambientes amostrados e/ou das condições climáticas no período de levantamento. Em geral, espécies grandes e/ou que transitam frequentemente em locais com solo saturado ou não compactado, espécies com atividades diurna e tolerante a presença humana são mais facilmente detectados por métodos qualitativos de levantamento.

Outro problema que pode ter ocorrido diz respeito à dificuldade de verificar a individualidade destes rastros, sendo possível que vários registros sejam de um único indivíduo ou de poucos indivíduos. Para minimizar este problema, buscou-se considerar, para grandes e médios mamíferos que se locomovem grandes distâncias, apenas um encontro para pegadas muito próximas; para médios e/ou pequenos mamíferos com área de vida restrita, consideraram-se todos os vestígios distantes ao menos por 100 metros. Para a contagem do número de encontros com vestígios e/ou animais de espécies grupais como Cebus apella e Nasua nasua, por exemplo, considerou-se cada encontro ou cada grupo de animais como um encontro. Não foi considerado o número de indivíduos dentro do grupo.

Todas as sete ordens de mamíferos registradas foram representadas tanto no fragmento quanto na área de pastagem, exceto na mata ciliar, onde nenhuma espécie de Artiodactyla e Primates foi registrada.

A ordem Carnívora foi a mais representada na Fazenda Figueira, sendo responsável por $38 \%$ do total de espécies, e sendo também a ordem de maior representatividade em todos os ambientes amostrados (Figura 15), fato este que demonstrou estar, esta comunidade, relativamente estruturada pela manutenção de todos os níveis tróficos, principalmente de espécies de topo de cadeia alimentar. A ordem Rodentia foi a segunda de maior representatividade na fazenda, seguida pela ordem Xenarthra.

A porcentagem das ordens esteve de acordo com o esperado, pois os carnívoros e os roedores são os as duas ordens com maior número de espécies, sendo, a primeira, composta por animais relativamente grandes que deixam vestígios com freqüência. A ordem Xenarthra, apesar de pouco conspícua, é constituída por várias espécies que se 
locomovem frequentemente por locais com acúmulo de areia, deixando rastros com relativa facilidade.

As demais ordens foram representativas de uma baixa porcentagem da comunidade sendo compostas por poucas espécies, como o caso de Perissodactyla, composta por uma única espécie, ou Didelphimorphia, que é composta por uma maioria de espécies pequenas, e dificilmente registrada em campo através do método qualitativo.

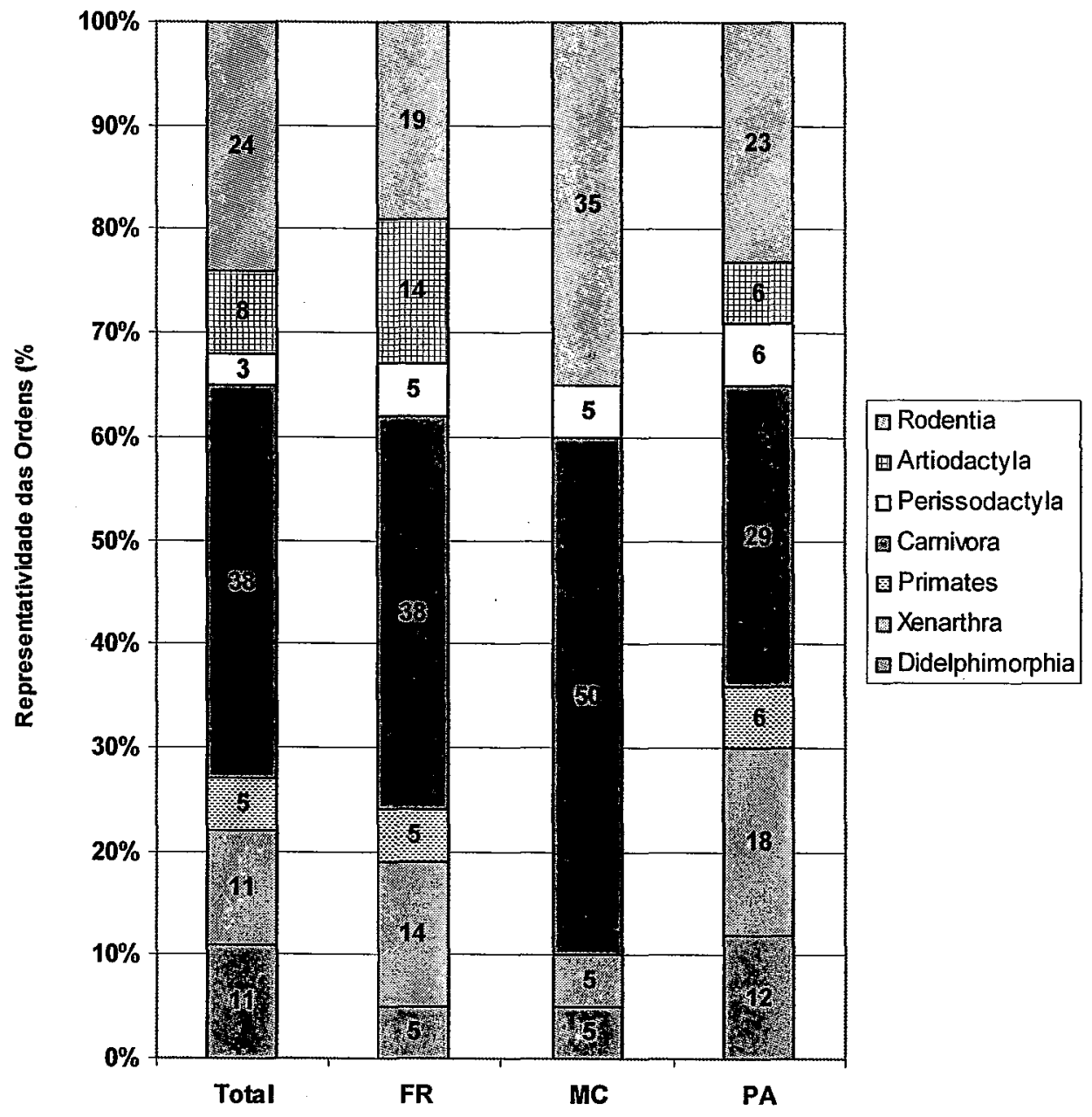

Figura 15 - Abundância relativa das ordens de mamíferos não-voadores nos diferentes ambientes da Fazenda Figueira 
O levantamento por meio de rastros foi o que resultou em um maior número de espécies. No total, foram registradas 25 espécies por meio de rastros para os períodos de levantamento (164 registros). O gráfico da abundância de rastros encontrados por espécies de mamíferos (Figura 16), mostrou que houve uma maior abundância de Tapirus terrestris, Procyon cancrivorus, Leopardus pardalis, Dasypus novemcinctus e Cerdocyon thous. Entretanto, este resultado pode indicar não necessariamente um predomínio destas espécies em $\gamma$, mas sim uma maior facilidade dos rastros destas espécies ficarem marcados no solo (problema da metodologia). Quando considerados os pequenos mamíferos, separadamente, $M$. coypus e Silvilagus brasiliensis foram às espécies mais abundantes.

T. terrestris foi, uma das espécies mais abundantes na Fazenda Figueira. Este fato pode ter ocorrido devido a seu hábito generalista, que tornou o uso de ambientes secundários, como os remanescentes da Fazenda Figueira, favorável, como sugerido por Timo (2003), em função da grande densidade de espécies arbustivas.

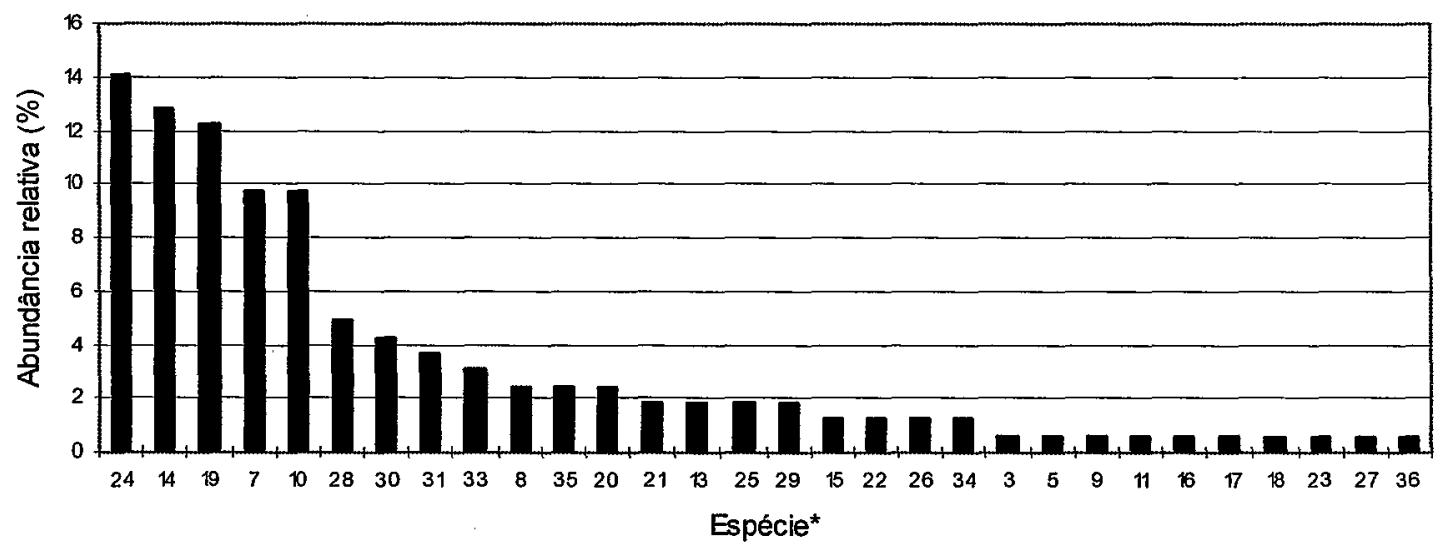

* 03, C. minimus; 05, T. tetradactyla; 07, D. novemcinctus; 08, D. septemcinctus; 09, C. apella; 10, C. thous; $11, P$. gymnocercus; 13, N. nasua; 14, P. cancrivorus; 15, C. chinga; 16, G. vittata; 17, L. longicaudis; 18, P. brasiliensis; 19 , L. pardalis; 20, L. tigrinus; 21, L. wiedii; 22, H. yagouaroundi; 23, P. concolor; 24, T. terrestris; 25, M. americana; 26, O. bezoarticus; 27, T. tajacu; 28, A. paca; 29, C. aparea; 30, D. azarae; 31, H. hydrochaeris; 33, M. coypus; 34, N. squamipes; 35, S. brasiliensis; 36, L. europaeus.

Figura 16 - Abundância de rastros para as espécies de mamíferos não-voadores 
O levantamento realizado através dos métodos diretos resultou em um número pequeno de registros (33) e de espécies (10), das quais duas (Didelphis albiventris e $S$. brasiliensis) não haviam sido registradas através do método indireto, mostrando-se, este método, insuficiente para levantamentos de mamíferos, porém complementar ao levantamento qualitativo por meio de vestígios.

Dentre as espécies registradas pelo método direto, C. apella, S. brasiliensis, e $C$. thous foram as mais abundantes e/ou as mais frequentemente encontradas (Figura 17). A abundância da primeira espécie está de acordo com o trabalho de Cosson et al. (1999b), que cita a espécie como bastante abundante em fragmentos florestais em função de seu hábito alimentar e comportamento generalista. Entretanto, outras espécies de primatas não foram encontradas, por serem muito vulneráveis a fragmentação devido às características destas espécies, com uma locomoção muito deficiente em ambientes abertos, sendo importante, nestes casos, a junção dos fragmentos por remanescente linear, como sugerido por Laurance \& Laurance (1999).

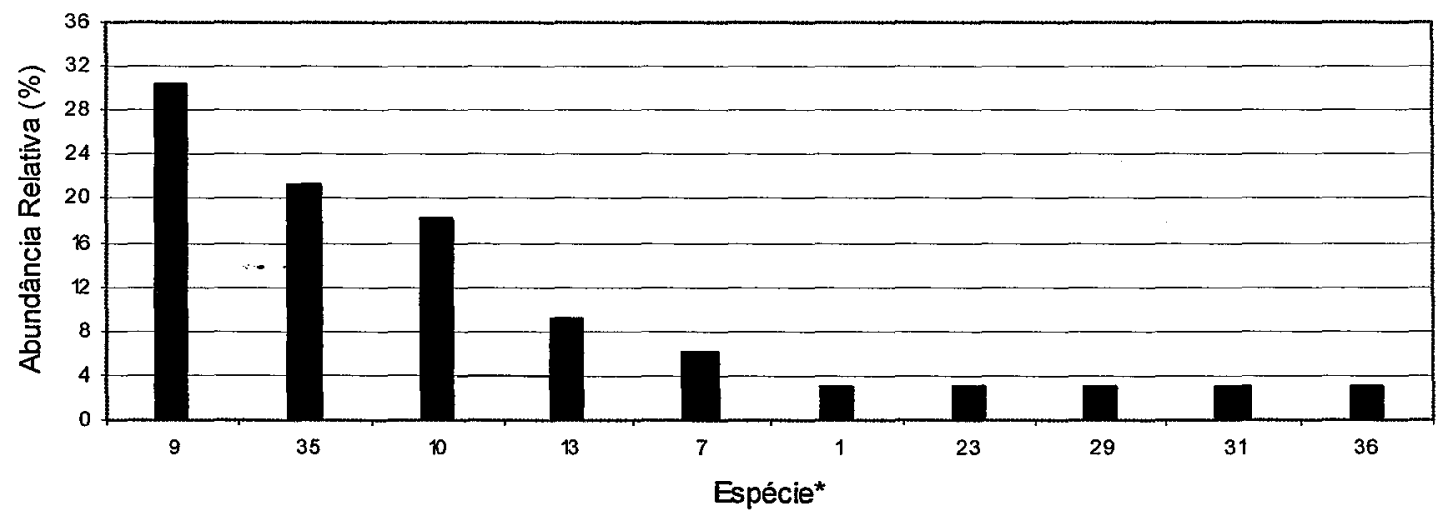

* 01, D. albiventris; 07, D. novemcinctus; 09, C. apella; 10, C. thous; 13, N. nasua; 23, P. concolor; 29, C. aparea; 31 , H. hydrochaeris; $35, S$. brasiliensis; 36, L. europaeus.

Figura 17 - Abundância de espécies de mamíferos não-voadores registrados através de observações 
Das 35 espécies, Chrysocyon brachyurus, L. pardalis, Leopardus tigrinus, Puma concolor e P. brasiliensis, constam na Lista Oficial da Fauna Brasileira Ameaçada de Extinção (Fundação Biodiversistas et al., 2003), o que mostrou que a área de estudo pode ser um importante local para a conservação destas espécies, que ainda estão conseguindo se manter no local. Estas quatro espécies, com exceção de L. tigrinus, por serem predadores de topo de cadeia alimentar, reforçam ainda mais o bom estado de conservação dos remanescentes florestais na Fazenda Figueira, semelhante a outras localidades (Gargaglioni et al., 1998).

Dentre os registros, observou-se a presença de várias espécies de topo de cadeia alimentar. Como predador de grande porte, foi registrado $P$. concolor, que preda animais também de grande porte, como referido por Iriante et al. (1990), que verificaram uma dieta para $P$. concolor composta principalmente por mamíferos de grande porte como cervídios e de médio porte como os grandes roedores. E de predadores de médio porte, como P. brasiliensis, L. pardalis, L. tigrinus, Leopardus wiedii, e Herpailurus yagouaroundi, que se alimentam de presas de pequeno e médio porte. L. pardalis foi registrada por Wang (2002) predando mamíferos do tamanho de D. novemcinctus.

C. brachyurus, foi registrado apenas por relato de moradores locais, podendo significar que a área não comportou mais suas populações, e/ou a espécie não se encontrava na área no período de levantamento, pois certamente utiliza a fazenda eventualmente como parte de seus territórios, o que é muito provável se considerar a extensão do território destas espécies generalistas, apresentando hábito alimentar muito variado, como relatado por Bestelmeyer \& Westbrook (1998) e Juarez \& Marinho-Filho (2002), que observaram C. brachyurus alimentando-se de vegetais e animais como Ozotocerus bezoarticus, além de outros itens.

Pseudalopex gymnocercus foi registrado por rastro. Entretanto, o método mais eficiente, considerando a semelhança entre os rastros desta espécie com outros canídeos silvestres e domesticados, foi através da análise de pêlos em amostradas fezes destes predadores. No total foram encontradas 11 fezes deste canídeo na Fazenda Figueira, que continham pêlos de Akodon spp. (3), N. squamipes (2), S. brasiliensis (1), um marsupial ainda não identificado (4), um fragmento de pêlo de cervídeo (provavelmente de $M$. 
americana), além de itens que não foram mamíferos, portanto desconsiderados neste trabalho. $\mathrm{O}$ canídeo provavelmente não matou o cervídeo, alimentando-se deste já morto, possivelmente por um predador de maior porte como $P$. concolor. Através do número de fezes de $P$. gymnocercus encontradas, a espécie pareceu bastante abundante na área. Entretanto estas fezes podem ser de um mesmo animal ou de poucos.

Das espécies registradas para a Fazenda Figueira, as que mais apresentam as características de espécies indicadoras foram T. terrestris e Tayassu tajacu, pois são espécies grandes, precisam de ambientes bem estruturados, mas não apresentam uma área de vida muito extensa, que ultrapasse os limites da fazenda. Destas duas espécies, a segunda foi a principal indicadora, pois não foi registrada utilizando ou ultrapassando ambientes de pastagem.

O monitoramento de espécies estritamente carnívoras como os felinos de médio e grande porte poderiam propiciar um eficiente indicativo de qualidade ambiental, baseando-se no pressuposto de que quanto maior a abundância de espécies de médio porte, mais alterado estará o ambiente, como sugerido por Terborgh (1992) e Cosson et al. (1999b).

Além da fragmentação, que certamente levou a uma descaracterização da comunidade de mamíferos não-voadores, foram verificados: a presença constante de gado dentro, principalmente, de pequenos cursos de água, destruindo a estrutura do subbosque nestes locais; a presença freqüente de caçadores; e a invasão, das bordas dos remanescentes e da beira das estradas que ultrapassam os remanescentes, por capim colonião (Panicum maximum), que na época de seca podem facilitar a entrada de fogo nestes remanescentes florestais.

Visando a conservação das espécies de mamíferos não-voadores, o monitoramento e uso de estratégias que busquem a conservação de algumas espécies alvo (espécies "guarda-chuva") seria importante. Quanto às espécies alvo, recomendam-se o uso de espécies grandes e que apresentem grande área de vida, visando englobar diversas outras espécies dentro desta área. Neste caso as espécies de topo de cadeia alimentar como $P$. concolor e $L$. pardalis seriam as melhor qualificadas, pois são bastante vulneráveis em decorrência da grande extensão de hábitat necessária para suportá-las 
(Coppolitto et al., 2004). Entretanto, para a conservação de espécies de topo de cadeia, seria importante o acompanhamento das condições à que estão submetidas as populações das espécies de presa potenciais.

A conservação através do uso de espécie "guarda-chuva" pode ser mais efetiva se estas forem, também, espécies "bandeira", como é o caso de $P$. concolor, ou mesmo de L. pardalis. O uso de espécies exclusivamente "bandeira", como T. terrestris, seria uma alternativa, porém não muito efetiva como sugerido por Caro et al. (2004).

De uma forma geral, a Fazenda Figueira apresenta um número razoável de remanescentes florestais, estando estes relativamente conservados, podendo suportar uma alta diversidade de espécies, principalmente os não-voadores. As áreas de pastagens não parecem estar interferindo enormemente na comunidade de mamíferos, sendo que a maior parte das espécies ultrapassa estes ambientes com freqüência, provavelmente pela distância entre os remanescentes não ser muito grande, fato este que minimiza os efeitos do ambiente fragmentado, possibilitando a manutenção desta comunidade.

Este levantamento foi parte de um estudo de conservação, que buscou verificar a composição da mastofauna na Fazenda Figueira. O ideal, segundo Selman \& Doar (1992), seria realizar um estudo detalhado do arranjo espacial dos remanescentes, corredores e entorno (aspectos como proximidade, densidade e conectividade), e de heterogeneidade dos ambientes, para depois estabelecer as áreas para a conservação de acordo com objetivos pré-definidos.

Como o procedimento completo não foi realizado, o que foi feito são apenas inferências sobre o atual estado das espécies nos ambientes, e a melhor maneira de conservá-las. Sugere-se assim, a conexão dos fragmentos por corredores, facilitando-se a movimentação para as espécies mais sensíveis; a ampliação das áreas florestais, junto com o fechamento das estradas que cortam os fragmentos; a construção de aceiro e o controle do capim colonião ( $P$. maximum), nas bordas dos fragmentos e estradas, evitando-se fogo; o impedimento da entrada de gado nos remanescentes, e da presença de caçadores na área. 


\section{CONCLUSÕES}

\subsection{Estudo de mamíferos voadores}

Embora o tempo de levantamento tenha sido reduzido, pode-se considera-lo válido em função do esforço amostral, através do qual um tempo mínimo de 39 ou 73 horas de levantamento teriam sido suficientes para o registro de $90 \%$ ou $95 \%$ da riqueza da área.

A comunidade de morcegos da Fazenda Figueira está constituída por uma riqueza elevada de espécies, sendo a maioria frugívora da família Phyllostomidae, valor este próximo às outras áreas do baixo Tibagi.

Tonatia silvicola e Mesophilla macconnelli foram registradas pela primeira vez para a Bacia do Tibagi, onde Myotis ruber foi a única espécie ameaçada sendo, junto com T. silvicola, considerada como pouco tolerante à fragmentação, e uma potencial indicadora de degradação ambiental.

A maior parte das espécies foi considerada generalista com relação ao uso dos ambientes, onde apenas Anoura caudifera, T. silvicola, Lasiurus blossevillii e Myotis nigricans, foram restritas aos ambientes florestais. Desta forma, foi verificada a passagem entre os fragmentos por quase todas as espécies, indicando que a maioria foi pouco sensível à presença de área aberta, e nenhuma relação foi observada com relação ao uso de ambientes abertos com o tamanho da espécie.

Tanto a abundância das espécies como os índices de diversidade de espécies mostraram maiores valores para o fragmento, seguindo-se pelas áreas de pastagem e finalmente pela mata ciliar, indicando que a maior área conservada da fazenda estava atuando como refúgio, e à medida que foi se distanciando desta área, a abundância e 
diversidade apresentaram um decréscimo. A similaridade também decresce com a distância entre os ambientes, porém a característica estrutural dos ambientes foi a variável responsável pela maior similaridade.

A comunidade da Fazenda Figueira, como em todas as áreas do Brasil, foi heterogênea, com a dominância por poucas espécies. No caso da fazenda, Artibeus lituratus, Carollia perspicillata e Sturnira lilium, foram dominantes, sendo a primeira espécie a dominante em áreas de pastagem ou mais tolerante a este tipo de ambiente do que a última que dominou em ambientes florestais.

$\mathrm{Na}$ área da Fazenda Figueira amostrada foi registrada uma proporção semelhante de indivíduos jovens e adultos, uma proporção maior de fêmeas, e uma razão sexual para a comunidade e para a maior parte das espécies de 3 fêmeas para um macho.

\subsection{Estudo de mamíferos não-voadores}

A riqueza de espécies de mamíferos não-voadores foi relativamente alta, além de propiciar o registro de espécies que ainda não haviam sido registradas para a Bacia do rio Tibagi, mesmo com um tempo reduzido de levantamento, considerando a extensão da área amostrada, onde um tempo mínimo de 9 ou 15 dias seriam suficientes para o registro de $90 \%$ ou $95 \%$ da riqueza.

A comunidade de mamíferos não-voadores de médio e grande porte foi generalista com relação ao uso dos ambientes, utilizando áreas abertas para a translocação entre os fragmentos. Quanto aos pequenos mamíferos, a taxa de captura extremamente baixa impossibilitou qualquer análise específica sobre o grupo, entretanto, foi possível verificar a influência negativa da fragmentação sobre o marsupial $M$. paulensis, forçado a forragear em ambiente de pastagem.

A Ordem Carnivora foi a de maior representatividade em toda a fazenda, e também nos diferentes ambientes amostrados, porém, cuidado foi tomado para a interpretação deste e qualquer outro tipo de dado que inferiu sobre a abundância de uma dada espécie, devido aos diversos problemas do método de levantamento empregado neste estudo. 
Entre os métodos utilizados, o método indireto de levantamento por meio de rastros foi o de maior eficácia no registro de um grande número de espécies em período reduzido de tempo. Entretanto, este método vai perdendo sua viabilidade com o decréscimo do tamanho da espécie e em função do hábito ecológico das mesmas. $\mathrm{O}$ método direto foi pouco eficiente, porém complementar.

De uma forma geral a área fragmentada da Fazenda Figueira mostrou-se relativamente conservada, possibilitando a manutenção de espécies ameaçadas e de importante papel na manutenção dos ecossistemas como Chrysocyon brachyurus, Leopardus pardalis, Leopardus tigrinus, Puma concolor e Pteronura brasiliensis, além de espécies menos tolerantes a fragmentação e que necessitam de ambiente bem estruturado como Tapirus terrestris e Tayassu tajacu.

\subsection{Considerações finais}

O levantamento da Fazenda Figueira proporcionou uma visão geral da composição da mastofauna, bem como seu estado de conservação, através de espécies possíveis de indicar o estado de degradação dos hábitats naturais.

A alta riqueza e diversidade encontradas na fazenda resultaram, provavelmente, da descaracterização da mastofauna original, seja através de mudanças na abundância das espécies que persistiram no ambiente, dos processos de emigração e imigração ou da introdução de espécies exóticas. Outros fatores observados, e que certamente estavam influenciando ou que podem vir a afetar a comunidade de mamíferos na Fazenda Figueira foram: a pressão de caça; a destruição da estrutura vegetal do sub-bosque nos cursos de água, pela freqüente entrada de gado; e, a presença de capim colonião (Panicum maximum) nas bordas dos fragmentos e estradas, que podem facilitar a entrada de fogo nestes ambientes.

Baseado nesta composição de espécies de mamíferos voadores e não-voadores, nas observações feitas em campo com relação à distribuição espacial dos remanescentes, e dos possíveis riscos à que as espécies estavam submetidas, foi possível identificar 
alguns procedimentos e estratégias de importância à manutenção destas populações no ambiente fragmentado, e em conjunto com as atividades econômicas aí desenvolvidas: 1) T. silvicola e M. ruber, entre as espécies de morcegos, $T$. terrestris e T. tajacu, entre os mamíferos não-voadores, foram consideradas como as espécies mais sensíveis à fragmentação e à descaracterização do ambiente florestal, podendo ser potenciais espécies indicadoras de degradação ambiental para o monitoramento da mastofauna, visando sua conservação;

2) Em função da dificuldade em se desenvolver e aplicar técnicas de manejo sobre comunidades, o uso de espécies "guarda-chuva" e/ou "bandeira" seria uma boa solução, onde qualquer estratégia aplicada sobre uma ou poucas espécies "guarda-chuva", poderia garantir a conservação de diversas espécies co-existentes, e no caso da espécie alvo ser também uma espécie "bandeira", aumentar as possibilidades de conservação da área, desde que esta característica seja explorada publicitariamente. Neste caso, foi indicado o uso de $P$ concolor e $L$ pardalis, que podem ser consideradas tanto como espécie "guardachuva" como "bandeira", para a conservação de mamíferos não-voadores, o que proporcionaria a conservação não apenas das demais espécies de mamíferos nãovoadores da área como, também, as espécies voadoras.

3) Uma forma de realizar o monitoramento das espécies indicadoras, "guarda-chuva" e/ou "bandeira" seria através de levantamentos periódicos, que possibilitem verificar a abundância das espécies no ambiente, e, se possível, a área de uso dos indivíduos através de estudos populacionais. Sugere-se que o monitoramento seja feito ao menos uma vez por ano nos primeiros anos, espaçando este tempo caso nenhuma alteração venha a ser observada.

4) O manejo de populações seria uma alternativa para buscar estabelecer um equilíbrio em todas as partes da comunidade, que pode ser realizado através da introdução ou do controle de uma ou mais espécies, após a verificação de uma descaracterização muito grande na comunidade, por parte do monitoramento, que inviabilize a manutenção do ecossistema.

5) No caso de não ser possível a realização do monitoramento de espécies, algumas estratégias, mesmo que não apresentem resultados visíveis, poderiam auxiliar na 
conservação da mastofauna da Fazenda Figueira. Dentre estas estratégias estão: a conexão dos fragmentos florestais, que pode auxiliar na translocação dos animais entre os remanescentes florestais, ou mesmo a ampliar a área de forrageio para as espécies; o impedimento da entrada de gado dentro dos remanescentes e em cursos de água, diminuindo problemas de assoreamento e degradação da estrutura vegetal do sub-bosque; o controle da caça, para diminuir a mortandade de animais e o estresse sobre as populações alvo; a construção de aceiro ao redor dos fragmentos, e o controle do capim colonião ( $P$. maximum) nas bordas dos remanescentes e estradas, minimizando a possibilidade de incêndios nos fragmentos. 


\section{REFERÊNCIAS BIBLIOGRÁFICAS}

ALHO, C.J.R.; PEREIRA, L.A.; PAULA, A.C. Patterns of habitat utilization by small mammal populations in cerrado biome of central Brazil. Mammalia, v.50, n.4, p.447-460, 1986.

ALMEIDA, A. Independência das florestas plantadas com a fauna silvestre. IPEF, v.10, n.29, p.37-44, 1996. (Série Técnica).

ÁVILA-PIRES, F.D. Observações gerais sobre a mastozoologia do cerrado. Anais da Academia Brasileira de Ciências, v.38, Supl. p.331-340, 1966.

BAPTISTA, M.; MELLO, M. Preliminary inventory of the bat species of the Poço das Antas Biological Reserve, RJ. Chiroptera Neotropical, v.7, n.1/2, p.133-135, 2001.

BECKER, M.; DALPONTE, J.C. Rastros de mamíferos silvestres brasileiros: um guia de campo. 2.ed. Brasília: Editora Universidade de Brasília, 1999. 180p.

BERNARD, E.; FENTON, M.B. Bat mobility and roosts in a fragmented landscape in Central Amazonia, Brazil. Biotropica, v.35, n.2, p.262-277, 2003.

BERNARD, E.; ALBERNAZ, A.L.K.M.; MAGNUSSON, W.E. Bat species composition in three localities in the Amazon Basin. Studies on Neotropical Fauna and Environment, v.36, n.3, p.177-184, 2001. 
BREDT, A.; CAETANO JÚNIOR, J.; MAGALHÃES, E.D. Chave visual para a identificação de morcegos do Brasil (compact disc). Distrito Federal: FAPDF, 2002.

BROOKS, D.M.; EISENBERG, J.F. Estado y biologia de los tapires neotropicales: perspectiva general. In: FANG, T.G.; MONTENEGRO, O.L.; BODMER, R.E (Ed.). Manejo y conservación de fauna silvestre en América Latina. La Paz: Instituto de Ecologia, Universidad Mayor de San Andrés, 1999. p.409-413.

BROWN JÚNIOR, K.S.; BROWN, G.G. Habitat alteration and species loss in Brazilian forests. In: WHITMORE, T. C.; SAYER, J. A. (Ed.). Tropical deforestation and species extinction. London: Chapman \& Hall, 1992. p.119-147.

CAREY, A. B.; HARRINGTON, C. A. Small mammals in young forest. Implications for management for sustainability. Forest Ecology and Management, v.154, p.289$309,2001$.

CARO, T.; ENGILIS JÚNIOR; A.; FITZHERBERT, E.; GARDNER, E. Preliminary assessment of the flagship species concept at a small scale. Animal Conservation, v.7, p.63-70, 2004.

CEBALLOS, G.; NAVARRO, D.L. Diversity and conservation of mexican mammals. In: MORAES, M.A.; SCHMIDLY, D.J. (Ed.). Latin American mammalogy: history, biodiversity and conservation. London: Oklahoma Museum of Natural History Publication, 1991. p.167-198.

CHIARELLO, A.G. Effects of fragmentation of the Atlantic forest on mammals communities in south-eastern Brazil. Biological Conservation, v. 89, p.71-82, 1999. 
CHIARELLO, A.G. Conservation value of a native forest fragment in a region of extensive agriculture. Revista Brasileira de Biologia, v.60, n.2, p.237-247, May 2000 .

CIMADI, A.V. Mamíferos de Santa Catarina. Florianópolis: FATMA, 1996. 302p.

COLE, F.R.; WILSON, D.E.. Mammalian diversity and natural history. In: WILSON, D.E. COLE, F.R.; NICHOLS, J.D.; RUDRAN, R.; FOSTER, M.S. (Ed.). Measuring and monitoring biological diversity: standard methods for mammals. Washington: Smithsonian Institution Press, 1996. 409p.

COPPOLITTO, P.; GOMEZ, H.; MAISELS, F.; WALLACE, R. Selection criteria for suites of landscape species as a basis for site-based conservation. Biological Conservation, v.115, p.419-430, 2004.

COSSON, J.F.; PONS, J.M.; MASSON, D. Effects of forest fragmentation on frugivorous and nectarivorous bats in French Guiana. Jornal of Tropical Ecology, v.15, p.515-534, 1999a.

COSSON, J.F.; RINGUET, S.; CLAESSES, O.; MASSARY, J.C.; DALECKY, A.; VILLIERS, J.F.; GRAMJON, L.; PONS, J.M. Ecological changes in recent landbridge islands in French Guiana, with emphasis on vertebrate communities. Biological Conservation, v.91, p.213-222, 1999b.

DIAS, M.C.; VIEIRA, A.O.S.; PAIVA, M.R.C. Florística e fitossociologia das espécies arbóreas das florestas da Bacia do rio Tibagi. In: MEDRI, M.E.; BIANCHINI, E.; SHIBATTA, O.A.; PIMENTA, J.A. (Ed.). A Bacia do rio Tibagi. Londrina: Ed. dos Editores, 2002. cap.8, p.109-124. 
ELMHAGEN, B.; ANGERBJÖRN, A. The applicability of metapopulation theory to large mammals. Oikos, v.94, p.89-100, 2001.

EMMONS, L.H.; FEER, F. Neotropical rainforest mammals: a field guide. 2.ed. Chicago: University of Chicago Press, 1997. 307p.

ENGEL, L.; MELLO, D.A. Rodents in agroecosystems in the cerrado province of the Federal District (Brasília/DF, Brazil). Ciência e Cultura, v.45, n.2, p.128-133, Mar/Apr 1993.

EISENBERG, J.F. La fauna contemporánea de mamíferos de América del Sur. In: FANG, T.G.; MONTENEGRO, O.L.; BODMER, R.E (Ed.). Manejo y conservación de fauna silvestre en América Latina. La Paz: Instituto de Ecología, Universidad Mayor de San Andrés, 1999. p.3-14.

EISENBERG, J.F.; REDFORD, K.H. Mammals of the neotropics: the central neotropics. Chicago: The Univercity of Chicago Press, 1998. 190p.

ERWIN, T.L. The tropical forest canopy: the heart of biotic diversity. In: WILSON, E.O.; PETER, F.M.(Ed.). Biodiversity. Washington: National Academy Press, 1988. p.105-109

ESTEVAN, D.A. As espécies arbóreas e a sua estrutura em fragmento florestal da Fazenda Figueira (Londrina - Paraná). Londrina, 2004. 26p. Monografia (Bacharelado) - Universidade Estadual de Londrina.

ESTRADA, A.; COATES-ESTRADA, R. Bats in continuous forest, forest fragments and in an agricultural mosaic habitat-islands at Los Tuxtlas, Mexico. Biological Conservation, v.103, p.237-245, 2002. 
FALCÃO, F.C.; REBÊLO, V.F.; TALAMONI, S.A. Struture of bat assemblage (Mammalia, Chiroptera) in Serra do Caraça Reserve, south-east Brazil. Revista Brasileira de Zoologia, v.20, n.2, p.347-350, 2003.

FARIA, D.M. Comunidade de morcegos em uma paisagem fragmentada da mata atlântica do sul da Bahia, Brasil. Campinas, 2002. 134p. Tese (Doutorado) - Instituto de Biologia, Universidade Estadual de Campinas.

FÉLIX, J.S.; REIS, N.R.; LIMA, I.P.; COSTA, E.F.; PERACCHI, A.L. Is the area of the Arthur Thomas Park, with its 82.72 ha, sufficient to maintain viable chiropteran populations? Chiroptera Neotropical, v.7, n.1/2, p.129-133, 2001.

FUNDAÇÃO BIODIVERSISTAS; SOCIEDADE BRASILEIRA DE ZOOLOGIA; INSTITUTO BRASILEIRO DO MEIO AMBIENTE E DOS RECURSOS NATURAIS RENOVÁVEIS; MINISTÉRIO DO MEIO AMBIENTE. Lista das espécies da fauna brasileira ameaçadas de extinção. Belo Horizonte: Fundação Biodiversistas, 2003. 25p. (Instrução Normativa, 3).

GARGAGLIONI, L.H.; BATALHÃO, M.E.; LAPETA, M.J.L.; CARVALHO, M.F.; ROSSI, R.V.; VERULI, V.P. Mamíferos da Estação Ecológica de Jataí, Luiz Antônio, São Paulo. Papéis Avulsos de Zoologia, v.40, n.17, p.267-287, 1998.

GASCON, C.; LOVEJOY, T.E.; BIERREGAARD JÚNIOR, R.; MALCOLM, J.R.; STOUFFER, P.C.; VASCONCELOS, H.L.; LAURANCE, W.F.; ZIMMERMAN, B.; TOCHER, M.; BORGES, S. Matrix habitat and species richness in tropical Forest remnants. Biological Conservation., v.91, p.223-229, 1999.

GENTILE, R.; FERNANDEZ, F.A.S. Influence of habitat struture on a streamside small mammal community in a Brazilian rural area. Mammalia, v.63, n.1, p.29-40, 1999. 
GHELER-COSTA, C. Mamíferos não-voadores do Campus "Luiz de Queiroz", da Universidade de São Paulo, em Piracicaba, Estado de São Paulo. Piracicaba, 2002. 72p. Dissertação (Mestrado) - Escola Superior de Agricultura "Luiz de Queiroz", Universidade de São Paulo.

HARRINGTON, G.N.; FREEMAN, A.N.D.; CROME, F.H.J. The effects of fragmentation of an Australian tropical rain forest on populations and assemblages of small mammals. Journal of Tropical Ecology, v.17, p.225-240, 2001.

JORGE, M.C.L.; PIVELLO, V.R.; MEIRELES, S.T.; VIVO, M. Riqueza e abundância de pequenos mamíferos em ambientes de cerrado e floresta, na reserva cerrado Péde-gigante, Parque Estadual de Vassununga (Santa Rita do Passa Quatro, SP). Naturalia, v.26, p.287-302, 2001.

JULIÁ, J.P.; RICHARD, E. Estado de conservación de las corzuelas (Mazama sp.) en el noroeste argentino. In: FANG, T.G.; MONTENEGRO, O.L.; BODMER, R.E (Ed.). Manejo y conservación de fauna silvestre en América Latina. La Paz: Instituto de Ecología, Universidad Mayor de San Andrés, 1999. p.447-451.

KREBS, C.J. Ecological methodology. New York: Harper Collins, 1989. 654p.

LAURANCE, S.G.; LAURANCE, W.F. Tropical wildlife: use of linear rainforest remnants by arboreal mammals. Biological Conservation, v.91, p.231-239, 1999.

LAURANCE, W.F. Introduction and synthesis. Biological Conservation, v.91, p.101107, 1999a.

LAURANCE, W.F. Reflections on the tropical deforestation crisis. Biological Conservation, v.91, p.109-117, 1999 b. 
LAW, B.S.; LEAN, M. Common blosson bats (Syconycteris australis) as pollinators in fragmented Australian tropical rainforest. Biological Conservation, v.91, n.2/3, p.201-212, 1999.

LIDICKER JÚNIOR, W.Z. Responses of mammals to habitat edges: an overview. Landscape Ecology, v.14, p.333-343, 1999.

LIM, B.K.; ENGSTROM, M.D. Species diversity of bats (Mammalia: Chiroptera) in Iwokrama forest, Guyana, and the Guianan subregion: implications for conservation. Biodiversity and Conservation, v.10, p.613-657, 2001.

LIMA, M.G.; GASCON, C. The conservation value of linear forest remnants in central Amazonia. Biological Conservation, v.91, p.241-247, 1999.

LINDENMAYER, D.B.; MARGULES, C.R.; BOTKIN, D.B. Indicators of biodiversity of ecologically sustainable forest management. Conservation Biology, v.14, n.4, p.941-950, 2000a.

LINDENMAYER, D.B.; McCARTHY, M.A.; PARRIS, K.M.; POPE, M.L. Habitat fragmentation, landscape context, and mammalian assemblages in southeastern Australia. Journal of Mammalogy, v.81, n.3, p.787-797, 2000 b.

MAGURRAN, A.E. Diversidad ecológica y su medición. Barcelona: Ediciones Vedrà, 1989. 200p.

MARINHO-FILHO, J.; SAZIMA, I. Brazilian bats and conservation biology: a first survey. In: KUNZ, T.H.; RACEY, P.A. (Ed.) Bat biology and conservation. Washinton; London: Smithsonian Institution Press, 1998. p.282-294, 
MASTUSCELLI, P. Diretrizes para conservação da fauna no Estado de São Paulo: diagnósticos e propostas. São Paulo: Secretaria do Meio Ambiente, 1996. 55p.

McCULLOUGH, D.R. Metapopulations and wildlife conservation. Washington: Island Press, 1996. 429p.

MEDRI, M.E.; BIANCHINI, E.; SHIBATTA, O.A.; PIMENTA, J.A. (Ed.) A Bacia do rio Tibagi. Londrina: Ed. dos Editores, 2002. 595p.

MENDONÇA, F.A.; DANNI-OLIVEIRA, I.M. Dinâmica atmosférica e tipos climáticos predominantes da Bacia do rio Tibagi. In: MEDRI, M.E.; BIANCHINI, E.; SHIBATTA, O.A.; PIMENTA, J.A. (Ed.) A Bacia do rio Tibagi. Londrina: Ed. dos Editores, 2002. cap.4, p.63-66.

MORENO, C.E.; HALFFTER, G. Spatial and temporal analysis of $\alpha, \beta$ e $\gamma$ diversities of bats in a fragmented landscape. Biodiversity and Conservation, v.10, p.367-382, 2001.

MUELLER-DOMBÓIS, D.; ELLENBERG, H. Aims and methods of vegetation ecology. New York: John Wiley, 1974. 547p.

NOWAK, R..M. Walker's bats of the world. Baltimore; London: Johns Hopkins University Press, 1994. 287p.

OLIVEIRA, T.G.; CASSARO, K. Guia de identificação dos felinos brasileiros, 2.ed. São Paulo: Sociedade de Zoologicos do Brasil, 1999. 60p.

PEDRO, W.A.; PASSOS, F.C.; LIM, B.K. Morcegos (Chiroptera; Mammalia) da Estação Ecológica de Caetetus, Estado de São Paulo. Chiroptera Neotropical, v.7, n.1/2, p.136-140, 2001. 
PERACCHI, A.L.; ROCHA, V.J.; REIS, N.R. Mamíferos não voadores da Bacia do rio Tibagi. In: MEDRI, M.E.; BIANCHINI, E.; SHIBATTA, O.A.; PIMENTA, J.A. (Ed.) A Bacia do rio Tibagi. Londrina: Ed. dos Editores, 2002. cap.13, p.245-249.

PHILLIPS, O.L. The changing ecology of tropical forests. Biodiversity and Conservation, v.6, p.291-311, 1997.

PITMAN, M.R.P.L.; OLIVEIRA, T.G.; PAULA, R.C.; INDRUSIAK, C. Manual de identificação, prevenção e controle de predação por carnívoros. Brasilia: Edições IBAMA, 2002. 83 p.

QUESADA, M.; STONER, K.E.; ROSAS-GUERRERO, V.; PALACIOS-GUEVARA, C.; LOBO, J.A. Effects of habitat disruption on the activity of nectarivorous bats (Chiroptera: Plyllostomidae) in a dry tropical forest: implications for the reproductive success of the neotropical tree Ceiba grandiflora. Oecologia, v.135, p.400-406, 2003.

RAMOS JÚNIOR, V.A.; PESSUTTI, C.; CHIEREGATTO, C.A.F.S. Guia de identificação dos canídeos silvestres brasileiros (compact disc). Sorocaba: Joy Joy Studio, 2003.

REDFORD, K.H.; ROBINSON, J.G. Park size and the conservation of forest mammals in Latin America. In: MARES, M.A.; SCHMIDLY, D.J. (Ed.). Latin American mammalogy, history, biodiversity, and conservation. London: University of Oklahoma Press, 1991. p.227-234.

REIS, N.R.; PERACCHI, A.L.; LIMA, I.P. Morcegos da Bacia do rio Tibagi. In: MEDRI, M.E.; BIANCHINI, E.; SHIBATTA, O.A.; PIMENTA, J.A. (Ed.) A Bacia do rio Tibagi. Londrina: Ed. dos Editores, 2002. cap.14, p.251-270. 
REIS, N.R.; BARBIERI, M.L.S.; LIMA, I.P.; PERACCHI, A.L. O que é melhor para manter a riqueza de espécies de morcegos (Mammalia, Chiroptera): um fragmento florestal grande ou vários fragmentos de pequeno tamanho? Revista Brasileira de Zoologia, v.20, n.2, p.225-230, Jun 2003.

ROBERGE, J.M.; ANGELSTAM, P. Usefulness of the umbrella species concept as a conservation tool. Conservation Biology, v.18, n.1, p.76-85, 2004.

SAX, D.F.; GAINES, S.D. Species diversity: from global decreases to local increases. Trends in Ecology and Evolution, v.18, n.1, p.561-566, 2003.

SELMAN, P.; DOAR, N. An investigation of the potential for landscape ecology to act as a basis for rural land use plans. Journal of Environmental Management, v.35, p.281-299, 1992.

SILVA, C.R. Riqueza e diversidade de mamíferos não-voadores em um mosaico formado por plantios de Eucalyptus saligna e remanescentes de Floresta Atlântica no município de Pilar do Sul, SP. Piracicaba, 2001. 81p. Dissertação (Mestrado) Escola Superior de Agricultura "Luis de Queiroz", Universidade de São Paulo.

SOARES, F.S.; MEDRI, M.E. Alguns aspectos da colonização da Bacia do rio Tibagi. In: MEDRI, M.E.; BIANCHINI, E.; SHIBATTA, O.A.; PIMENTA, J.A. (Ed.) A Bacia do rio Tibagi. Londrina: Ed. dos Editores, 2002. cap.5, p.69-79.

SCHULZE, M.D.; SEAVY, N.E.; WHITACRE, D.F. A comparison of the Phyllostomid bat assemblages in undisturbed neotropical forest and in forest fragments of a slashand-burn farming mosaic in Petén, Guatemala. Biotropica, v.32, n.1, p.174-184, 2000 . 
STIPP, N.A.F. Principais tipos de solos da Bacia do rio Tibagi. In: MEDRI, M.E.; BIANCHINI, E.; SHIBATTA, O.A.; PIMENTA, J.A. (Ed.) A Bacia do rio Tibagi. Londrina: Ed. dos Editores, 2002. cap.2, p.39-43.

STOCKWELL, C.A.; ASHLEY, M.V. Diversity, rapid adaptation and conservation. Conservation Biology, v.18, n.1, p.272-273, 2004.

STONER, K.E.; QUESADA, M.; ROSAS-GUERRERO, V.; LOBO, J.A. Effects of forest fragmentation on the colima long-nosed bat (Musonycteris harrisoni) foraging in tropical dry forest of Jalisco, Mexico. Biotropica, v.34, n.3, p.462-467, 2002.

SUÁREZ, O.V.; BONAVETURA, S.M. Habitat use and diet in sympatric species of the low Paraná delta, Argentina. Mammalia, v.65, n.2, p.167-176, 2001.

TABARELLI, M.; MANTOVANI, W.; PERES, C.A. Effects of habitat fragmentation on plant guild structure in the montane Atlantic forest of southeastern Brazil. Biological Conservation, v.91, p.119-127, 1999.

TERBORGH, J. Maintenance of diversity in tropical forests. Biotropica, v.24, n.2b, p.283-292, 1992.

TIMO, T.P.C. Influência da fragmentação e matriz sobre a comunidade de mamíferos de médio e grande porte em uma floresta de terra firme na Amazônia central. Manaus, 2003. 46p. Dissertação (Mestrado) - Programa de Pós-Graduação em Biologia Tropical e Recursos Naturais. Instituto Nacional de Pesquisa da Amazônia, Universidade Federal do Amazonas.

TOREZAN, J.M.D. Nota sobre a vegetação da Bacia do rio Tibagi. In: MEDRI, M.E.; BIANCHINI, E.; SHIBATTA, O.A.; PIMENTA, J.A. (Ed.) A Bacia do rio Tibagi. Londrina: Ed. dos Editores, 2002. cap.7, p.103-107. 
TOREZAN, J.M.D.; SILVEIRA, M. Fatores ambientais, diversidade e similaridade em florestas da bacia do rio Tibagi. In: MEDRI, M.E.; BIANCHINI, E.; SHIBATTA, O.A.; PIMENTA, J.A. (Ed.) A Bacia do rio Tibagi. Londrina: Ed. dos Editores, 2002. cap.9, p.125-131.

TOZETTI, A.M. Diversidade e padrão de atividade de mamíferos de médio e grande porte em diferentes fisionomias de Cerrado na Estação Ecológica de Itirapina, SP. São Paulo, 2002. 76p. Dissertação (Mestrado) - Instituto de Biociências, Universidade de São Paulo.

TRAJANO, E. Movements of cave bats in southeastern Brazil, with emphasis on the population ecology of the common vampire bat, Desmodus rotundus (Chiroptera). Biotropica, v.28, n.1, p.121-129, 1996.

VIZOTTO, L.D.; TADDEI, V.A. Chave para determinação de quirópteros brasileiros. São José do Rio Preto: s.ed., 1973. 72p.

VOSS, R.S.; EMMONS, L.H. Mammalian diversity in neotropical lowland rainforest. A preliminary assessment. New York: Bulletin of the American Museum of Natural History, n.230, p.1-115, 1996.

WANG, E. Diets of Ocelots (Lepardus pardalis), Margays (L. wiedii), and Oncillas ( $L$. tigrinus) in the Atlantic rainforest in southeast Brazil. Studies on Neotropical Fauna and Environment, v.37,n.3, p.207-212, 2002.

WALLAUER, J.P.; BECKER, M.; 'MARINS-SÁ, L.G.; LIERMANN, L.M.; PERRETTO, S.H.; SCHERMACK, V. Levantamento dos mamíferos da Floresta Nacional de Três Barras, Santa Catarina. Biotemas, v.13, n.1, p.103-127, 2000. 
WHITE, D.; HOLMANN, F.; FUJISAKA, S.; REATEGUI, K.; LASCANO, C. Will intensifying pasture management in Latin America protect forest - or Is it the other way round? In: ANGELSEN, A.; KAIMOWITZ, D. (Ed.). Agricultural technologies and tropical deforestation. New York: CABI, CIFOR, 1999. p.91111.

WIENS, J.A. Wildlife in patchy environments: petapopulations, mosaics, and management. In: McCULLOUGH, D.R. Metapopulations and wildlife conservation. California: Island Press, 1996. cap. 4, p.53-84.

WICKRAMASINGHE, L.P.; HARRIS, S.; JONES, G.; VAUGHAN, N. Bat activity and species richness on organic and conventional farms: impact of agricultural intensification. Journal of Applied Ecology, v.40, p.984-993, 2003.

WILSON, D.E.; REEDER, D.M. (Ed.). Mammal species of the world: a taxonomic and geographic reference. 2.ed. Washington: Smithsonian Institution Press, 1993. 1206p.

WILSON, D.E.; NICHOLS, J.D.; RUDRAN, R.; SOUTHWELL, C. Introduction. In: WILSON, D.E. COLE, F.R.; NICHOLS, J.D.; RUDRAN, R.; FOSTER, M.S. (Ed.). Measuring and monitoring biological diversity: standard methods for mammals. Washington: Smithsonian Institution Press, 1996. p.1-7. 